\title{
Improving health literacy, self efficacy and personal skills: towards culturally tailored behavioural inreventions for African women
}

Citation for published version (APA):

Onoya-Saleh, D. (2010). Improving health literacy, self efficacy and personal skills: towards culturally tailored behavioural inreventions for African women. [Doctoral Thesis, Maastricht University]. Maastricht University. https://doi.org/10.26481/dis.20100506do

Document status and date:

Published: 01/01/2010

DOI:

10.26481/dis.20100506do

Document Version:

Publisher's PDF, also known as Version of record

Please check the document version of this publication:

- A submitted manuscript is the version of the article upon submission and before peer-review. There can be important differences between the submitted version and the official published version of record.

People interested in the research are advised to contact the author for the final version of the publication, or visit the DOI to the publisher's website.

- The final author version and the galley proof are versions of the publication after peer review.

- The final published version features the final layout of the paper including the volume, issue and page numbers.

Link to publication

\footnotetext{
General rights rights.

- You may freely distribute the URL identifying the publication in the public portal. please follow below link for the End User Agreement:

www.umlib.nl/taverne-license

Take down policy

If you believe that this document breaches copyright please contact us at:

repository@maastrichtuniversity.nl

providing details and we will investigate your claim.
}

Copyright and moral rights for the publications made accessible in the public portal are retained by the authors and/or other copyright owners and it is a condition of accessing publications that users recognise and abide by the legal requirements associated with these

- Users may download and print one copy of any publication from the public portal for the purpose of private study or research.

- You may not further distribute the material or use it for any profit-making activity or commercial gain

If the publication is distributed under the terms of Article 25fa of the Dutch Copyright Act, indicated by the "Taverne" license above, 


\section{IMPROVING HEALTH LITERACY, SELF EFFICACY AND PERSONAL SKILLS:}

TOWARDS CULTURALLY TAILORED BEHAVIOURAL INREVENTIONS FOR AFRICAN WOMEN

\section{DISSERTATION}

To obtain the degree Doctor at the Maastricht University on the authority of Rector Magnificus, Prof. Dr. G.P.M.F. Mols in accord with the decision of the board of Deans, to be defended in public on Thursday May 6, 2010 at 14.00 hours

by

Dorina Onoya 


\section{Supervisor(s):}

Prof.dr. H. B. van den Borne

Prof.dr. S. P. Reddy (Medical Research Council, South Africa)

Co-supervisor(s):

Dr. R. A. C. Ruiter

\section{Assessment committee:}

Prof.dr. G. J. Kok, (Chairman)

Dr. A. Bos

Prof.dr. H. Crebolder

Prof.dr. H. Hospers

Dr. Shamagonam James (Medical Research Council, South Africa)

Cover graphics: Keith Mallet (Keith Mallet Studio)

The studies presented in this thesis were conducted at the National Health Promotion Research and Development Group, Medical Research Council (MRC), South Africa. The WiLLOW Project was funded by the MRC and the SISTA Project was funded by the NIH (grant \#3P30 Al050409-06SI). 


\section{Contents}

Chapter 1

Page 6

General introduction

Chapter 2 Page 43

Preference for dry sex, condom use and risk of STI among HIVnegative black women in the Western Cape Province, South Africa

Chapter 3 Page 61

Economic pressure and sexual relationships of young Black women in peri-urban areas of the Western Cape Province of South Africa

Chapter 4 Page 78

Comparing Sexually Transmitted Infection Risk and Sexual Behaviour Profiles of Pregnant versus Non-Pregnant, HIV Negative Black Women in the Western Cape Province, South Africa

\section{Chapter 5} Page 94

SISTA South Africa: the adaptation of an efficacious HIV prevention trial conducted with African-American Women for isiXhosa speaking South African women

Chapter 6 Page 111

Facilitators and barriers to recruitment and retention of HIV negative black South African women to behavioural HIV prevention programs

\section{Chapter 7} Page 131

Correlates of condom use frequency among isiXhosa speaking women living with HIV in the Western Cape Province of South Africa: a preliminary study 
Chapter 8 Page 156

Condom use promotion among isiXhosa speaking women living with HIV in the Western Cape Province, South Africa: a pilot study

Chapter 9 Page 178

General discussion

Summary Page 205

Samenvatting Page 209 Acknowledgements Page 213 Curriculum vitae Page 214 Appendix A : Additional analyses for Chapter 4 Page 215 
Chapter 1

General Introduction 
South Africa is experiencing one of the largest HIV epidemics in the world in terms of the rates of HIV transmission, HIV prevalence and its impact on the society. A recent estimate of the national HIV prevalence among individuals 2 years and older was $10.8 \%$ with females having a higher prevalence compared to males $(13.3 \%$ compared to $8.2 \%)$. The HIV prevalence increases with age, peaking at $33.3 \%$ among females aged $15-29$ years. Furthermore compared to the national average, the HIV prevalence is higher among black females at $24.4 \%$, peaking at $37.9 \%$ among black females aged $25-29$ years (Shisana et al., 2005).

There is great variability in the HIV prevalence among and within provinces. Mpumalanga Province has the highest HIV prevalence at $23 \%$ and Western Cape Province has the lowest prevalence at 3.2\% (Shisana et al., 2005). The Western Cape Province of South Africa is a wealthy and highly urbanised province, $87 \%$ of its population lives in the Cape Town metropolis. Although the Western Cape province has the lowest HIV prevalence in South Africa, there are steep inequalities in the prevalence of HIV that depend on racial categories, socioeconomic status and geographic locations (Shaikh, \& Adendorff, 2000; Shaikh et al., 2006). The 2004 prevalence of HIV in Cape Town was estimated at $3.7 \%$ in Cape Town central, $7.1 \%$ in Stellenbosch, $22 \%$ in Khayelitsha, $0.7 \%$ in Mitchel's plain and $16 \%$ in Gugulethu. Khayelitsha and Gugulethu are almost all black urban townships with large informal settlements where at least $50 \%$ of adults are unemployed (Shaikh et al., 2006). Furthermore HIV positive individuals in the Western Cape are more likely to be black women living in urban informal localities (Connolly, Colvin, Shisana, \& Stoker, 2004; Dorrington, Johnson, Bradshaw, \& Daniel, 2006; Kleinschmidt, Pettifor, Morris, MacPhail, \& Rees, 2007; Shaikh, \& Adendorff, 2000; Shaikh et al., 2006). There is an urgent need for increased efforts to develop targeted HIV prevention interventions among young black women in the Western Cape 
Province as they constitute the largest subgroup of the population who are driving the epidemic and most likely to suffer from adverse effects of the excess HIV mortality and morbidity (Bollinger, Cooper Arnold, \& Stover, 2004; Gouws, Stanecki, Lyerla \& Ghys, 2008; Gilbert \& Walker, 2002).

\section{Sexual Health Promotion and Public Health Approaches to HIV Prevention}

Health promotion has been defined as the combination of actions and conditions of living, including health education, that are conducive to health (Green \& Kreuter, 1999). Generally speaking public health approaches to HIV prevention include HIV and AIDS surveillance, behavioural and biomedical research and prevention programs, and public health policy (Beatty, Wheeler, \& Gaiter, 2004).

Schaalma, Abraham, Gillmore, and Kok (2004) have shown that health promotion activities should be driven by an accurate understanding of health problems and should include activities that are evidence-based and ecological in perspective. Therefore health promotion activities aiming to reduce the risk of HIV by influencing sexual behaviour should be based on clear definitions of sexual behaviours and modifiable cognitive determinants of safer sex, and should create the appropriate social and political context that facilitate the development of prerequisite social skills eg. negotiation of sex and refusal of high risk sexual behaviour (Schaalma et al., 2004). The health promotion matrix as applied to the prevention of STI/HIV is a proposed framework of activities that health education, institutional and legislative structures should conduct at primary prevention, early detection and patient care levels, in order to reduce the impact and spread of the HIV epidemic (Reddy, van den Borne, 
\& Yach, 1995). While these activities are all necessary, the consensus among various authors is that the quality of planning before implementation has great bearing on the potential success of HIV prevention activities. Reddy, van den Borne, and Yach, (1995) proposed a model for planning and evaluating health education interventions which entails understanding the health problem, identifying target modifiable behaviours, understanding the population specific determinants for changing the behaviour, intervention development and implementation. The key aspect of this model is the provision for using the evaluation results to inform policy development and improve the intervention and eventual dissemination processes.

The response to the HIV epidemic in South Africa has, to date, included extensive epidemiological research, multi-media HIV awareness and education campaigns (e.g., LoveLife), voluntary counselling and testing (VCT) services, the implementation of HIV treatment and care programs, and clinic-based STI treatment and PMTCT (prevention of mother to child transmission) programs (Bollinger et al., 2004; Chersich, \& Gray, 2005: Connelly, \& Rosen, 2006; Harrison, Smit, \& Myer, 2000; Kaaya, Mukoma, Flisher, \& Klepp, 2002; Nattrass, 2006; Steen et al., 2000; Stirling, Rees, Kasedde, \& Hankins, 2008; UNAIDS, 2008; Western Cape Department of Health, 2006).

As a vaccine that gives a sterilising immunity to HIV infection is currently not available, interventions that promote behavioural changes and condom use are currently the most powerful tools to prevent HIV infection and transmission (Lyles et al., 2007). In the research to understand HIVIAIDS risk behaviours an array of behavioural science theories have been applied (social cognitive theory, Bandura, 1994; theory of reasoned action, Fishbein \& Middlestadt, 1989; health belief model, Rosenstock, Strecher, \& Becker, 1994; theory of planned behaviour, Ajzen, 1991; AIDS risk reduction model, Catania, Kegeles, \& Coates, 1990; trans-theoretical model of behaviour change, Prochaska, 
DiClemente, \& Norcross, 1992), and although they cannot be applied blindly across settings, they have accelerated the understanding of determinants of sexual risk behaviours and condom use (Sheeran, Abraham, \& Orbell, 1999). The literature has shown that effective risk-reduction behavioural strategies for HIVIAIDS should include sessions that generate conversations aimed at imparting arguments for a positive attitude towards HIV testing, protective sexual behaviour including condom use, clear information on HIV infection pathways and specific aspects of HIVIAIDS prevention, training on specific skills in negotiating sex and condom use, and allow participants to establish condom use behaviour patterns in their normal lives (Albarracin et al., 2005; Harrison, Smit, \& Myers, 2000; Herbst et al., 2007; Lyles et al., 2007). Furthermore, interventions seem to work best when they are locally designed or adapted, peer administered, targeted towards specific risk groups and transmitted through engaging rather than passive methods (Albarracin et al., 2005; Harrison, Smit, \& Myers, 2000; Herbst et al., 2007; Lyles et al., 2007).

While the literature on behavioural interventions aiming to reduce sexual risk behaviours among young people in South Africa is currently limited, important interventions have been developed and evaluated. These include the evaluation of a life skills program on HIV and AIDS prevention among secondary school students by James and colleagues (James, Reddy, Ruiter, McCauley, \& van den Borne, 2006). The study found limited effect on condom use and psychosocial determinants of safe sex practice. However, further analyses found that students who received the full intervention were more positive in their perceptions about sexual behaviour and social connectedness (at 10-month follow-up) and reported less sex and more condom use (at 6month follow-up) than students in the partial and control groups. The results of a peer-led HIV prevention intervention among male prison inmates indicated that experimental groups were more positive about sexual communication, 
self-efficacy, and intention to perform safer sex promoting activities such as HIV testing and condom use (Sifunda et al., 2008). The adapted Stepping Stone intervention conducted among 16-23 year old youths in rural South Africa did not result in reduced incidence of HIV or sexual behaviours. However, the study found a reduced incidence of HSV-2 among intervention participants and reduced perpetration of intimate partner violence by men in the intervention group (Jewkes et al., 2006). The HIV risk reduction counselling intervention conducted among STI clinic patients in Cape Town was found to improve risk reduction practices, lower rates of unprotected intercourse, and greater likelihood of receiving HIV testing after the intervention (Simbayi et al., 2004). A structural intervention for the prevention of gender-based violence and HIV resulted in reduction of intimate partner violence experience in the intervention group and improved HIV-related communication, increased visits to voluntary counselling and testing centres, and reduced unprotected sex at last intercourse with a non-spousal partner among young intervention participants (13-35 years old) (Pronyk et al., 2006). However, there is a great need for the expansion of the development and implementation of targeted group-specific behavioural interventions to promote safe sex strategies among black women. To this end it is necessary to increase the understanding of psychosocial determinants of protective behaviour and condom use that apply to specific groups of black South African women.

In the sub-Saharan context the HIV epidemic is spread through heterosexual contact. Although there is a wealth of knowledge on determinants of condom use among heterosexual populations of unspecified HIV status (HIV naïve individuals), there is very little information on determinants of condom use among HIV negative or positive individuals, particularly women. In the next section, a non-exhaustive overview of the psychosocial determinants of 
condom use among South African heterosexual men and women is presented with some comparisons made with findings from international settings.

\section{Psychosocial determinants of protective behaviour among HIV naïve individuals}

\section{Knowledge about HIV}

According to abovementioned social cognitive models of human behaviour, individuals will use condoms once they acquire the relevant knowledge about HIV transmission pathways and methods for prevention, develop favourable attitudes to the recommended action, have the behavioural skills necessary for doing the action, and feel capable doing it. In South Africa the general awareness about HIV and condoms among the youth and the general population is very high (Shisana et al., 2005). However, the measured rate of condom use does not always match the observed level of knowledge (Pettifor et al., 2005; Pettifor, MacPhail, Bertozzi, \& Rees, 2007). Moreover, there are still many misconceptions about HIV transmission, the physical appearance of HIV positive individuals, and correct condom use (Liddell, Giles, \& Rae, 2008; Shisana et al., 2005; Camlin \& Chimbwete, 2003).

Haile, Chambers, and Garrison (2007) found that HIV knowledge was associated with a greater likelihood for HIV testing. The apparent low translation of HIV knowledge into protective behaviour may be because of poor understanding of the information about risk and severity of HIV infection. It has been shown that incomplete or incorrect knowledge is associated with higher acceptance of HIV myths which are associated with a lower rate of condom use (Teborang, 2008; Liddell, Giles, \& Rae, 2008; Reddy, Meyer-Weitz, van den Borne, \& Kok, 1999; Simbayi et al., 2005). A recent study found that black 
South Africans who strongly endorsed AIDS myths viewed condoms as less important and had a lower intention to use condoms (Liddell, Giles, \& Rae, 2008). It was found that among South African women, condom use at last sex was associated with knowledge that condoms are effective in preventing HIV transmission (Camlin \& Chimbwete, 2003). Similarly among African American women it was found that those who believed that condoms are effective in preventing diseases were more likely to use them for disease prevention purposes (Anderson, Blackbill, \& Mosher, 1996).

It has been proposed that experiential knowledge of HIVIAIDS or knowledge gained through some experience may have stronger impact on perception of HIV risk and intention to use condoms than general HIV knowledge. Palekar, Pettifor, Behets, and MacPhail (2008) found that young people who knew someone who died of AIDS had higher odds of reporting HIV related behaviour change (condom use at last intercourse, number of partners in previous 12 months), perceiving that HIV is serious and perceiving a moderate risk of contracting HIV compared to those who did not. Similarly, Liddell, Giles, and Rae (2008) found that individuals who knew HIV positive people, and/or people who had died of AIDS-related illnesses, had higher intention to use condoms. However, Hendriksen, Pettifor, Lee, Coates, and Rees, (2007) found that this only applied to male participants. Camlin and Chimbwete (2003) found no association between having known someone who died of AIDS and condom use at last sex among women in South Africa.

While HIV knowledge is necessary for behaviour change, various studies conducted in developed countries have found a weak association between general HIV knowledge and condom use (O'Sullivan, Udell, \& Patel, 2006; Sheeran et al., 1999; Albarracin et al., 2005; Albarracin, Durantini, \& Earl, 2006). Furthermore, it has been found that correct knowledge about HIV and safer sex options have positive influences on behaviour change insofar as it is 
accompanied with exposure to active behavioural intervention strategies such as condom use skills trainings (Albarracin et al., 2005, Albarracin et al., 2006; Bankole, Ahmed, Neema, Ouedraogo, \& Konyani, 2007).

\section{Perceptions of personal risk to HIV}

The health belief model assumes that individuals are motivated to adopt protective behaviours when they feel susceptible to HIV infection and fear the severity of the condition (Rosenstock, Strecher, \& Becker, 1994). Currently there is a false sense of security among the general population in South Africa. It has been found that $66 \%$ of South Africans perceive themselves to be at low risk of contracting HIV (Shisana et al., 2005). Perception of personal risk for HIV infection has been found to be the major factor driving women in South Africa to overcome barriers to HIV testing and to use condoms (Maharaj \& Cleland, 2004). Conversely a low perception of personal risk has been associated to reluctance to test for HIV (Killewo et al., 1998). Among South African adolescents, it has been found that admitting HIV risk is tantamount to exposing themselves to possible stigma and those with low perception of risk had higher risk behaviours (Maclntyre, 2004). Similarly, among adolescents in Mozambique, it has been shown that correct assessment of HIV risk was associated with a greater likelihood of using a condom at last sex (Prata, Morris, Mazive, Vahidnia, \& Stehr, 2006). Participants of a study in Ghana who perceived a high level of susceptibility to HIV infection and a low level of barriers to condom use were almost six times as likely to have used condoms at last intercourse, compared to others (Adih, \& Alexander, 1999).

In contrast, studies among young South African women showed that higher perception of HIV risk was associated with decreased consistency of condom use. (Tassiopoulos, 2006; Pettifor, Measham, Rees, \& Padian, 2004). Vermeer, Bos, Mbwambo, Kaaya, and Schaalma (2009) found that among medical students in Tanzania, perceived susceptibility to HIV infection was 
associated with a reduced intention to test for HIV, while self-efficacy for testing for HIV was associated with higher intention to test. However, Maharaj and colleagues (2006) found that condom use was higher among women with a higher perceived risk of pregnancy. Similarly among women in the US, it was found that condoms were used more consistently when used for contraceptive purposes (Fleisher, Senie, Minkoff, \& Jaccard, 1994).

While it seems intuitive that the perceived risk of HIV infection would increase the motivation for behaviour change, current evidence shows a weak association between perception of HIV threat and adoption of protective behaviour (Sheeran, et al, 1999; Albarracin et al., 2005; Albarracín et al, 2006). Furthermore empirical data suggests that messages that increase perceived efficacy for protective behaviour are more likely to improve motivation for protective behaviour rather than fear-inducing messages (Ruiter, Abraham, \& Kok, 2001; Witte, 1992; Albarracin et al, 2006).

\section{Attitude toward condom use and subjective norms}

The theory of reasoned action posits that the intention to use condoms depends on the personal attitude to condom use and the value placed on what significant others think of condom use (Fishbein \& Middlestadt, 1989). Various studies provide evidence that supports the role of the theory of reasoned action in explaining condom use behaviour in the South African context. A study among young South Africans found that a negative attitude towards condom use and negative partner-related subjective norms were associated with unprotected sex among both male and female participants (Simbayi, et al., 2005). Similarly a recent study among university students in South Africa found that a favourable attitude towards condom use, and more normative support for condom use was associated with a greater rate of condom use (Heeren, Jemmott III, Mandeya, \& Tyler, 2007). Furthermore greater favourable hedonistic beliefs about condom use, greater partner and peer approval of 
condom use, greater condom use impulse control and technical skills were associated with firmer intention to use condoms (Heeren, Jemmott III, Mandeya, \& Tyler, 2009).

Madu and Peltzer (2003) presented a 5-factor structure of attitude to condom use among black South African students: poor relationships (interpersonal), personal endorsement of AIDS myths, inconvenience of condom use, perceived negative societal attitude to condom use, and nonavailability of condom use. Liddell, Giles and Rae, (2008), found that among young South Africans a positive attitude to condom use is associated with a higher level of formal education, strong traditional beliefs about illness, ancestral protection, and knowing someone who had died of HIV, suggesting that traditional beliefs about illness are not contradictory to the promotion of condom use among black South Africans. Positive attitude to condom use was negatively associated with endorsement of AIDS myths (Liddell, Giles, \& Rae, 2008).

Various studies have found an association between condom use with attitude towards condom use and normative support for condom use in Western Countries (Sheeran et al. 1999; Albarracin et al., 2005; Albarracin et al., 2006; Jemott, \& Jemott III, 1991). A study comparing South African and American (USA) students found that having a positive attitude, greater normative support and higher self-efficacy for condom use were associated with a higher intention to use condoms and higher frequency of condom use. However, subjective norms for condom use and condom use attitude were a stronger predictor of condom use intention and frequency among American student while self-efficacy for condom use was a stronger predictor of intention among South African students (Heeren et al., 2007).

Among female immigrants in the Netherlands, it was found that positive subjective norms towards condom use, greater HIV-AIDS knowledge and 
greater perceived relationship control were associated with higher protective behaviour (Wiggers, 2003).

\section{Self-efficacy for condom use and condom use communication}

Self-efficacy for condom use, a precursor to perceived behavioural control in the theory of planned behaviour (Ajzen, 2002), is the belief in one's ability to perform a prescribed behaviour. Various studies have provided evidence that self-efficacy for condom use is a necessary factor in the adoption of condom use across populations (Albarracin et al., 2005; Burns, \& Frank, 2005; Tassiopoulos, 2006; Heeren et al., 2007; Prata et al., 2006). Burns and Frank (2005) found that self-efficacy for safer sex and a higher AIDS health locus of control were associated with higher condom use among African American students. Similarly, it has been found that higher condom use selfefficacy, HIV knowledge and positive subjective condom use norms were associated with inconsistent condom use rather than complete lack of condom use (Tassiopoulos, 2006).

Condom use requires partner interaction and cooperation, therefore verbal communication about condom use is important to the adoption of condom use behaviour. According to Klein and Knäuper (2003), women with low sexual self-efficacy for discussing safer sex practices, low assertiveness in discussing safer sex practices and lower knowledge about STI had greater tendencies to avoid STI related thoughts. Furthermore women with greater tendencies to avoid thoughts about STI were less likely to engage in discussions about safer sex. Klein, Elifson, and Sterk (2004) found that lower communication with partner was associated with higher risk behaviour among women in Atlanta (USA). In the South African context, it has been found that condoms at first intercourse, communication about condom use at sexual debut, and self-efficacy for condom use were associated with condom use among young people (Hendriksen et al., 2007; Stirling et al., 2008). Reddy, 
Meyer-Weitz, van den Borne and Kok, (2000) found that condom-using behaviour was related to communication about condom use with the steady partner, general self-efficacy in condom use, experience with previous STI (Sexually Transmitted Infections), and condom use self-efficacy. Furthermore participants who were in some or regular stage of condom use were more likely to communicate with their partners about HIV and condom use than those who were in the pre-contemplation and contemplation stage of condom use change.

\section{Relationship power and assertive negotiation of condom use}

The theory of gender and power proposes that gender based unequal division of labour, power, and socially assigned gender roles manifested within sexual relationships, place women at a disadvantage in terms of negotiating safer sex and refusing unwanted sex (Wingood \& DiClemente, 2000). The theory of gender and power has been very useful in defining determinants of condom use among women (Wingood \& DiClemente, 2000). There is currently no consensus on the definition of "relationship power" (Jenkins, 2000). However, Pulerwitz, Gortmaker, and de Jong, (2002) developed a Sexual Relationship Power Scale (SRPS) that included two subscales that define relationship power among American women as: relationship control and decision making dominance, and found that women with high levels of relationship power had higher rates of condom use. In a later study it was found that higher education and income, higher perceived relationship power, positive attitude towards condom use, greater normative support for condom use and condom use self-efficacy were associated with consistent condom use among women in the USA (Pulerwitz, Amaro, de Jong, Gortmaker, \& Rudd, 2002). Furthermore they found that $52 \%$ of the variance in consistent condom use was attributable to perceived relationship power. Some studies have found no association between condom use and relationship power, however condom 
use was higher among women who indicated making decisions about contraceptives or condom use alone or with their partner (Harvey, Bird, Galavotti, Duncan, \& Greenberg, 2002; Soler et al., 2000).

A lower condom use consistency was found among South African women, who reported higher relationship power and women with higher shared intimate experiences with their partner had higher condom use consistency (Harrison, O'Sullivan, Hoffman, Dolezal, \& Moreli, 2006). Pettifor and colleagues (2004) found no direct association between relationship power and HIV infection. However, greater relationship control, condom use self-efficacy, and communication about condom use were associated with consistent condom use.

In summary, current evidence indicates that condom use in a heterosexual relationship among HIV naïve individuals depends on a variety of factors that may apply differently to different population groups. Interventions to improve condom use consistency are more likely to have a positive impact when they provide accurate knowledge about HIV infection and prevention strategies, communication and negotiation of condom use skill training, contain messages and engaging activities aimed at improving self-efficacy for negotiating condom use and self-efficacy for condom use and positive subjective norms about condom use.

Research among HIV negative and positive women in South Africa

The research on determinants of condom use in South Africa has been conducted mainly among individuals who are unaware of their HIV status. 
There is much less information on the determinants of condom use among HIV negative or HIV positive individuals, particularly women who have tested HIV negative or positive and thus are aware of their status. Considering the high risk of HIV infection among young black South African women, a greater commitment to assisting young black women who test HIV negative to maintain their negative status, and HIV positive women to increase condom use, is imperative.

It has been shown that individuals who have taken a HIV test have a higher level of education compared to non-testers. Furthermore having a readiness to test is associated to a higher perceived risk of contracting HIV (Fylkesnes, \& Siziya, 2004). Kalichman and Simbayi (2003) showed that compared to people who had tested HIV negative, individuals who were not tested for HIV had greater AIDS related stigmas and ascribed greater shame, guilt and social disapproval to people living with HIV. Moreover various studies evaluating the effect of VCT, the main direct HIV counselling and education interventions in South Africa, have found that VCT had a greater impact among HIV positive individuals compared to those who test HIV negative and untested individuals (Mola et al., 2006; Weinhardt, Michael, Johnson, \& Bickham, 1999). This suggests that HIV negative and positive individuals who know their status may be systematically different from HIV naïve individuals. A common approach intervention to increase condom use might not be as efficacious as an intervention specifically targeted at either HIV positive or HIV negative individuals. Further understanding of how currently available information on determinants of condom use among HIV naïve individuals in South Africa distinctly apply to HIV negative and HIV positive women is necessary to inform the development of group specific interventions among HIV negative and HIVpositive individuals. 


\section{Objectives of the thesis}

The objectives of this series of studies was firstly to understand the determinants and correlates of condom use among black HIV negative and HIV positive women living in the Western Cape Province, South Africa, secondly to present process data that suggest methods for the adaptation of behavioural interventions, and the recruitment and retention of black women in behavioural interventions, and thirdly to present the effect of a pilot test of an adapted behavioural intervention conducted among HIV positive isiXhosa speaking women.

Overviews of available information on determinants of condom use among HIV negative and positive women are presented followed by short descriptions of the studies conducted among HIV positive and negative isiXhosa speaking black women that form the present thesis.

\section{Determinants of condom use among HIV-negative women in South Africa}

Very little information on the correlates of condom use specific to HIV negative women is available, particularly in the South African context. While HIV negative women receive counselling at the VCT centre at the point of testing, behavioural interventions to improve condom use among this population are rare. The development of interventions targeted at HIV negative women (Who know their status), that reinforce the knowledge acquired through media campaigns and VCT, and supplement these with skills trainings pertaining to safe sex behaviours is urgently needed.

In this thesis three chapters examine the correlates of condom use and STI risk among HIV negative black women in the Western Cape Province of South Africa. The data for studies conducted among HIV negative women were drawn from baseline data of a randomised trial of an adapted SISTA 
(Sisters Informing other Sisters on the Topic of AIDS) intervention. SISTA is a five-session, peer-led HIV prevention intervention for African-American women, 18-29 years of age, based on Social Cognitive Theory and the Theory of Gender and Power. The intervention was adapted for black South African Xhosa speaking women and evaluated in a randomised controlled trial. This evaluation is currently being finalised and therefore not included in the series of studies presented in this thesis.

Chapter 2 presents an assessment of the role of the preference for dry sex on condom use among HIV negative black women in South Africa. Chapter 3 examines the determinants of condom use among women who report low risk behaviour, high risk, or high risk with a history of transactional sex. Chapter 4 compares STI prevalence and risk profiles between non pregnant VCT attendees and women who test for HIV as part of antenatal care.

\section{Determinants of protective behaviour among HIV-positive women}

Reported rates of unprotected sex among HIV-positive individuals in South Africa range between $50-70 \%$ (Eisele et al., 2008; Kiene et al 2006; Olley, Seedat, Gxamza, Reuter, \& Stein, 2005; Simbayi et al, 2007), indicating an urgent need to revisit and strengthen HIV prevention interventions among HIV positive individuals, particularly black HIV positive women in South Africa (Bunnell, Mermin, \& De Cock, 2006).

Most of the research on determinants of condom use among HIV positive women has been conducted in the USA. Various studies have identified knowledge about HIV transmission and HIV related health risks, negative attitude to condom use, low self-efficacy for condom use, low perceived behavioural control over condom use, difficulties with negotiation of safer sex practices, HIV disclosure and perceiving barriers to condom use as important predictors of unsafe sexual behaviours among HIV positive women 
in the USA (Bedimo et al 1998; Crepaz \& Marks, 2002; Kalitchman, 2000; Raiford, Wingood, \& DiClemente, 2007).

Studies among HIV-positive individuals in South Africa have found that alcohol use during sex, sex with a perceived HIV positive partner, sex with a casual partner, a undisclosed HIV status, and denial of HIV status are associated with HIV transmission behaviour (Kiene et al 2006; Olley et al., 2005; Simbayi et al, 2007). While these determinants are important and apply to both men and women living with HIV in South Africa, the high burden of HIVAIDS among black women indicates the need for further efforts to increase the understanding of psychosocial determinants of safe sex behaviours and the adoption of safer sex among black South African women who are aware of their HIV positive status. Determinants of condom use among African American HIV positive women may apply to black South African women, but there is currently no information on how they would apply to this population. This information would facilitate the translation of determinants of condom use into targeted interventions for this population of women.

In this thesis two chapters present studies conducted among HIV positive black women. The studies conducted among black HIV positive women were drawn from the pilot of the adapted WiLLOW (Women involved in Life Learning with Other Women) intervention. The WiLLOW intervention is a coping and risk behaviour reduction intervention first developed for African American HIV-positive women (Wingood et al., 2004). The intervention addresses issues of social support, self-esteem, HIV and STI knowledge, and self-efficacy and skills towards correct condom use and condom use negotiation. The original intervention was demonstrated to be efficacious in reducing unprotected vaginal intercourse and incidence of Chlamydia Trachomatis (CT) and Neisseria Gonorrhea (NG), and in changing psychosocial determinants of condom use (Wingood et al., 2004). 
Chapter 7 presents a cross-sectional study that examines proximal and distal determinants of condom use frequency among HIV positive black women in South Africa. Chapter 8 presents the results of the pilot of the WiLLOW intervention adapted for black Xhosa women in the Western Cape Province of South Africa.

Development and implementation of interventions among HIV negative women in South Africa

Currently very few behavioural interventions specifically addressing HIV negative and HIV positive young black South African women have been developed or tested and even fewer that have shown efficacy in reducing HIV incidence and STI prevalence (Harrison, Smit, \& Myer, 2000; James et al., 2006; Pettifor et al 2005).

The development of evidence-based HIV interventions is a resourceintensive process. The adaptation of compatible interventions for young black women is a way of accelerating the development process, as adaptation reduces the costs of designing a new program, enhances the research capacity of the local scientists adapting the program, increase community ownership of the program, and build the capacity of local community members (Reddy, Taylor, \& Sifunda, 2002; Rogers, 1995). While the adaptation of interventions previously efficacious in a different setting is an option for accelerating the process of finding appropriate interventions for black South African women, a structured approach is necessary to ensure transparent adaptations and appropriate evaluation of the adapted programs. A structured process of adapting evidence-based interventions increases the consistency in terms of how interventions are discussed and a transparent way in which decisions about which element are added or removed are made.

As the rate of development and adaptation of new HIV interventions for vulnerable populations in South Africa is set to increase, there is a need for 
process information about methods for adapting and implementing behavioural interventions in this context. These are important sources of knowledge about prevailing implementation challenges and opportunities that could facilitate the implementation of new programs and the development of strategies for the potential scale up of efficacious interventions. A key stage of the implementation of interventions is the recruitment and retention of participants in a program. Behavioural interventions need to reach vulnerable populations in order for them to be useful. Furthermore, it is important to recruit a sample of the target population as representative as possible to ensure that inferences about the result are made to the right population (Gross, Mallory, Heiat, \& Krumholz, 2002). Therefore, recruitment and retention process data, as well as contextual qualitative data on facilitators and barriers to participation in behavioural intervention, are necessary to inform the development of appropriate meta-interventions to reduce hindrances to the participation of vulnerable populations in HIV prevention initiatives (Albarracin, Durantini, Earl, Gunnoe, \& Leeper, 2008). Although some research has been done to understand potential barriers to community participation in vaccine trials and uptake of HIV related health services, very little has been done to understand barriers for participation in behavioural HIV prevention programs, especially among black women (Smit, et al., 2006; Cummings, Mengistu, Negash, Bekele, \& Ghile, 2006; Albarracin et al., 2008).

Two chapters present methodological information. Chapter 5 presents the process for adapting a HIV-intervention for African-American women to a setting for Black South African Xhosa women. Chapter 6 presents the recruitment process of a randomised controlled trial (RCT) of this intervention and qualitative data about facilitators and barriers to participation in HIV prevention programs. 


\section{Overview of thesis}

The studies are presented in two parts: studies conducted among HIV negative women and those conducted among HIV positive women. The health promotion matrix as applied to the prevention of STIs/HIV from Reddy, van den Borne, and Yach (1995) has been adapted for HIV prevention among HIV positive and HIV negative women. In the perspective of the health promotion matrix as applied to HIV prevention among HIV positive and HIV negative women (see Table 1 for a brief application), the studies conducted among HIV negative black women contribute to the development of health education interventions as early HIV prevention tools, albeit at different stages of the health promotion planning model. Chapters 2, 3 and 4 present studies that aim to provide greater understanding of determinants of condom use among HIV negative, isiXhosa speaking black women. While chapters 5 and 6 present methodological studies pertaining to the implementation of the SISTA study. The studies conducted among HIV positive women contribute to the development of health education interventions at the patient care level. Chapter 7 aims to add to the understanding of psychosocial determinants of condom use among HIV positive isiXhosa speaking black women and chapter 8 contributes to the development of a behavioural intervention for this population of women. 


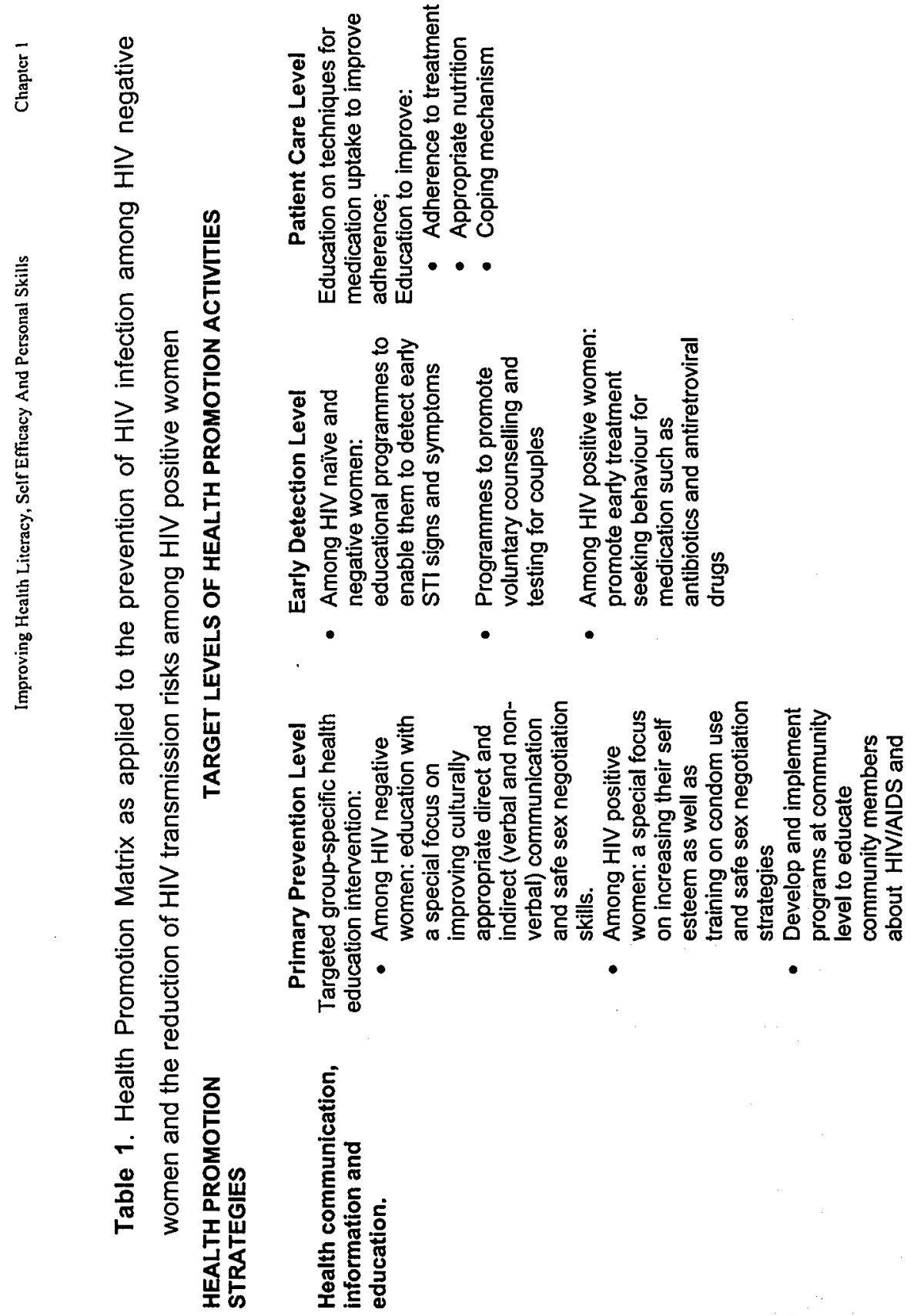


总
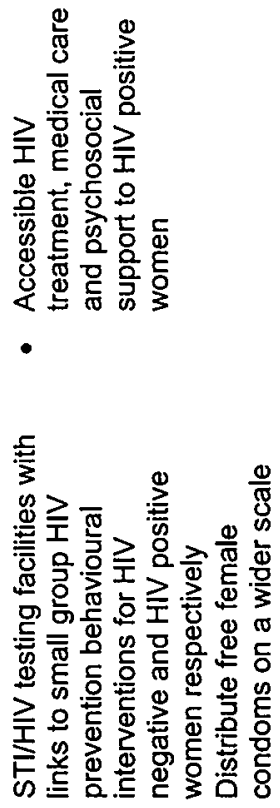

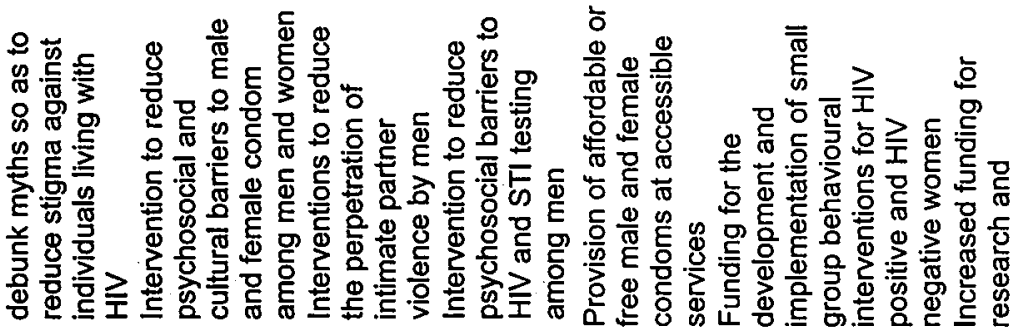

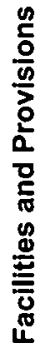




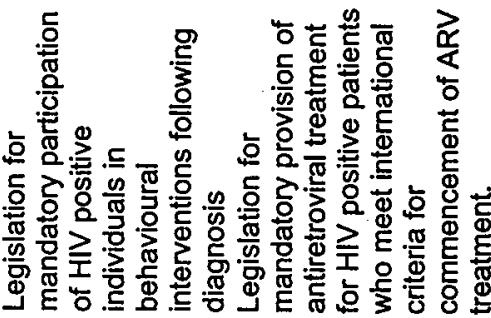

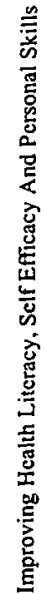

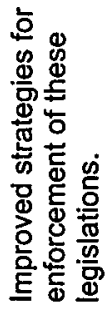

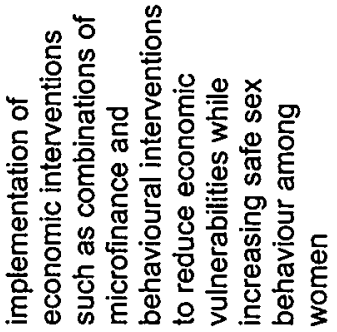
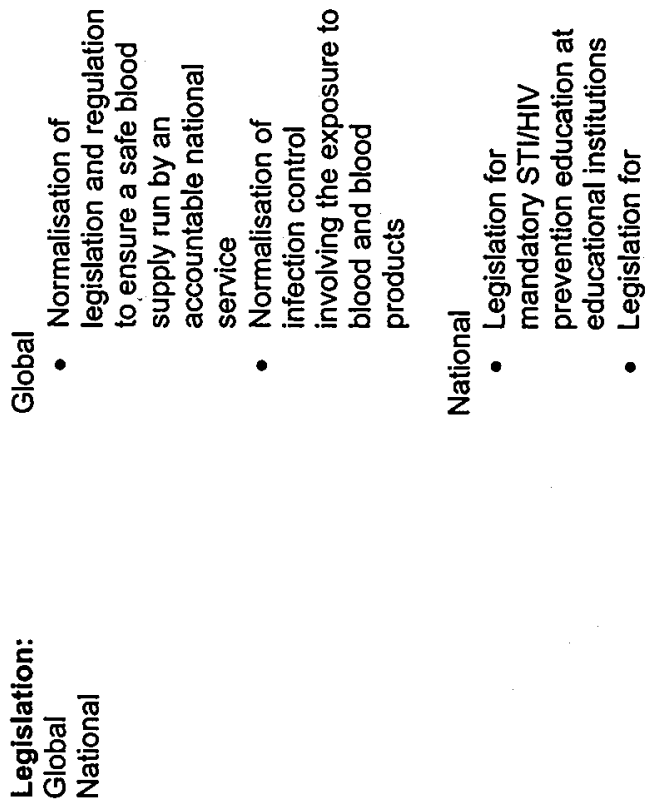


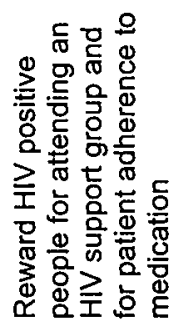

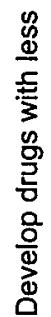

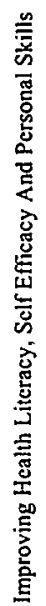
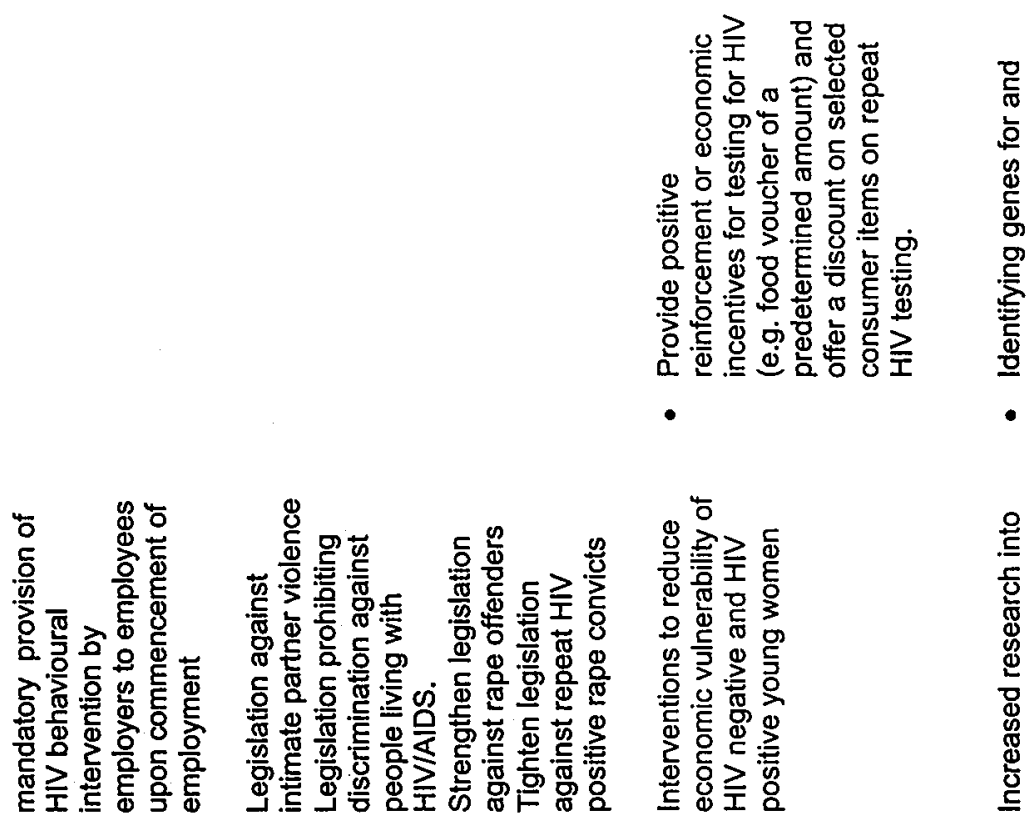

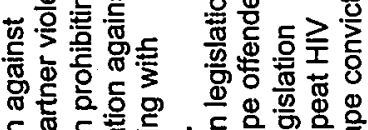

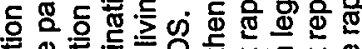

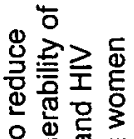

원 응

능 을

은 을 ㅁํㅇ

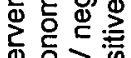

竞

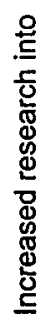

동

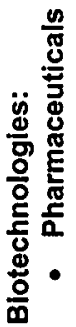




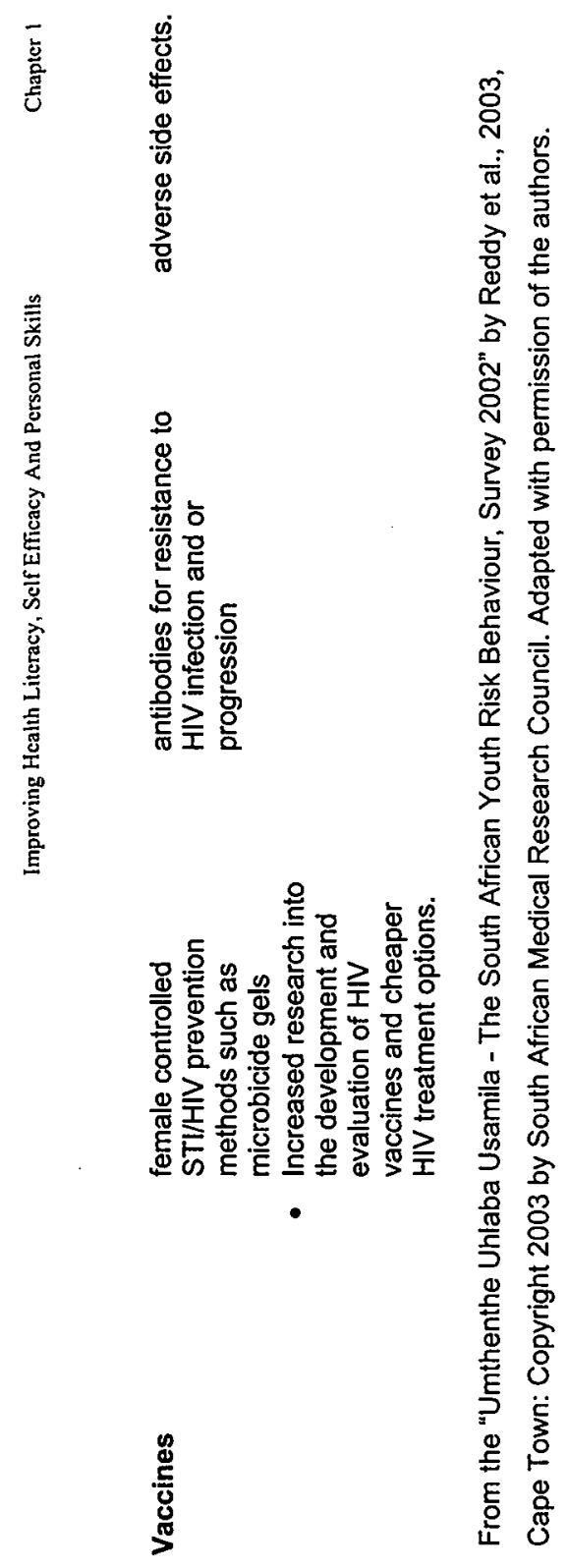


Chapters 2 to 8 are presented in the format of an independent research paper. In so far as the research was done on the same population, the chapters may partly overlap, particularly the introduction sections. Chapter 9 provides a general discussion of the results and limitations of each of the chapters and provides recommendations for future group specific HIV intervention among black South African women. 


\section{Reference}

AarØ, L.E., Flisher, A.J., Kaaya, S., Onya, H., Fuglesang, M., Klepp, K.-l. et al. (2006). Promoting sexual and reproductive health in early adolescence in South Africa and Tanzania: Development of a theory- and evidence-based intervention programme. Scandinavian Journal of Public Health, 34, $150-158$.

Adih, W.K., \& Alexander, C.S. (1999). Determinants of condom use to prevent HIV infection among youth in Ghana. Journal of Adolescent Health, 24, 63-72.

Ajzen, I. (2002). Perceived behavioural control, self-efficacy, locus of control and the theory of planned behaviour. Journal of Applied Social Psychology, 32, 665- 683.

Albarraci'n, D., Gillette, J.C., Earl, A.N., Glasman, L.R., Durantini, M.R., \& Ho, M.H. (2005). A test of major assumptions about behavior change: a comprehensive look at the effects of passive and active HIV-prevention interventions since the beginning of the epidemic. Psychological Bulletin, 131, 856-897.

Albarracin, D., Durantini, M.R., \& Earl, A. (2006). Empirical and Theoretical Conclusions of an Analysis of Outcomes of HIV-Prevention interventions. Current Directions in Psychological Science, 15, 73-78.

Albarracin, D., Durantini, M.R., Earl, A., Gunnoe, J.B., \& Leeper, J. (2008). Beyond the Most Willing Audiences: A Meta-Intervention to Increase Exposure to HIV-Prevention Programs by Vulnerable Populations. Health Psychology, 27, 638-644.

Anderson, J., Brackbill, R., \& Mosher, W. (1996). Condom use for disease prevention among unmarried U.S. women. Family Planning Perspectives, 28, 25-28.

Bandura, A. (1994). Social cognitive theory and exercise of control over HIV infection. In R. J. DiClemente \& J. L. Peterson (Eds.), Preventing AIDS: Theories and methods of behavioral interventions (pp. 25-59). New York: Plenum.

Bankole, A., Ahmed, F.H., Neema, S., Ouedraogo, C., \& Konyani, S. (2007). Knowledge of correct condom use and consistency of use among adolescents in four countries in Sub-Saharan Africa. African Journal of Reproductive Health, 11, 197-220.

Bartholomew, L.K., Parcel, G.S., Kok, G., \& Gottlieb, N.H. (2006). Planning health promotion programs: an intervention mapping approach $2^{\text {nd }}$ edition. Jossey-Bass, an imprint of Wiley, San Francisco.

Beatty, L.A., Wheeler, D., \& Gaiter, J. (2004). HIV Prevention Research for African Americans: Current and Future Directions. Journal of Black Psychology, 30, 40-58. 
Bedimo, A.L., Bennett, M., Kissinger, P., \& Clark, R.A. (1998). Understanding barriers to condom usage among HIV-infected African American women. Journal of The Association of Nurses in Aids Care, 9, 48-58.

Bollinger L, Cooper-Arnold K, Stover J. (2004). Where are the gaps? The effects of HIVprevention interventions on behavioral change. Studies in Family Planning, 35, 2738.

Bunnell, R., Mermin, J., \& De Cock, K.M. (2006). HIV prevention for a threatened Continent: implementing positive prevention in Africa. Journal of the African Medical Association, 296, 855-858.

Burns, M.J., \& Frank, D.R. (2005). AIDS health locus of control, self-efficacy for safer sexual practices, and future time orientation as predictors of condom use in African American college Students. Journal of Black Psychology, 31, 172-188.

Camlin, C.S., \& Chimbwete, C.E. (2003). Does knowing someone with AIDS affect condom use? An analysis from South Africa. AIDS Education and Prevention, 15, 231-244.

Catania, J. A., Kegeles, S. M., \& Coates, T. J. (1990). Toward an understanding of risk behavior: An AIDS risk reduction model. Health Education Quarterly, 17, 53-72.

Chersich, M., Gray, G. (2005): Progress and emerging challenges in preventing mother-to child transmission. Current Infectious Diseases Reports, 7, 393-400.

Connolly, C., Colvin, M., Shisana, O., Stoker, D. (2004). Epidemiology of HIV in South Africa - results of a national, community-based survey. South African Medical Journal, 94, 776-781.

Crepaz, N., \& Marks, G. (2002). Towards an understanding of sexual risk behavior in people living with HIV: A review of social, psychological, and medical findings. AIDS, 16, 135-149.

Cummings, B., Mengistu, M., Negash, W., Bekele, A. \& Ghile, T. (2006). Barriers to and facilitators for female participation in an HIV prevention project in Rural Ethiopia: Findings from a qualitative evaluation. Culture, Health \& Sexuality, 8, 251-266.

Dorrington, R.E., Johnson, L., Bradshaw, D., \& Daniel, T.J. (2006). The Demographic Impact of HIVIAIDS in South Africa. National and provincial indicators for 2006. Cape Town: Centre for Actuarial Research, South African Medical Research Council and Actuarial Society of South Africa 
Eisele, T.P., Mathews, C., Chopra, M., Brown L., Silvestre, E., Daries, V. et al. (2008). High levels of risk behavior among people living with HIV initiating and waiting to start antiretroviral therapy in Cape Town, South Africa. AIDS and Behavior, 12, 570-577.

Fishbein, M., \& Middlestadt, S.E. (1989). Using the theory of reasoned action as a framework for understanding and changing AIDS-related behaviors. In V. M. Mays, G. W. Albee, \& S. F. Schneider (Eds.), Primary Prevention of AIDS: Psychological approaches (pp. 93- 1 10). Newbury Park, CA: Sage.

Fleisher, J.M., Senie, R.T., Minkoff, H., \& Jaccard, J. (1994). Condom use relative to knowledge of sexually transmitted disease prevention, method of birth control, and past or present infection. Journal of Community Health, 19, 394-407.

Fylkesnes, K., \& Siziya S. (2004). A randomized trial on acceptability of voluntary HIV counselling and testing. Tropical Medicine and International Health, 9, 566-572.

Gilbert, L., \& Walker, L. (2002). Treading the path of least resistance: HIVIAIDS and social inequalities: a South African case study. Social Science a Medicine, 54, 1093-1110.

Gouws, E., Stanecki, K.A., Lyerla, R., \& Ghys, P.D. (2008). The epidemiology of HIV infection among young people aged 15-24 years in southern Africa. AIDS, 22, S5-16.

Green, L.W., \& Kreuter, M.W. (1999). Health promotion planning: An educational and ecological approach (3rd ed.). Mountain View, CA: Mayfield.

Gross, G.P., Mallory, R., Heiat, A., \& Krumholz, H.M. (2002) Reporting the Recruitment Process in Clinical Trials: Who Are These Patients and How Did They Get There? Annals of Internal Medicine, 137, 10-16.

Haile, B.J., Chambers, J.W., Garrison, J.L. (2007). Correlates of HIV knowledge and testing: Results of a 2003 South African survey. Journal of Black Studies, 38, 194-208.

Harrison, A., O'Sullivan, L.F., Hoffman, S., Dolezal, C., \& Morrell, R. (2006). Gender role and relationship norms among young adults in South Africa: measuring the context of masculinity and HIV risk. Journal of Urban Health, 83, 709-722.

Harrison, A., Smit, J.A., \& Myer, L. (2000). Prevention of HIVIAIDS in South Africa: a review of behaviour change interventions, evidence and options for the future. South African Journal of Science, 96, 285-290.

Harvey, S.M., Bird, S.T., Galavotti, C., Duncan, E.A., \& Greenberg, D. (2002). Relationship power, sexual decision making and condom use among women at risk for HIV $I$ STOs. Women and Health, 36, 69-83. 
Heeren, G.A., Jemmott III, J.B., Mandeya, A., \& Tyler, J.C. (2007). Theory-based predictors of condom use among university Students in the United States and South Africa. AIDS Education and Prevention, 19, 1-12.

Heeren, G.A., Jemmott III, J.B., Mandeya, A., \& Tyler, J.C. (2009). Sub-Saharan African University Students' Beliefs about Condoms, Condom-use Intention, and Subsequent Condom Use: A Prospective Study. AIDS and Behavior, 13, 268-276.

Hendriksen, E.S., Pettifor, A., Lee, S-J., Coates, T.J., \& Rees, H.V. (2007). Predictors of Condom Use Among Young Adults in South Africa: The Reproductive Health and HIV Research Unit National Youth Survey American Journal of Public Health, 97, 12411248.

Herbst, J.H., Kay, L.S., Passin, W.F., Lyles, C.M., Crepaz, N., Marin, B.V. et al. (2007). A systematic review and meta-analysis of behavioral interventions to reduce HIV risk behaviors of Hispanics in the United States and Puerto Rico. AIDS and Behavior, 11, 25-47.

James, S., Reddy, P., Ruiter, R.A.C., McCauley, A., van den Borne, B. (2006). The impact of an HIV and AIDS life skills program on secondary school students in KwazuluNatal, South Africa. Aids Education and Prevention, 18, 281-294.

Jemmott, L. S., \& Jemmott, J.B. III (1991). Applying the theory of reasoned action to AIDS risk behavior: condom use among black Women. Nursing Research, 40, 195-254.

Jenkins, S.R. (2000). Introduction to the special issue: defining gender, relationships, and power. Sex Roles, 42, 467-493.

Jewkes, R., Nduna, M., Levin, J., Jama, N., Dunkle, K., Khuzwayo, N. et al. (2006). A cluster randomized-controlled trial to determine the effectiveness of Stepping Stones in preventing HIV infections and promoting safer sexual behaviour amongst youth in the rural Eastern Cape, South Africa: trial design, methods and baseline findings. Tropical Medicine and International Health, 11, 3-16.

Kalichman, S.C. (2000). HIV Transmission Risk Behaviors of Men and Women Living With HIV-AIDS: Prevalence, Predictors, and Emerging Clinical Interventions. Clinical Psychology: Science and Practice, 7, 32 - 47.

Kalichman, S.C., \& Simbayi, L.C. (2003) HIV testing attitudes, AIDS stigma, and voluntary HIV counselling and testing in a black township in Cape Town, South Africa. Sexually Transmitted Infections, 79, 442-447. 
Kiene, S. M., Christie, S., Cornman, D. H., Fisher, W. A., Shuper, P. A., Pillay, S., et al. (2006). Sexual risk behaviour among HIV positive individuals in clinical care in urban KwaZulu-Natal, South Africa. AIDS, 20, 1781-1784.

Killewo, J.Z., Kwesigabo, G., Comoro, C., Lugalla, J., Mhalu, F.S., Biberfeld, G. et al. (1998). Acceptability of voluntary HIV testing with counselling in a rural village in Kagera, Tanzania. AIDS Care, 10, 431-439.

Klein, H., Elifson, K.W., \& Sterk, C.E. (2004). Partner communication and HIV risk behaviors among "at risk" women. Soz.- Präventivmed, 49, 363-374.

Klein, R., \& Knäuper, B. (2003). The role of cognitive avoidance of STls for discussing safer sex practices and for condom use consisteny. Canadian Journal of Human Sexuality, $12,137-149$.

Kleinschmidt, I., Pettifor A., Morris, N., MacPhail, C., \& Rees, H. (2007). Geographic Distribution of Human Immunodeficiency Virus in South Africa. American Journal of Tropical Medicine and Hygene, 77, 1163-1169.

Liddell, C., Giles, M., \& Rae, G. (2008). The Culture of Condoms: Culturally Grounded Variables and their Association with Attitudes to Condoms. Psychosomatic Medicine, 70, 496-504.

Lyles, C.M., Kay, L.S., Crepaz, N., Herbst, J.H., Passin, W.F., Kim, A.S., et al (2007). Bestevidence interventions: findings from a systematic review of HIV behavioral interventions for US populations at high risk, 2000-2004. American Journal of Public Health, 97, 133-43.

Madu, S.N., \& Peltzer, K. (2003). Factor structure of condom attitude among black South African University students. Social behaviour and Personality, 31, 265-274.

Maharaj, P., \& Cleland, J. (2004). Condom use within marital and cohabiting partnerships in Kwa-Zulu Natal, South Africa. Studies in family planning, 35, 116-124.

Macintyre, K., Rutenberg, N., Brown, L., \& Karim, A. (2004). Understanding Perceptions of HIV Risk Among Adolescents in KwaZulu-Natal. AIDS and Behavior, 8, 237-250.

Mola, O.D., Mercer, M.A., Asghar, R.J., Gimbel-Sherr, K.H., Gimbel-Sherr, S., Micek, M.A. et al. (2006). Condom use after voluntary counselling and testing in central Mozambique. Tropical Medicine and International Health 11, 176-181.

Nattrass, N. (2006). South Africa's "Rollout" of highly active antiretroviral therapy: A critical assessment. Joumal of Acquired Immune Deficiency Syndromes, 43, 618-623. 
Raiford, J.L., Wingood, G.M., \& DiClemente, R.J. (2007). Correlates of Consistent Condom Use Among HIV-Positive African American Women. Women \& Health, 46, 41- 58.

Reddy, P., Meyer-Weitz, A., van den Borne, B., \& Kok G. (1999). STD-related

knowledge, beliefs and attitudes of Xhosa-speaking patients attending STD primary health-care clinics in South Africa. International Journal of STD \& AIDS, 10, 392-400.

Reddy, P., Taylor, S.E., \& Sifunda, S. (2002). Research capacity building and

collaboration between South African and American partners: the adaptation of an intervention model for HIVIAIDS prevention in corrections research. AIDS Education and Prevention, 14, 92-102.

Rogers, E.M. (1995). Diffusion of innovations ( $4^{\text {th }}$ ed.) New York: The Free Press.

Rosenstock, I. M., Strecher, V. J., \& Becker, M. H. (1994). The health belief model and HIV risk behavior change. In R. J. DiClemente \& J. L. Peterson (Eds.), Preventing AIDS: Theories and methods of behavioral interventions (pp. 5-22). New York: Plenum Press.

Ruiter, R.A.C., Abraham, C., \& Kok, G. (2001). Scary warnings and rational precautions: A review of the psychology of fear appeals. Psychology \& Health, 16, 613-630.

Schaalma, H.P., Abraham, C., Gillmore, M.R., \& Kok, G. (2004). Sex Education as Health Promotion: What Does It Take? Archives of Sexual Behavior, 33, 259-269.

Schaalma, H.P., Kok, G., Abraham, C., Hospers, H.J., Klepp, K.I. \& Parcel, G. (2002). HIV education for young people: intervention effectiveness, programme development, and future research. Prospects, 32, 187-206.

Simbayi, L.C., Kalichman, S.C., Skinner, D., Jooste, S., Cain, D., Cherry, C., et al. (2004). Theory-based HIV risk reduction counselling for sexually transmitted infection clinic patients in Cape Town, South Africa. Sexually Transmitted Diseases, 31, 727733.

Simbayi, L. C., Kalichman, S. C., Strebel, A., Cloete, A., Henda, N., \& Mqeketo, A. (2007). Disclosure of HIV status to sex partners and sexual risk behaviours among HIVpositive men and women, Cape Town, South Africa. Sexually Transmitted Infections, $83,29-34$.

Simbayi, L.C., Kalichman, S.C., Jooste, S., Cherry, C., Mfecane, S., \& Cain, D. (2005). Risk factors for HIV-AIDS among youth in Cape Town, South Africa. AIDS and Behavior, 9, 53-61. 
Olley, B. O., Seedat, S., Gxamza, F., Reuter, H., \& Stein, D. J. (2005). Determinants of unprotected sex among HIV-positive patients in South Africa. AIDS Care, 17, 1-9.

O'Sullivan, L.F., Udell, W., \& Patel, V.L. (2006). Young urban adults' heterosexual risk encounters and perceived risk and safety: a structured diary study. Journal of Sex Research, 43, 343-351.

Palekar, R., Pettifor, A., Behets, F., MacPhail, C. (2008). Association between knowing someone who died of AIDS and behavior change among South African youth. AIDS and Behavior, 12, 903-912.

Pettifor, A.E., Measham, D.M., Rees, H.V., \& Padian, N.S. (2004). Sexual Power and HIV Risk, South Africa. Emerging Infectious Diseases, 10, 1996-2004.

Pettifor, A.E., Kleinschmidt, I., Levin, J., Rees, H.V., MacPhail, C., Madikizela-Hlongwa, L. et al. (2005). A community-based study to examine the effect of a youth HIV prevention intervention on young people aged 15-24 in South Africa: results of the baseline survey. Tropical Medicine and International Health, 10, 971-980

Pettifor, A.E., MacPhail, C., Bertozzi, S., \& Rees, H.V. (2007) Challenge of evaluating a national HIV prevention programme: the case of loveLife, South Africa. Sexually Transmitted Infections, 83, i70-i74.

Prata, N., Morris, L., Mazive, E., Vahidnia, F., \& Stehr, M. (2006). Relationship between HIV risk perception and condom use: evidence from a population-based survey in Mozambique. International Family Planning Perspectives, 32, 192-200.

Prochaska, J. O., DiClemente, C. C., \& Norcross, J. C. (1992). In search of how people change. Applications to addictive behaviors. American Psychologist, 47, 1102-1114.

Pronyk, P.M., Hargreaves, J.R., Kim, J.C., Morison, L.A., Phetla, G., Watts, C. et al. (2006). Effect of a structural intervention for the prevention of intimate-partner violence and HIV in rural South Africa: a cluster randomised trial. Lancet, 368, 1973-1983.

Pulerwitz, J., Gortmaker, S.L., \& DeJong, W. (2000). Measuring sexual relationship power in HIVISTD research. Sex Roles, 42, 637-660.

Pulerwitz, J., Amaro, H., De Jong, W., Gortmaker, S.L., \& Rudd, R. (2002). Relationship power, condom use and HIV risk among women in the USA. AIDS Care, 14, 789800. 
Olley, B. O., Seedat, S., Gxamza, F., Reuter, H., \& Stein, D. J. (2005). Determinants of unprotected sex among HIV-positive patients in South Africa. AIDS Care, 17, 1-9.

O'Suilivan, L.F., Udell, W., \& Patel, V.L. (2006). Young urban adults' heterosexual risk encounters and perceived risk and safety: a structured diary study. Journal of Sex Research, 43, 343-351.

Palekar, R., Pettifor, A., Behets, F., MacPhail, C. (2008). Association between knowing someone who died of AIDS and behavior change among South African youth. AIDS and Behavior, 12, 903-912.

Pettifor, A.E., Measham, D.M., Rees, H.V., \& Padian, N.S. (2004). Sexual Power and HIV Risk, South Africa. Emerging Infectious Diseases, 10, 1996-2004.

Pettifor, A.E., Kleinschmidt, I., Levin, J., Rees, H.V., MacPhail, C., Madikizela-Hlongwa, L. et al. (2005). A community-based study to examine the effect of a youth HIV prevention intervention on young people aged 15-24 in South Africa: results of the baseline survey. Tropical Medicine and International Health, 10, 971-980

Pettifor, A.E., MacPhail, C., Bertozzi, S., \& Rees, H.V. (2007) Challenge of evaluating a national HIV prevention programme: the case of loveLife, South Africa. Sexually Transmitted Infections, 83, i70-i74.

Prata, N., Morris, L., Mazive, E., Vahidnia, F., \& Stehr, M. (2006). Relationship between HIV risk perception and condom use: evidence from a population-based survey in Mozambique. International Family Planning Perspectives, 32, 192-200.

Prochaska, J. O., DiClemente, C. C., \& Norcross, J. C. (1992). In search of how people change. Applications to addictive behaviors. American Psychologist, 47, 1102-1114.

Pronyk, P.M., Hargreaves, J.R., Kim, J.C., Morison, L.A., Phetla, G., Watts, C. et al. (2006). Effect of a structural intervention for the prevention of intimate-partner violence and HIV in rural South Africa: a cluster randomised trial. Lancet, 368, 1973-1983.

Pulerwitz, J., Gortmaker, S.L., \& DeJong, W. (2000). Measuring sexual relationship power in HIVISTD research. Sex Roles, 42, 637-660.

Pulerwitz, J., Amaro, H., De Jong, W., Gortmaker, S.L., \& Rudd, R. (2002). Relationship power, condom use and HIV risk among women in the USA. AIDS Care, 14, 789800. 
Raiford, J.L., Wingood, G.M., \& DiClemente, R.J. (2007). Correlates of Consistent Condom Use Among HIV-Positive African American Women. Women \& Health, 46, 41- 58.

Reddy, P., Meyer-Weitz, A., van den Borne, B., \& Kok G. (1999). STD-related

knowledge, beliefs and attitudes of Xhosa-speaking patients attending STD primary health-care clinics in South Africa. International Journal of STD \& AIDS, 10, 392-400. Reddy, P., Taylor, S.E., \& Sifunda, S. (2002). Research capacity building and collaboration between South African and American partners: the adaptation of an intervention model for HIVIAIDS prevention in corrections research. AIDS Education and Prevention, 14, 92-102.

Rogers, E.M. (1995). Diffusion of innovations ( $4^{\text {th }}$ ed.) New York: The Free Press.

Rosenstock, I. M., Strecher, V. J., \& Becker, M. H. (1994). The health belief model and HIV risk behavior change. In R. J. DiClemente \& J. L. Peterson (Eds.), Preventing AIDS: Theories and methods of behavioral interventions (pp. 5-22). New York: Plenum Press.

Ruiter, R.A.C., Abraham, C., \& Kok, G. (2001). Scary warnings and rational precautions: A review of the psychology of fear appeals. Psychology \& Health, 16, 613-630.

Schaalma, H.P., Abraham, C., Gillmore, M.R., \& Kok, G. (2004). Sex Education as Health Promotion: What Does It Take? Archives of Sexual Behavior, 33, 259-269.

Schaalma, H.P., Kok, G., Abraham, C., Hospers, H.J., Klepp, K.I. \& Parcel, G. (2002). HIV education for young people: intervention effectiveness, programme development, and future research. Prospects, 32, 187-206.

Simbayi, L.C., Kalichman, S.C., Skinner, D., Jooste, S., Cain, D., Cherry, C., et al. (2004).Theory-based HIV risk reduction counselling for sexually transmitted infection clinic patients in Cape Town, South Africa. Sexually Transmitted Diseases, 31, 727733.

Simbayi, L. C., Kalichman, S. C., Strebel, A., Cloete, A., Henda, N., \& Mqeketo, A. (2007). Disclosure of HIV status to sex partners and sexual risk behaviours among HIVpositive men and women, Cape Town, South Africa. Sexually Transmitted Infections, $83,29-34$.

Simbayi, L.C., Kalichman, S.C., Jooste, S., Cherry, C., Mfecane, S., \& Cain, D. (2005). Risk factors for HIV-AIDS among youth in Cape Town, South Africa. AIDS and Behavior, 9, 53-61. 
Shaikh, N., Abdullah, F., Lombard, C.J., Smith, L., Bradshaw, D., \& Makubalo, L. (2006). Masking through averages - intraprovincial heterogeneity in HIV prevalence within the Western Cape. South African Medical Journal, 96, 539-543.

Shaikh, N., \& Adendorff, T. (2000). Health Status Report. Health Status and Health Service Evaluation Report 1999-2000. Western Cape Department of Health, 2000.

Sheeran, P., Abraham, C., \& Orbell, S. (1999). Psychosocial correlates of heterosexual condom use: A meta-analysis. Psychological Bulletin, 125, 90-132.

Shisana, O., Rehle, T., Simbayi, L.C., Parker, W., Zuma, K., Connolly, C et al. (2005). South African national HIV prevalence, HIV incidence, behaviour and communication survey, 2005. Cape Town: HSRC Press.

Sifunda, S., Reddy, P.S., Braithwaite, R., Stephens, T., Bhengu, S., Ruiter, R.A.C. et al. (2008). Intervention for Prison Inmates in South Africa The Effectiveness of a PeerLed HIVIAIDS and STI Health Education Health Education and Behavior, 35, 494508.

Smit, J., Middelkoop, K., Myer, L., Seedat, S., Bekker, L-G., \& Stein, D.J. (2006). Willingness to participate in HIV vaccine research in a peri-urban South African community. International Journal of STD \& AIDS, 17, 176-179.

Soler, H., Quadagno, D., Sly, D.F., Riehman, K.S., Eberstein, I.W., \& Harrison, D.F. (2000). Relationship dynamics, ethnicity and condom use among low-income women Family Planning Perspectives, 32, 82-101.

Steen, R., Vuylsteke, B., Decoito, T., Ralepeli, S., Fehler, G., Conley, J. et al. (2000) Evidence of Declining STD Prevalence in a South African Mining Community Following a Core-Group Intervention. Sexually Transmitted Diseases, 27, 1-8.

Stirling, M., Rees, H., Kaseddea, S., \& Hankins, C. (2008). Addressing the vulnerability of young women and girls to stop the HIV epidemic in southern Africa. AIDS, 22, S1-S3.

Tassiopoulos, K.K., Seage III, G.R., Sam, N. E., Ao, T.T.H., Masenga, E.J., Hughes, M.D., et al. (2006). Sexual Behavior, Psychosocial and Knowledge Differences between Consistent, Inconsistent and Non-Users of Condoms: A Study of Female Bar and Hotel Workers in Moshi, Tanzania. AIDS and Behavior, 10, 405-413. 
Tenborang, E.Y. (2008). Perceptions of HIVIAIDS risk and sexual behaviour among youth in Cape Town, South Africa. Dissertation Abstracts International Section A: Humanities and Social Sciences, 69, 2477.

UNAIDS (2008). Report on the global HIV epidemic. UNAIDS; Geneva

Vermeer, W., Bos., A.E.R., Mbwambo, J., Kaaya, S., Schaalma, H.P. (2009). Social cognitive variables predicting voluntary counselling and testing among Tanzanian medical students. Patient Education and Counselling, 75, 135, 140.

Weinhardt, L.S., Michael, P., Johnson, B.T., \& Bickham N.L. (1999). Effects of HIV counselling and testing on sexual risk behaviour: a meta-analytic review of published research, 1985-1997. American Journal of Public Health, 89, 1397-1405.

Western Cape Department of Health. (2006). The Western Cape Antiretroviral Programme: Monitoring Report, June (2006). Cape Town: Provincial Government of the Western Cape.

Wigger, L.C.W., de Wit, J.B.F., Gras, M.J., Coutinho, R.A., \& van den Hoek. (2003). Risk behavior and social-cognitive determinants of condom use among ethnic minority communities in Amsterdam. AIDS Education and Prevention, 15, 430-447.

Wingood, G.M., \& DiClemente, R.J. (2000). Application of the Theory of Gender and Power to Examine HIV-Related Exposures, Risk Factors, and Effective Interventions for Women. Health Education \& Behavior, 27, 539-565.

Wingood, G.M., DiClemente, R.J., Mikhail, I., Lang, D.L., McCree, D.H., Davies, S.L., et al. (2004). A Randomized Controlled Trial to Reduce HIV Transmission Risk Behaviors and Sexually Transmitted Diseases among Women Living With HIV: The WILLOW Program. Journal of Acquired Immune Deficiency Syndrome, 37, S58-S67.

Witte, K. (1992). The role of threat and efficacy in AIDS prevention. International Quarterly of Community Health Education, 12, 225-249. 



\section{Chapter 2}

\section{Preference for dry sex, condom use and risk of STI}

\section{among HIV-negative black women in the Western}

\section{Cape Province, South Africa}

Published as: Priscilla Reddy, Dorina Saleh-Onoya, Sibusiso Sifunda, Delia Lang, Gina Wingood, Bart van den Borne, and Robert A.C. Ruiter. (2009). Preference for dry sex, condom use and risk of STI among HIV-negative black women in the Western Cape province, South Africa. South African Journal of Science 105, 73-76. 


\section{Introduction}

The practice of wiping, douching or inserting substances into the vagina is reportedly common in sub-Saharan Africa (Beksinska, Rees, Kleinschmidt, \& McIntyre, 1999; Myer, Kuhn, Stein., Wright, \& Denny, 2005; Brown \& Brown, 2000; Brown, Brown, \& Ayowa, 1993; Civic, \& Wilson, 1996). Intercourse following such vaginal treatment is referred to as "dry sex" (Beksinska, Rees, Kleinschmidt, \& Mclntyre, 1999; Myer, Kuhn, Stein., Wright, \& Denny, 2005). The most common reasons offered by women for these practices include the enhancement of sexual experience through sensations of vaginal dryness, tightness or warming; cleansing of the vagina before or after intercourse; treatment or prevention of $\mathrm{STI}$; restoration and tightening of the vagina after delivery; or the satisfaction of a partner (Beksinska, Rees, Kleinschmidt, \& Mclntyre, 1999; Myer, Kuhn, Stein., Wright, \& Denny, 2005; Brown \& Brown, 2000). Although the evidence in the literature is inconclusive, (Beksinska, Rees, Kleinschmidt, \& Mclntyre, 1999; Myer, Kuhn, Stein., Wright, \& Denny, 2005; Brown \& Brown, 2000; Brown, Brown, \& Ayowa, 1993), it has been suggested that "dry sex" may increase the risk of HIV infection among women through the sloughing of the vaginal wall during sex, or possible inflammation, ulceration or epithelial damage caused by the insertion of substances in the vagina (Myer, Kuhn, Stein., Wright, \& Denny, 2005; Brown, Brown, \& Ayowa, 1993).

In a study conducted among Zimbabwean women, participants indicated that condoms frequently burst when used in conjunction with drying agents or "because the vagina was so tight", and condoms may block the effect of some "love agents" such as lovedrops (a commercial agent imported from South Africa) or mutundo wegudo (a traditional powder believed to have been made from baboon's urine, which when rubbed on incisions on the body is believed to magically cause a man to remain faithful to one woman) (Civic, \& Wilson, 
1996). In South Africa, where the HIV prevalence among pregnant women attending public health services in 2006 was $29.1 \%$, (Department of Health of South Africa, 2007) there is increasing concern over the high prevalence of the practice of "dry sex" (Beksinska, Rees, Kleinschmidt, \& Mclntyre, 1999; Baleta. 1998). It has been reported that $60 \%$ of men and $46 \%$ of interviewed women indicated preferring dry sex over lubricated sex (Beksinska, Rees, Kleinschmidt, \& Mclntyre, 1999). The most common materials used included tissues, towels or toilet paper; very few of the women reported using traditional herbs to dry the vagina. The specific materials or substances may vary widely across population groups (Beksinska, Rees, Kleinschmidt, \& McIntyre, 1999; Myer, Kuhn, Stein., Wright, \& Denny, 2005).

Many studies have focused on elucidating the mechanisms through which substances inserted into the vagina, or dry sex practices, may directly increase the risk of HIV in women (Beksinska, Rees, Kleinschmidt, \& Mclntyre, 1999; Myer, Kuhn, Stein., Wright, \& Denny, 2005; Brown \& Brown, 2000; Brown, Brown, \& Ayowa, 1993; Civic, \& Wilson, 1996). A preference for the practice of dry sex among women could, however, reduce their desire to use condoms. Research into the implications of the preference for dry sex among women on their uptake of condoms use is therefore important. The objectives of this study were to describe dry sex behaviour among Xhosa women in South Africa, and to evaluate the association of the preference for dry sex with the rate of condom use and the prevalence of sexually transmitted infections (STIs) involving Chlamydia trachomatis (CT), Neisseria gonorrhoea (NG) and Trichomonas vaginalis (TV).

\section{Methods}

Study setting and participants 
Data for this study were drawn from baseline measures of a randomised, controlled trial, which evaluated an HIV risk-reduction intervention programme designed for isiXhosa-speaking women living in peri-urban areas of the Western Cape Province, South Africa. This RCT is currently being completed. The Western Cape Province is the second wealthiest province in South Africa. It is highly urbanised with $87 \%$ of its population living in the Cape metropolis. Only $21 \%$ of the population is classified as black, $54 \%$ is "coloured" and the rest is "white" (Shaikh, \& Adendorff, 2000). There are, however, acute differences in health provision, health status and HIV prevalence that are closely related to racial, socio-economic and type-of-locality differences (Shaikh et al., 2006). HIV prevalence is lowest among people living in wealthy formal urban settlements and highest in poor, informal urban settlements (referred to as townships), where at least $50 \%$ of adults are unemployed (Shaikh et al., 2006).

Recruitment into the intervention study occurred between January 2006 and December 2007. Women were eligible to participate if they were black, isiXhosa- speaking women aged between 18 and 35 , sought voluntary counselling and testing (VCT) services at any one of five peri-urban primary health care clinics, and had tested HIV-negative in the previous eight weeks. Participants were reassured that their identities would be treated as confidential.

\section{Data collection}

All 446 women gave written informed consent to complete an interviewer- administered behavioural questionnaire and provided one selfadministered vaginal swab. Participants were guided to self-administer the vaginal swab in a sterile manner (Van de Wijgert et al., 2006).

The questionnaire was translated into isiXhosa by bilingual researchers and checked for linguistic appropriateness, comprehension and cultural 
relevance, and then translated back from isiXhosa into English, to ensure accuracy and meaning of constructs. The questionnaires were computerbased (ACASI) and administered by trained, isiXhosa-speaking, black, female interviewers. This assessment procedure took about an hour to complete. Participants were given R20 (approx. \$2.74) for completing the assessment procedures.

All participants' vaginal swabs were tested for $C T, N G$, and TV. Tests for CT and NG were conducted using the COBAS Amplicor CT/NG PCR-based assay (Roche Molecular Diagnostics) (Crotchfelt et al., 1997). The PCR test for TV was done using a PCR with the primers set TVK3/TVK7 (Crucitti et al., 2003). STI results were coded 0 for a negative result and 1 for a positive result. Those who tested positive for any one STI were referred to a contracted medical practitioner in their respective areas and were given single-dose prescriptions of azithromycin (1 g) for CT, ciprofloxacin (500 mg) for NG or metronidazole $(2 \mathrm{~g})$ for TV infection (Pepin, \& Mabey, 2003). The medical practitioner supervised the uptake of the treatment. The study protocol was approved by the Ethics Committee of the South African Medical Association (SAMA) and the Emory University Institutional Review Board (IRB) prior to implementation.

\section{Measures}

The variable 'Minimum of $1 \mathrm{STI}$ ' was created from the STI test results and denotes frequency of infection with at least one STI (coded Yes $=1$ and $\mathrm{No}=0$ ).

The questionnaire included measures of condom use at last sexual encounter, number of sex partners in the past six months, preference for dry sex, preference or otherwise of main partner for dry sex, frequency of sex in past months, frequency of condom use in the past month, rate of condom use, personal attitude towards condom use, perceived attitude of main partner 
towards condom use, perceived attitude of main partner towards STI testing, STI history, length of main relationship, whether living with main sex partner, use of vaginal douching and frequency thereof, solutions regularly used to wash the vagina, and control over the direction of the relationship. The measurement details of these variables are described in greater detail in Table 1.

\section{Data analysis}

Frequencies and percentages, or means and standard deviations (SD), were used to describe categorical and continuous variables, respectively. Logistic regression was used to evaluate univariate relationships with preference for dry sex. Variables with a significant univariate relationship with preference for dry sex were included in the multivariate regression model. The adjusted relationships of these measures with preference for dry sex were modelled in a multivariate logistic regression model. Significance level was set at the $5 \%$ level for all analyses. All analyses were conducted in SPSS version 15 (SPSS Inc., Chicago, IL).

Table 1. Description of study variables

\begin{tabular}{|l|l|l|}
\hline Variables & Questions & Coding \\
\hline Preference for dry sex & $\begin{array}{l}\text { Do you prefer that your vagina be } \\
\text { dry during sex? }\end{array}$ & $\begin{array}{l}1=\text { Yes and } \\
0=\text { No }\end{array}$ \\
\hline Age at last birthday & $\begin{array}{l}\text { How old were you on your last } \\
\text { birthday? }\end{array}$ & \\
\hline Age of main sex partner & How old is your main partner? & \\
\hline Length of main & How long have you been in this & \\
\hline
\end{tabular}




\begin{tabular}{|c|c|c|}
\hline relationship in months & relationship? & \\
\hline $\begin{array}{l}\text { Number of sex partners in } \\
\text { the past } 6 \text { months }\end{array}$ & $\begin{array}{l}\text { In the past } 6 \text { months, how many } \\
\text { men have you had vaginal sex } \\
\text { with? }\end{array}$ & \\
\hline Condom use at last sex & $\begin{array}{l}\text { The last time you had vaginal sex } \\
\text { with your main partner, did you use } \\
\text { a condom? }\end{array}$ & $\begin{array}{l}1=\text { Yes and } \\
0=\text { No }\end{array}$ \\
\hline $\begin{array}{l}\text { Frequency of sex in past } \\
\text { month }\end{array}$ & $\begin{array}{l}\text { In the last } 30 \text { days, how many } \\
\text { times have you had vaginal sex? }\end{array}$ & \\
\hline $\begin{array}{l}\text { Frequency of condom use } \\
\text { in past month }\end{array}$ & $\begin{array}{l}\text { Of the number of times that you } \\
\text { had sex in the last } 30 \text { days, how } \\
\text { many times did you use a } \\
\text { condom? }\end{array}$ & \\
\hline $\begin{array}{l}\text { Rate of condom use in } \\
\text { past } 30 \text { days }\end{array}$ & $\begin{array}{l}\text { Determined by dividing frequency } \\
\text { of condom use in past month by } \\
\text { frequency of sex in past months. }\end{array}$ & \\
\hline $\begin{array}{l}\text { Main sex partner prefers } \\
\text { dry sex }\end{array}$ & $\begin{array}{l}\text { Does your main partner prefer that } \\
\text { your vagina be dry during sex? }\end{array}$ & $\begin{array}{l}1=\text { Yes and } \\
0=\text { No }\end{array}$ \\
\hline $\begin{array}{l}\text { Washed the inside of } \\
\text { vagina with a special } \\
\text { solution }\end{array}$ & $\begin{array}{l}\text { Have you ever washed the inside } \\
\text { of your vagina with a special } \\
\text { solution? }\end{array}$ & $\begin{array}{l}1=\text { Yes and } \\
0=\text { No }\end{array}$ \\
\hline $\begin{array}{l}\text { Frequency of vaginal } \\
\text { douching in past } 30 \text { days }\end{array}$ & $\begin{array}{l}\text { How many times, in the past } 30 \\
\text { days, have you washed the inside }\end{array}$ & \\
\hline
\end{tabular}




\begin{tabular}{|c|c|c|}
\hline & of your vagina? & \\
\hline $\begin{array}{l}\text { Common solution used to } \\
\text { wash the inside of vagina }\end{array}$ & $\begin{array}{l}\text { What do you use to wash the } \\
\text { inside of your vagina? }\end{array}$ & $\begin{array}{l}1=\text { Aphrodisiac, } \\
2=\text { Antiseptic } \\
\text { solution } \\
3=\text { Detergent } \\
4=\text { Traditional } \\
\text { medicine }\end{array}$ \\
\hline STI history & Have you ever had an STI? & $\begin{array}{l}1=\text { Yes and } \\
0=\text { No }\end{array}$ \\
\hline $\begin{array}{l}\text { Personal attitude to } \\
\text { condoms }\end{array}$ & $\begin{array}{l}3 \text { items scale (e.g., "condoms } \\
\text { change the climax or orgasm"); } \alpha \\
=0.82\end{array}$ & $\begin{array}{l}1 \text { = strongly } \\
\text { disagree to } \\
5 \text { = strongly } \\
\text { agree }\end{array}$ \\
\hline $\begin{array}{l}\text { Negative perceptions } \\
\text { about partner's attitude to } \\
\text { condoms }\end{array}$ & $\begin{array}{l}4 \text { items scale (e.g., "If I asked my } \\
\text { partner to use a condom, he would } \\
\text { think I didn't trust him".); } \alpha=0.89\end{array}$ & $\begin{array}{l}1=\text { strongly } \\
\text { disagree to } \\
5=\text { strongly } \\
\text { agree }\end{array}$ \\
\hline $\begin{array}{l}\text { Negative perceptions } \\
\text { about partner's attitude to } \\
\text { testing for STI }\end{array}$ & $\begin{array}{l}4 \text { items scale (e.g. "If I ask my } \\
\text { partner to test for STI, he may } \\
\text { think that I believe that he gave me } \\
\text { an STI"); } \alpha=0.88\end{array}$ & $\begin{array}{l}1 \text { = strongly } \\
\text { disagree to } \\
5=\text { strongly } \\
\text { agree }\end{array}$ \\
\hline $\begin{array}{l}\text { Control over the direction } \\
\text { of the relationship }\end{array}$ & $\begin{array}{l}4 \text { items scale (e.g., "My main } \\
\text { sexual partner has more to say } \\
\text { than I do about important decisions }\end{array}$ & $\begin{array}{l}1=\text { strongly } \\
\text { agree } \\
\text { to } 4 \text { = strongly }\end{array}$ \\
\hline
\end{tabular}




\begin{tabular}{|l|l|l|}
\hline & $\begin{array}{l}\text { that affect us", "When my main } \\
\text { partner and I disagree, he gets his } \\
\text { way most of the time."); } \alpha=0.85\end{array}$ & \\
\hline $\begin{array}{l}\text { Living with main sex } \\
\text { partner }\end{array}$ & $\begin{array}{l}\text { Do you live with your main sexual } \\
\text { partner? }\end{array}$ & $\begin{array}{l}1=\text { Yes and } \\
0=\text { No }\end{array}$ \\
\hline
\end{tabular}

\section{Results}

The demographic characteristics of the study sample are presented in Table 2. The mean age of participants was 23 years. The majority $(88.42 \%)$ had reached secondary school, but only $25.84 \%$ had at least a Grade 12 level of education. Most women were unemployed $(75.28 \%)$ and financially dependent on their male partners $(30.11 \%)$, parents or grandparents $(26.97 \%)$, or other members of their families or friends $(12.36 \%)$.

\section{Univariate Models}

In total, $159(36.72 \%)$ women indicated preferring dry sex. Of these, 135 $(84.91 \%)$ indicated that their partners also preferred dry sex. The results of the univariate test of independence between preference for dry sex and questionnaire variables and STI prevalence are presented in Table 3. Participants with a preference for dry sex were significantly older, more likely to have been living with their main male partner, more likely to indicate that their partner also preferred dry sex, and more likely to have had an STI in the past. Furthermore, participants who preferred dry sex had been in a relationship with their main partner for significantly longer periods, reported significantly lower control over the direction of their relationship, and had stronger negative perceptions about their partner's attitude towards condom use as well as testing for an STI. There was no univariate association between preference for 
dry sex and either the rate of condom use in past 30 days, condom use at last sex, or STI (CT, NG, and TV) prevalence.

Table 2. Demographic profile of participants

\begin{tabular}{ll}
\hline Variables & $\mathrm{n}(\%)$ \\
\hline Age Mean (SD) & $23.37(4.21)$ \\
Highest level of education & $51(11.56)$ \\
Primary school & $276(62.59)$ \\
Secondary school & $102(23.13)$ \\
Matric (Grade 12) & $12(2.72)$ \\
Tertiary & \\
Employment status & $96(21.92)$ \\
Employed & $335(76.48)$ \\
Unemployed & $7(1.60)$ \\
Self-employed & \\
Main source of income & \\
Job & $77(17.30)$ \\
Child grant & $42(9.44)$ \\
Disability grant & $8(1.80)$ \\
Sexual partner & $120(26.97)$ \\
Parents or grandparents & $134(30.11)$ \\
Family members or friends & $55(12.36)$ \\
Other & $9(2.02)$ \\
\hline &
\end{tabular}


赔

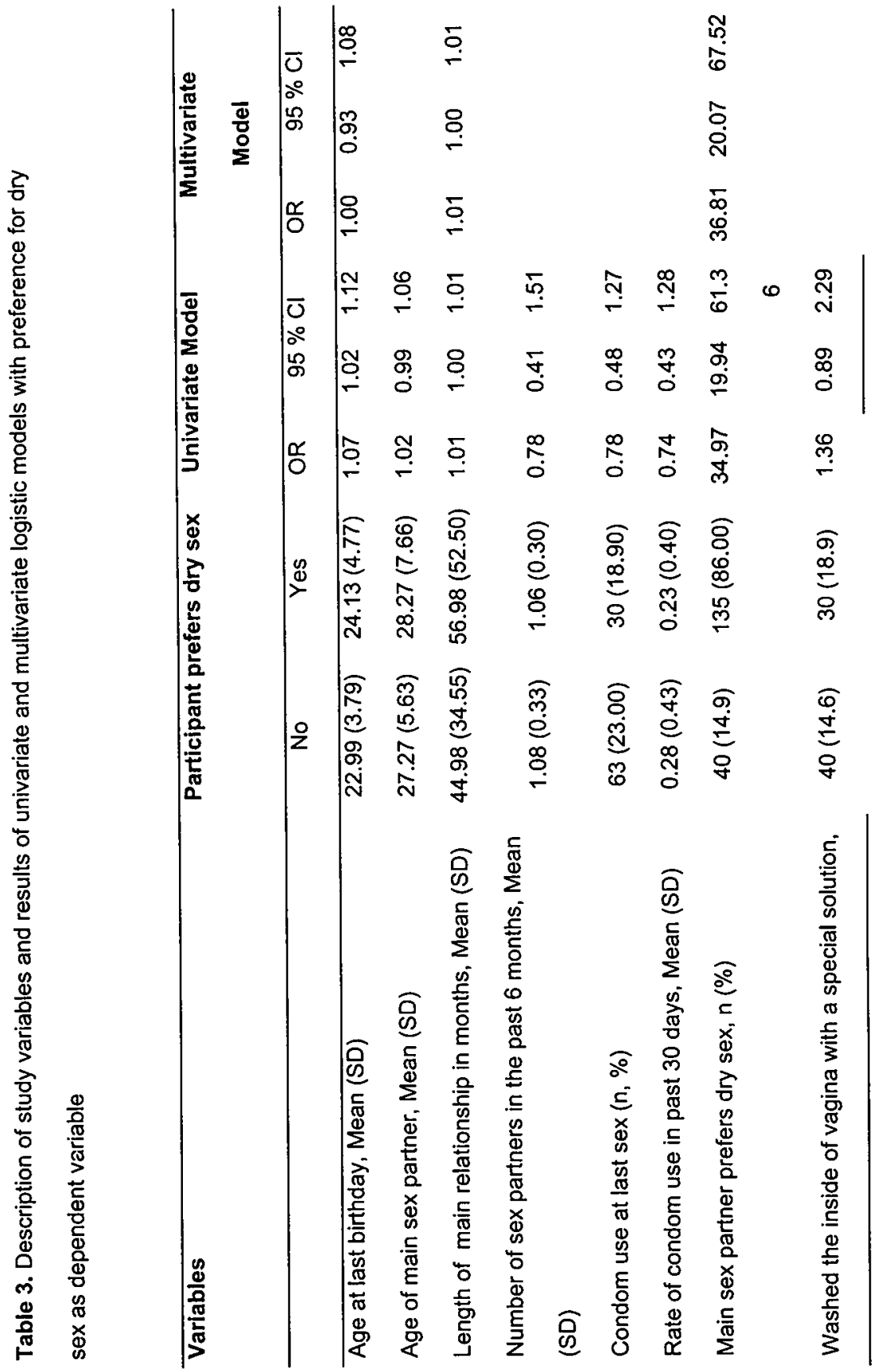

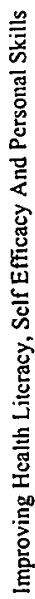




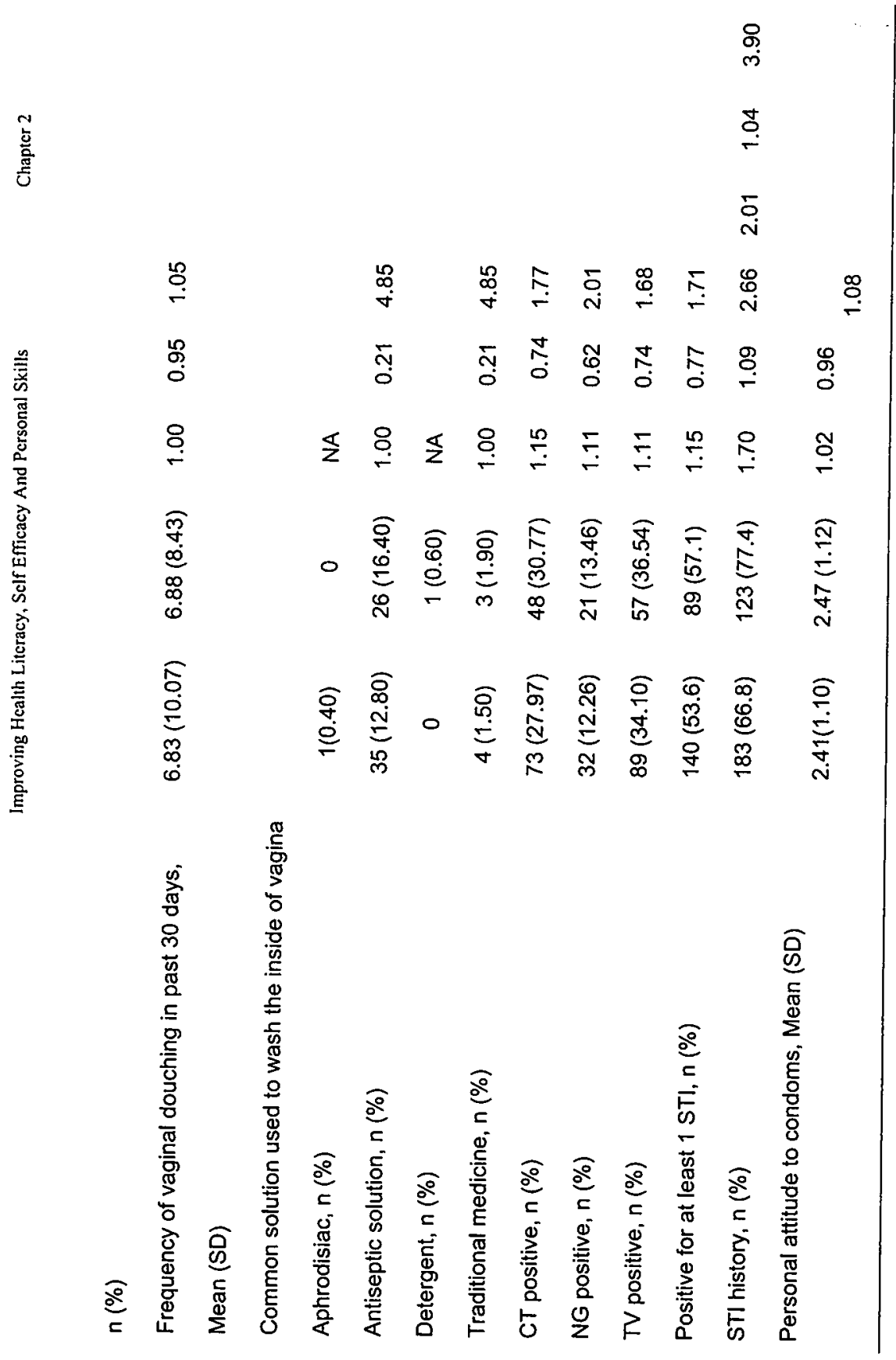




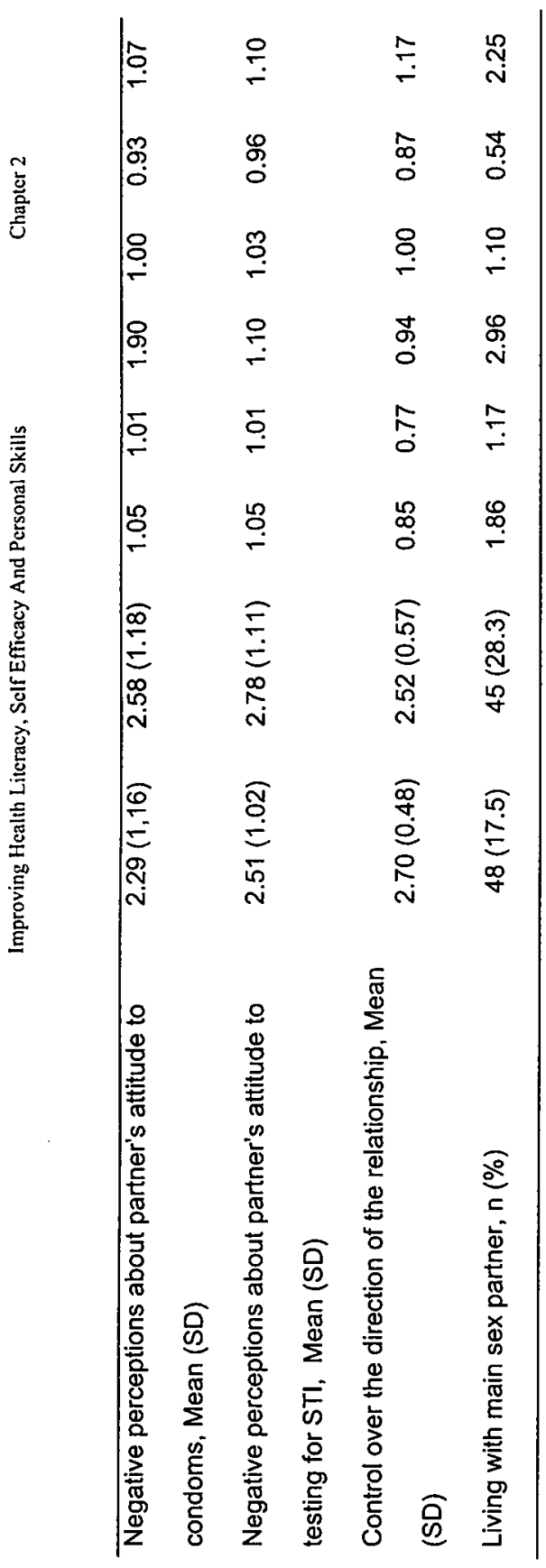




\section{Multivariate model}

Variables that revealed significant univariate associations with preference for dry sex were further explored in a multivariate logistic model to determine whether these associations were unique and independent. The multivariate regression analysis modelled individual variables' associations with preference for dry sex while adjusting for the effect of interrelations between them. Among the variables that were entered in the multivariate model, only STI history, length of relationship and having a partner who preferred dry sex remained significantly associated with preference for dry sex. Women who preferred dry sex were more likely to indicate that their partner also preferred dry sex, more likely to have had a history of STI, and more likely to have been in the relationship for a longer period (see Table 3).

\section{Discussion}

The results of this study indicate that preference for dry sex is not directly related to either the rate of condom use in the past 30 days, condom use at last intercourse, or STI prevalence. The preference for dry sex may, however, affect condom use through partner-related variables that may have an impact on the adoption of condom use by women. In the univariate model, participants who preferred dry sex strongly indicated that their partner also preferred dry sex, perceived highly negative partner attitudes towards both condom use and $\mathrm{STI}$ tests, indicated having little control over the direction of their relationship, and were more likely to have a history of STI. When these associations were tested in a multivariate logistic model, only three variables remained significant: women who preferred dry sex were more likely to have had a partner who preferred dry sex, more likely to have had a history of STI, and more likely to have been in the relationship for a long period.. 
A review of the literature shows that the practice of dry sex has been previously associated with an STI history among men, who were likely to indicate as reasons for practicing dry sex, enjoyment, "feeling well", and pleasure. Women, on the other hand, have reported participating in dry sex mainly to satisfy their partners (Beksinska, Rees, Kleinschmidt, \& McIntyre, 1999; Myer, Kuhn, Stein., Wright, \& Denny, 2005; Brown \& Brown, 2000).

We postulate that the risk of STI associated with dry sex may be related to the nature of the relationship in which it is practiced, and as such may be an indicator for a relationship in which the male partner's sexual preferences are dominant. Since no data on the subject of dry sex was collected among men in this study, it is difficult to assert the position of the (main) male partner on dry sex. Furthermore, men's preference for dry sex and their attitude towards STI testing and condom use were measured with single-item variables that only expressed the perceptions of the women on these issues, and should be interpreted cautiously. Since the measure of STI history was obtained through self-reports of past STI episodes, this is not a strong enough variable to test the association between preference for dry sex and STI risk.

The interpretation of the results is limited to the population in which the research was done, and further research should be extended to men and women of different populations. The results provide no conclusive evidence for an association between women's preference for dry sex and condom use, and highlight the need for further research in the characteristics of relationships within which dry sex occurs, men's position on the practice of dry sex, and the implications for condom use, preferably using a longitudinal design to make causal inferences possible. 


\section{References}

Baleta, A. (1998). Concern voiced over "dry sex" practices in South Africa. Lancet, 352, 1292.

Beksinska, M.E., Rees, H.V., Kleinschmidt, I., \& Mcintyre J. (1999). The practice and prevalence of dry sex among men and women in South Africa: a risk factor for sexualiy transmitted infections? Sexually Transmitted infections, 75, 178-180.

Brown, J.E., \& Brown, R.C. (2000). Traditional intra-vaginal practices and the heterosexual transmission of disease: a review. Sexually Transmitted Diseases, 27, 183-187.

Brown, R.C., Brown, J.E., \& Ayowa, O.B. (1993). The use and physical effects of intravaginal substances in Zairian women. Sexually Transmitted Diseases, 20, 96-99.

Civic, D., \& Wilson, D. (1996). Dry sex in Zimbabwe and implications for condom use. Social Science and Medicine, 42, 91-98.

Crotchfelt, K.A., Welsh, L.E., Debonville, D., Rosenstraus, M., \& Quinn, T.C. (1997). Detection of Neisseria gonorrhoeae and Chlamydia trachomatis in genitourinary specimens from men and women by a co-amplification PCR assay. Journal of Clinical Microbiology, 35, 1536-1540.

Crucitti, T., Van Dyck, E., Tehe, A., Abdellati, S., Vuylsteke, B., Buve, A. et al., (2003). Comparison of culture and different PCR assays for detection of Trichomonas vaginalis in self collected vaginal swabs specimen. Sexually Transmitted Infections, 79, 393-398.

Department of Health of South Africa (2007). National HIV and syphilis antenatal seroprevalence survey in South Africa 2007. Department of Health, Pretoria.

Myer, L., Kuhn, L., Stein, Z.A., Wright, T.C. Jr., \& Denny, L. (2005). Intravaginal practices, bacterial vaginosis, and women's susceptibility to HIV infection: epidemiological evidence and biological mechanisms. Sexually Transmitted Diseases, 5, 786-794.

Pepin, J., \& Mabey, D. (2003). Sexually transmitted infections in Africa: singie dose treatment is now affordable. Sexually Transmitted Infections, 79, 432-434.

Shaikh, N., \& Adendorff, T. (2000). Health Status Report. Health Status and Health Service Evaluation Report 1999-2000. Western Cape Department of Health, Cape Town.

Shaikh, N., Abdullah, F., Lombard, C.J., Smith, L., Bradshaw, D. \& Makubalo, L. (2006). Masking through averages - intraprovincial heterogeneity in HIV prevalence within the Western Cape. South Africa Medical Journal, 96, 539-543. 
Van de Wijgert, J., Altini, L., Jones, H., de Kock, A., Young, T., Williamson, A-L. et al. (2006). Two methods of self sampling compared to clinician sampling to detect reproductive tract infections in Gugulethu, South Africa. Sexually Transmitted Infections, 33, 516-523. 


\section{Chapter 3}

\section{Economic pressure and sexual relationships of young Black women in peri-urban areas of the Western Cape Province of South Africa}

Submitted as: Dorina Saleh-Onoya, Priscilla Reddy, Sibusiso Sifunda, Delia Lang, Gina Wingood, Bart van den Borne, Robert A.C. Ruiter. Economic pressure and sexual relationships of young Black women in peri-urban areas of the Western Cape Province of South Africa 


\section{Introduction}

Anecdotal evidence and several qualitative studies suggest that transactional sex, which is defined as the exchange of gifts or money for sex, is common among young women throughout Sub-Saharan Africa (Luke, 2003; Chatterji, Murray, London and Anglewicz, 2004). The reported proportion of sexually active women in 12 Sub-Saharan African countries (Benin, Burkina Faso, Mali, Togo, Zambia, Central African Republic, Chad, Guinea, Kenya, Niger, Nigeria and Zimbabwe) engaging in transactional sex varies from $2 \%$ in Niger to $11 \%$ in Zambia (Chatterji, Murray, London and Anglewicz, 2004). In a recent study among women in Soweto, South Africa, $21.1 \%$ of respondents reported ever having had sex with a non primary partner in exchange for gifts or money (Dunkle et al., 2004a).

Transactional sexual relationships are sexual relationships where the giving of gifts or services is an important factor (Leclerc-Madlala, 2004). Although, prostitution has a similar definition, transactional sex differs in important ways: participants of transactional sex are constructed as "girlfriends" and "boyfriends" and not "prostitutes" and "clients", and the exchange of gifts or money are often as much about the expression of love and commitment as they are about meeting the financial needs of women and the acquisition of sex for men (Poulin, 2007; Hunter, 2002; Leclerc-Madlala, 2004; Halperin and Epstein, 2004, Swidler and Watkins, 2007). Transactional sex is intricately connected to multiple partner behaviour among both men and women ((Dunkle, 2007; Luke, 2003; Manganja, 2007; Poulin, 2007; Swidler and Watkins, 2007; Hunter, 2002; Leclerc-Madlala, 2004). In this context, men secure sexual favours from women through the giving of material goods or cash and women expect to share their partners with other women or otherwise be dubbed as "selfish women" and tolerate unfaithful male partners (LeclercMadlala, 2004; Swidler and Watkins, 2007). 
Research into the agency and motivation of South African women for exchanging sex for material gain have found that although some women's participation in transactional sex may be motivated by poverty and desperation, young women are increasingly exploiting sexual relationships to access a fashionable lifestyle and items (Hunter, 2002; Leclerc-Madlala, 2004). However, qualitative data have shown that although women exercise their power to enter in sexual relationships, because of age or economic asymmetries in these relationships they often have reduced bargaining power and motivation for negotiating and using condoms with their partners (Hunter, 2002; Luke, 2003; Dunkle et al., 2004b).

The literature shows that young South African women have relatively high knowledge about HIV transmission and prevention (Leclerc-Madlala, 2004). However this knowledge has not translated into high rates of condom use. Furthermore the negotiation of condom use by women in mostly male dominated relationships, particularly transactional relationships, is not always successful and may result in inter-partner violence (Pettifor, Measham, Rees, \& Padian, 2004; Gilbert \& Walker, 2002; Wood \& Jewkes, 2001; Wood, Maforah, \& Jewkes, 1998; Dunkle et al 2007). Gender based violence has repeatedly been associated with transactional sex in the South African context (Dunkle et al., 2004, 2007; Manganja, 2007; Luke, 2003).

Considering the reported high prevalence of transactional sex among young women in South Africa and the inherent high risk of contracting STI and HIV, very few studies have evaluated the uptake of condom use among women who report participation in transactional sex. Most studies have highlighted the strong association between transactional sex with high risk of HIV and gender based violence. However data on actual protective behaviour and condom use for women who participate in transactional sex are important as potential quantitative measures of STI and HIV risk and necessary to 
establish baseline data against which improvements in protective behaviour could be assessed.

In this paper we compare: (a) women with a history of transactional sexual behaviour, (b) women who report a history of non transactional high risk sexual behaviour and (c) women who report never participating in either high risk sexual behaviour or transactional sex on indices of condom use, sexually transmitted infection (STI) and history of gender based violence.

\section{Methods}

\section{Study setting and participants}

Data for this study was drawn from baseline measures of a randomized controlled trial of a HIV risk reduction intervention among black isiXhosa speaking women in peri-urban areas of the Western Cape Province, South Africa. Participants were recruited from townships (formal and informal) of small semi-rural towns.

The Western Cape is the second wealthiest province in South Africa with a better socioeconomic profile than other provinces. It is highly urbanized with $87 \%$ of its population living in the Cape metropolis. Only $21 \%$ of the population is classified as black, $54 \%$ are "coloured" and the rest are "white" (Shaikh, \& Adendorff, 2000). However, there are acute differences in health provision, health status and HIV prevalence that also run on racial, socioeconomic and type of locality lines. The HIV prevalence is lowest among people living in wealthy formal urban settlements and highest in poor urban informal settlements (referred to as townships) where the majority is black and at least $50 \%$ of adults are unemployed (Shaikh et al., 2006).

Recruitment into the study occurred between January 2006 and December 2007. Women were eligible to participate if they were black, 
isiXhosa speaking women aged between 18 and 35 , sought voluntary counselling and testing (VCT) services at any one of 5 peri-urban primary health care clinics and had tested HIV negative in the previous 8 weeks. Participants were reassured that their identities would be treated as confidential

Data collection

All 446 women gave written informed consent to complete an interviewer administered behavioural questionnaire and provided 1 self-administered vaginal swab. Participants were guided to self-administer the vaginal swab in a sterile manner (Van de Wijgert et al., 2006).

The questionnaire was translated into isiXhosa by bilingual researchers and checked for linguistic appropriateness, comprehension, and cultural relevance, and then back translated from isiXhosa into English to ensure accuracy and meaning of constructs. The questionnaires were computerbased (ACASI) and administered by trained, isiXhosa speaking, black female interviewers. The assessment procedure took about an hour to complete. Participants were given R20 (approx. \$2.74) for completing the assessment procedures. Those who tested positive for any one STI were referred to a contracted medical practitioner in their respective areas, who supervised the uptake of single dose prescriptions of Azithromycin (1g) for CT, Ciprofloxacin (500 mg) for NG or Metronidazole (2g) for TV infection (Pepin, \& Mabey, 2003). The study protocol was approved by the Ethics Committee of the South African Medical Association (SAMA) prior to implementation.

All participants' vaginal swabs were tested for CT, NG, and TV. Tests for CT and NG were conducted using the COBAS $\otimes$ Amplicor CT/NG PCR based assay (Roche Molecular Diagnostics) (Crotchfelt, Welsh, Debonville, Rosenstraus, \& Quinn, 1997). The PCR test for TV was done using a PCR with 
the primers set TVK3/TVK7 (Crucitti et al., 2003). STI results were coded 0 for a negative result and 1 for a positive result.

\section{Measures}

Measures that were assessed with single items are presented in Table 1.

Minimum of $1 \mathrm{STI}$ : The variable 'Minimum of $1 \mathrm{STI}$ ' was created from the STI test results and denotes frequency of infection with at least 1 STI (coded Yes $=1 ;$ No $=0)$.

HIV Knowledge was evaluated with a 10 item index with false and true answer options (e.g., "If both partners are HIV positive it's OK to have unprotected sex"). These items were coded such that a score of 1 indicated a correct answer and a score of 0 an incorrect answers. The scores were summed to create HIV knowledge (range: 0-10).

Data analysis

Frequencies and mean scores were used to describe categorical and continuous variables respectively. Univariate multinomial logistic regression was used to assess the association of variables under study and sexual behaviour and to compare the associations between participant who reported a history of transactional sexual relationships with those who reported a history of high risk relationship and those who reported never engaging in high risk sexual relationships. Variables that were significant in the univariate models were included in the multivariate multinomial logistic regression model to determine unique contributions. Significance level was set at the $5 \%$ level for all analyses. All analyses were conducted in SPSS version 15 (SPSS Inc., Chicago, IL) and STATA 8 (STATA Corp., College Station, TX). 
Table 1. Descriptions of questionnaire variables

\begin{tabular}{|c|c|c|}
\hline Variable & Question & Coding \\
\hline $\begin{array}{l}\text { History of high risk } \\
\text { sexual relationships }\end{array}$ & $\begin{array}{l}\text { a) Have you ever been sexually involved } \\
\text { with an older man, a secret lover or had a } \\
\text { one night stand? } \\
\text { b) Did the man give you a gift or money? }\end{array}$ & $\begin{array}{l}0=\text { No to } a \\
1=\text { Yes to a } \\
\text { (High risk) } \\
2=\text { Yes to a and } \\
b \\
\text { (High risk \& } \\
\text { transactional) }\end{array}$ \\
\hline Condom use at last sex & $\begin{array}{l}\text { The last time you had vaginal sex with your main } \\
\text { partner, did you use a condom? }\end{array}$ & Yes $=1 ;$ No $=0$ \\
\hline Number of sex partners & $\begin{array}{l}\text { In the past } 6 \text { months, how many men have you } \\
\text { had vaginal sex with? }\end{array}$ & \\
\hline $\begin{array}{l}\text { Frequency of sex in } \\
\text { past months }\end{array}$ & $\begin{array}{l}\text { In the last } 30 \text { days, how many times have you } \\
\text { had vaginal sex? }\end{array}$ & \\
\hline $\begin{array}{l}\text { Frequency of condom } \\
\text { use in past month }\end{array}$ & $\begin{array}{l}\text { Of the number of times that you had sex in the } \\
\text { last } 30 \text { days, how many times did you use a } \\
\text { condom? }\end{array}$ & \\
\hline Rate of condom use & $\begin{array}{l}\text { Calculated by dividing frequency of condom use } \\
\text { in past month by frequency of sex in past } \\
\text { months. }\end{array}$ & \\
\hline STI history & Have you ever had an STI?" & Yes $=1 ;$ No $=0$ \\
\hline $\begin{array}{l}\text { Request for condom } \\
\text { use }\end{array}$ & $\begin{array}{l}\text { During the past } 3 \text { months, did you ask your main } \\
\text { sexual partner to use a condom? }\end{array}$ & Yes $=1 ;$ No $=0$ \\
\hline $\begin{array}{l}\text { Frequency of requests } \\
\text { for condom use }\end{array}$ & $\begin{array}{l}\text { During the past } 3 \text { months, how many times did } \\
\text { you ask your main sexual partner to use a } \\
\text { condom? }\end{array}$ & \\
\hline $\begin{array}{l}\text { Frequency of request to } \\
\text { apply condom on } \\
\text { partner }\end{array}$ & $\begin{array}{l}\text { During the past } 3 \text { months, how many times did } \\
\text { you ask your main sexual partner if you should } \\
\text { put the condom on him? }\end{array}$ & \\
\hline Inter-partner violence & $\begin{array}{l}\text { In the past } 12 \text { months, has you main sexual } \\
\text { partner or any other partner kicked you, bit you, }\end{array}$ & Yes $=1 ;$ No $=0$ \\
\hline
\end{tabular}




\begin{tabular}{|c|c|c|}
\hline & dragged you, or beat you up? & \\
\hline $\begin{array}{l}\text { Partner pressured not to } \\
\text { use condom }\end{array}$ & $\begin{array}{l}\text { During the past } 3 \text { months, did your main sexual } \\
\text { partner pressure you not to use a condom when } \\
\text { you asked him to? }\end{array}$ & Yes $=1 ;$ No $=0$ \\
\hline $\begin{array}{l}\text { Partner has threatened } \\
\text { with a weapon }\end{array}$ & $\begin{array}{l}\text { Has your main sexual partner or any other } \\
\text { partner ever threatened to use or actually used a } \\
\text { gun, knife or other weapon against you? }\end{array}$ & Yes $=1 ;$ No $=0$ \\
\hline $\begin{array}{l}\text { Physically forced to } \\
\text { have sex by partner }\end{array}$ & $\begin{array}{l}\text { Has your current boyfriend or husband or any } \\
\text { other partner ever physically forced you to have } \\
\text { sex when you didn't want to? }\end{array}$ & Yes $=1 ;$ No $=0$ \\
\hline $\begin{array}{l}\text { Partner pressured not to } \\
\text { use condom }\end{array}$ & $\begin{array}{l}\text { During the past } 3 \text { months, how often has your } \\
\text { main sexual partner pressured you not to use a } \\
\text { condom when you asked him to? }\end{array}$ & Yes $=1 ;$ No $=0$ \\
\hline
\end{tabular}

\section{Results}

\section{Demographics}

Table 2 presents the demographic characteristics of the participants. The mean age of participants was 23 years. The majority $(88.42 \%)$ had reached secondary school and only $25.87 \%$ had at least a Matric (grade 12) level of education. Most women were unemployed $(75.28 \%$ ) and financially dependent on their male partner $(26.97 \%)$, parents or grandparents $(30.11 \%)$, or other members of their families or friends $(12.36 \%)$.

\section{Univariate models}

Results of exploratory univariate comparison are shown in Table 3. The univariate models indicated that compared to participants with a history of transactional sex, those who reported never engaging in high risk sexual relationships were significantly less likely to have been pressured by a partner not to use a condom, more likely to have a history of STI, less likely to have been physically forced to have sex by a partner, and less likely to have been 
threatened with a weapon by a partner. Compared to participants with a history of transactional sex, participants who reported a history of high risk sexual relationships reported significantly lower rates of condom use in the past month and less likely to have been threatened with a weapon by a partner.

Table 2. Demographic characteristics of study sample

\begin{tabular}{ll}
\hline & Total (\%) \\
\hline Age Mean (SD) & $23.37(4.21)$ \\
Prighest level of education, $\mathrm{n}(\%)$ & $51(11.56)$ \\
Secondary School & $276(62.59)$ \\
Matric (Grade 12) & $102(23.13)$ \\
Tertiary & $12(2.72)$ \\
Employment status & \\
Employed & $103(23.14)$ \\
Unemployed & $335(75.28)$ \\
Self employed & $7(1.57)$ \\
& \\
Main source of income & \\
Job & \\
Child grant & $77(17.30)$ \\
Disability grant & $42(9.44)$ \\
Sexual partner & $8(1.80)$ \\
Parents or grandparents & $120(26.97)$ \\
Family members or friends & $134(30.11)$ \\
Other & $55(12.36)$ \\
& $9(2.02)$ \\
& \\
\hline
\end{tabular}




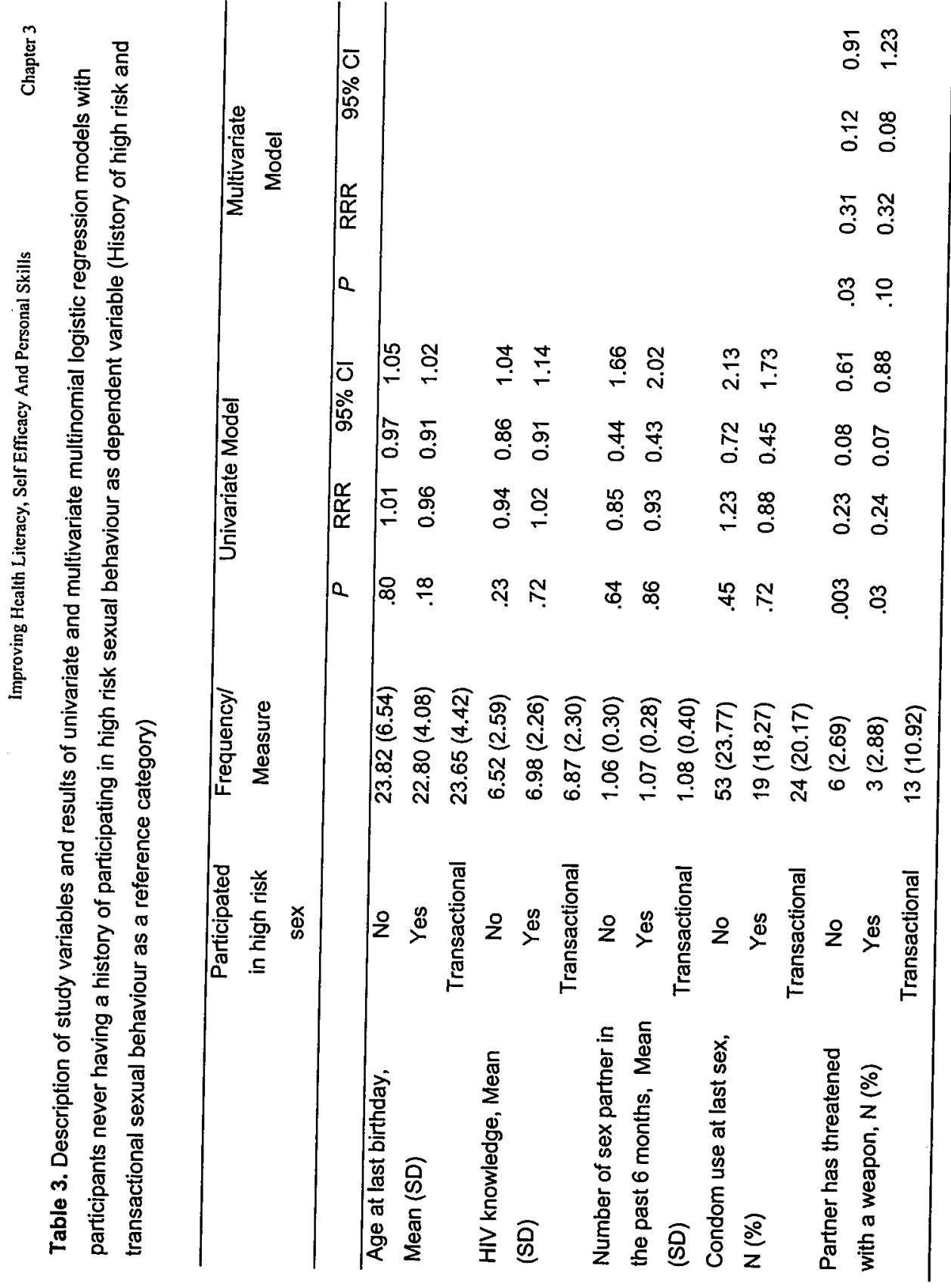




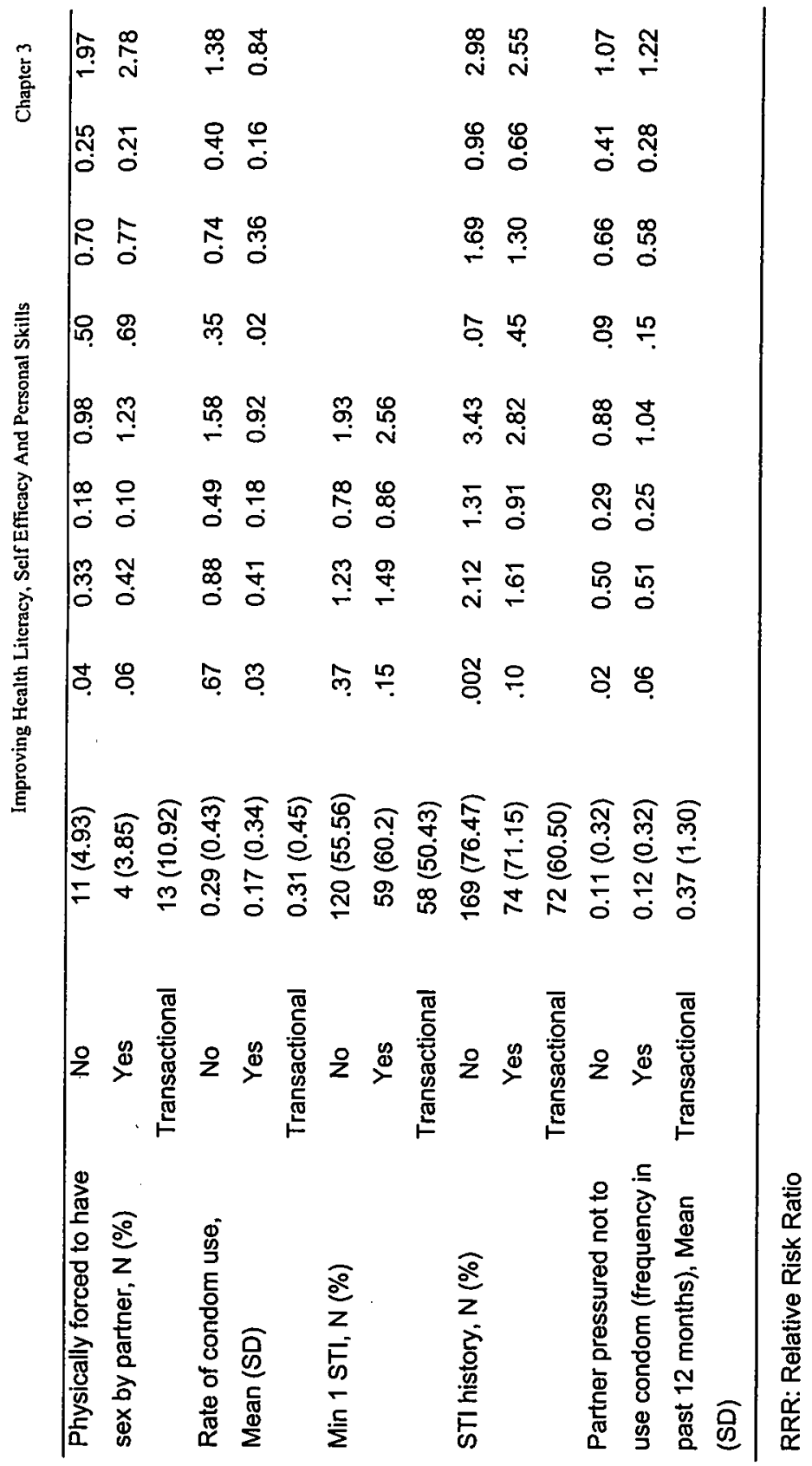




\section{Multivariate model}

Table 3 also presents the results of the multivariate model. The results indicated that compared to participants with a history of transactional sex, those who only reported a history of high risk relationships had a significantly lower rate of condom use and those who reported never participating in high risk relationships were significantly less likely to have been threatened with the use of a weapon by a partner.

\section{Discussion}

This is one of the first studies to have found that women who report a history of transactional sex have a higher rate of condom use with their main partner than respondents who only reported a history of high risk relationships. The results also indicate that women who report a history of transactional sex are also significantly more likely to report having been threatened with the use of a weapon.

It appears that women who report participating in transactional sex are more assertive in their efforts to use condoms with their main partner. These results could suggest that women who report participating in transactional sex have a higher perception of STI and HIV risk compared to those who do not. Previous findings among pregnant women in Soweto, South Africa, indicated that women who participate in transactional sex are at higher risks of contracting HIV (Dunkle et al., 2004). Our results do not indicate a significant difference in the prevalence of STI or in reported history of STI episodes. However the significantly lower rate of condom use among those participants who indicated having a history of high risk sexual relationships but never participating in transactional sex may indicate a hidden risk to STI among these women. 
The association between transactional sex and gender based violence and even sexual violence has been previously reported (Pettifor, Measham, Rees, \& Padian, 2004; Gilbert \& Walker, 2002; Wood \& Jewkes, 2001; Wood, Maforah, \& Jewkes, 1998; Dunkle et al 2004b) which makes the higher rate of condom use in this population all the more encouraging. These findings reiterate the urgent need for more interventions to reduce gender based violence perpetrated by men.

A key finding is the apparent lower rate of condom use among women who indicated never participating in transactional sex who seem to be at equally high risk of contracting HIV and STI. Indicating that more work is needed to link STI infection to HIV risk in HIV prevention programs and raise the perception of risk among this population of women.

We did not assess condom use with non-primary partners; this would have provided key information regarding efforts of women who participate in transactional sex to protect themselves from being infected by extra partners. However data on condom use with a main partner is an important outcome as it indicates some attempts by these women to use condoms. As the variables in this study were self reports measured with single items, the results should be interpreted with caution. The interpretations of these results are limited to the population from which the participants were recruited and further research is needed into different populations of women in South Africa. Furthermore our sample consisted of women who were aware of their HIV negative status who could be different to those who are unaware of their HIV status.

\section{Conclusion}

It is widely recognized that transactional sex is an important factor in the spread of HIV in South Africa. The findings in this study reiterate the urgent need to address the inter-partner violence experienced by women with a history of transactional sex in South Africa and the importance of addressing 
the low uptake of condom use among those who report no history of transactional sex who are at equally high risk of contracting STI and HIV. 


\section{References}

Chatterii, M., Murray, N., London, D., \& Anglewicz, P. (2004). The Factors Influencing Transactional Sex Among Young Men and Women in 12 Sub-Saharan African Countries. Social Biology, 52, 56-72.

Crotchfelt, K.A., Welsh, L.E., Debonville, D., Rosenstraus, M., \& Quinn, T.C. (1997). Detection of Neisseria gonorrhoeae and Chlamydia trachomatis in Genitourinary Specimens from Men and Women by a Co-amplification PCR Assay. Joumal of Clinical Microbiology, 35, 1536-1540.

Crucitti, T., Van Dyck, E., Tehe, A., Abdellati, S., Vuylsteke, B., Buve, A., \& Laga, M. (2003). Comparison of culture and different PCR assays for detection of Trichomonas vaginalis in self collected vaginal swabs specimen. Sexually Transmitted Infection, 79, 393-398.

Dunkle, K.L., Jewkes, R.K., Brown, H.C., Gray, G.E., McIntryre, J.A., \& Harlow, S.D. (2004a) . Transactional sex among women in Soweto, South Africa: prevalence, risk factors and association with HIV infection. Social Science \& Medicine, 59, 15811592.

Dunkle, K.L., Jewkes, R.K, Brown, H.C., Gray, G.E., McIntryre, J.A., \& Harlow, S.D. (2004b) . Gender-based violence, relationship power, and risk of HIV infection in women attending antenatal clinics in South Africa. Lancet, 363, 1415-21.

Gilbert, L., \& Walker, L. (2002). Treading the path of least resistance: HIVIAIDS and social inequalities: a South African case study. Social Science a Medicine, 54, 1093-1110.

Halperin, D.T., \& Epstein, H. (2004). Concurrent sexual partnerships help to explain Africa's high HIV prevalence: implications for prevention. The Lancet 2004; 364: 4-6.

Hunter, M. (2002). The Materiality of Everyday Sex: thinking beyond 'prostitution' African Studies, 61, 100-120.

Leclerc-Madlala, S. (2004). Transactional Sex and the Pursuit of Modernity. Social Dynamics 29, 1-21.

Luke, N. (2003). Age and economic asymmetries in the sexual relationships of adolescent girls in sub-Saharan Africa. Studies in Family Planning, 34, 67-86.

Maganja, R.K., Maman, S., Groves, A., \& Mbwambo, J. K. (2007). Skinning the goat and pulling the load: transactional sex among youth in Dar es Salaam, Tanzania. AIDS Care, 19, 974-981. 
Pepin, J., \& Mabey, D. (2003). Sexually transmitted infections in Africa: single dose treatment is now affordable. Sexually Transmitted Infections, 79, 432-434.

Pettifor, A.E., Measham, D.M., Rees, H.V., \& Padian, N.S. (2004). Sexual Power and HIV Risk, South Africa. Emerging Infectious Diseases, 10, 1996-2004.

Poulin, M. (2007). Sex, money, and premarital partnerships in southern Malawi. Social Science \& Medicine, 65, 2383-2393.

Shaikh, N., Abdullah, F., Lombard, C.J., Smith, L., Bradshaw, D., \& Makubalo, L. (2006). Masking through averages - intraprovincial heterogeneity in HIV prevalence within the Western Cape. South African Medical Journal, 96, 539-543.

Shaikh, N., \& Adendorff, T. (2000). Health Status Report. Health Status and Health Service Evaluation Report 1999-2000. Western Cape Department of Health, 2000.

Swidler, A. \& Watkins, S.C. (2007). Ties of Dependence: AIDS and Transactional Sex in Rural Malawi. Studies in Family Planning, 38, 147-162.

Van de Wijgert, J., Altini, L., Jones, H., de Kock, A., Young, T., Williamson, A-L., et al. (2006). Two methods of self sampling compared to clinician sampling to detect reproductive tract infections in Gugulethu, South Africa. Sexually Transmitted Infections, 33, 516-523.

Wood, K. \& Jewkes, R. (2001). 'Dangerous love': reflectional on violence among Xhosa township youth. In Morrel R, editor. Changing men in southern Africa. Pietermaritzburg: University of Natal Press: 2001; pp 317-136.

Wood, K., Maforah, F., \& Jewkes, R. (1998). "He forces me to love him": putting violence on adolescent sexual health agendas. Social Science and Medicine, 47, 233-242. 


\section{Chapter 4}

\section{Comparing Sexually Transmitted Infection Risk}

and Sexual Behaviour Profiles of Pregnant versus Non-Pregnant, HIV Negative Black Women in the Western Cape Province, South Africa

Submitted as: Dorina Saleh-Onoya, Priscilla Reddy, Sibusiso Sifunda, Delia Lang, Gina Wingood, Bart van den Borne, and Robert A.C. Ruiter. Comparing Sexually Transmitted Infection Risk and Sexual Behaviour Profiles of Pregnant versus Non-Pregnant, HIV Negative Black Women in the Western Cape Province, South Africa 


\section{Introduction}

Although South Africa is experiencing some of the highest HIV prevalence estimates in the world, recent projections indicate that the prevalence in the country is reaching a plateau and that antiretroviral treatment programs could have a significant impact on reducing the number of AIDS deaths per year. However, new incidence of HIV infection is still high and continues to be driven by the high HIV incidence among the 15-24 year age group, particularly among young women (Dorrington, Johnson, Bradshaw, \& Daniel, 2006).

In 2005 , a survey which included a nationally representative sample of 15-24 year old young people estimated the annual HIV infection incidence at $3.3 \%$, with females having a 8 times higher incidence compared to males (6.5\% compared to $0.8 \%$ ). The HIV prevalence among sexually active $15-24$ year old females was estimated at $20.2 \%$, and the prevalence for young females aged 25-29 was 33.3\% (Shisana, Rehle, Simbayi, Parker, Zuma, Bhana, et al., 2005).

Voluntary counselling and testing for HIV service (VCT) is a critical entry point to a variety of HIV related services for HIV positive people. VCT, which is extensively supported by both government and non-governmental organisations (NGO), provides an opportunity for direct counselling and education on HIV risk and prevention options in South Africa.

Various studies evaluating the effect of VCT on protective behaviours have found that VCT has a greater impact among HIV positive individuals compared to those who test HIV negative and untested individuals (Weinhardt, Michael, Johnson, \& Bickham, 1999). Following VCT, people who have tested HIV positive are more likely to significantly reduce their frequency of unprotected intercourse, increase condom use, and have a lower incidence of sexually transmitted infections (STI) compared to HIV negative and untested 
individuals (Mola, Mercer, Asghar, Gimbel-Sherr, Gimbel-Sherr, Micek et al, 2006).

The acceptability of VCT among pregnant women attending public antenatal health services in African developing countries is reportedly $69 \%$ (Range, 33 - 95\%) (Cartoux, Meda, Van de Perre, Newell, de Vincenzi, Dabis, et al., 1998). As a result, HIV prevalence data from antenatal surveys is often more readily and regularly available than HIV data on non pregnant women (Garcia-Calleja, Gouws, \& Ghys, 2006). The 2005 national antenatal survey estimated the HIV prevalence among pregnant women in public services at $30.2 \%$ which is higher than the 2005 national average of $24 \%$ among black females in the 2005 household survey (Department of Health of South Africa, 2006; Dorrington, Johnson, Bradshaw, \& Daniel, 2006).

It is clear that, in South Africa, young black females should continue to be the primary focus of HIV prevention interventions as they constitute the largest subgroup of the population that is driving the epidemic and most likely to suffer from adverse effects of the excess HIV mortality and morbidity (Gilbert, \& Walker, 2002). However it should be recognized that young black South African women do not constitute a homogeneous population. It is therefore important to identify the varying determinants of the high risk of STI and HIV within subgroups of this population, particularly among those who test HIV negative at VCT. In a context where much more focus has been placed on HIV prevention among pregnant women, it is important to consider that in order to prevent HIV in pregnant women and eventually children, the focus should be on non pregnant, HIV negative women.

There is a paucity of published information about the impact of VCT on STI profiles and protective behaviours among black non pregnant VCT attendees. Furthermore, very little is known about the difference in STI profiles, risky sexual behaviour, determinants and barriers of protective behaviours 
between women who test for HIV as part of antenatal care and test HIV negative, and their non pregnant counterparts. This information will contribute new knowledge for the development of targeted post VCT interventions for black pregnant and non pregnant VCT attendees which will in turn improve VCT services' capacity to positively impact on protective behaviour among women with HIV negative test results.

The objectives of this study were to compare the prevalence of STI Chlamydia trachomatis (CT), Neisseria gonorrhoea (NG) and Trichomonas vaginalis (TV), and psychosocial determinants of safe sex behaviours between women who were pregnant at time of VCT to the non pregnant women.

\section{Methods}

\section{Study setting and participants}

Data for this study was drawn from baseline measures of a randomized trial of a HIV risk reduction behavioural intervention among black isiXhosa speaking women in peri-urban areas of the Western Cape Province, South Africa. Participants were recruited from townships (formal and informal) of small semi-rural towns in the Western Cape Province.

The Western Cape Province is the second wealthiest in South Africa, has a generally better socioeconomic profile than other provinces. This is reflected in a health service delivery and health outcomes in general. It is highly urbanised with $87 \%$ of its population living in the Cape metropolis. Only $21 \%$ of the population is black, $54 \%$ are "coloured" and rest are "white" (Shaikh, \& Adendorff, 2000). However, there are acute differences in health provision, health status and HIV prevalence that also run on racial, socioeconomic and type of locality lines. The 2004 prevalence of HIV in Cape 
Town was estimated at 3.7\% in Cape Town central, $7.1 \%$ in Stellenbosch, $22 \%$ in Khayelitsha, $0.7 \%$ in Mitchel's plain and $16 \%$ in Gugulethu. Khayelitsha and Gugulethu are almost all black townships with large informal settlements where at least $50 \%$ of adults are unemployed (Shaikh, Abdullah, Lombard, Smit, Bradshaw, \& Makubalo, 2006).

Recruitment into the study occurred between January 2006 and December 2007. Women were eligible to participate if they were black, isiXhosa speaking women aged between 18 and 35 , sought voluntary counselling and testing (VCT) services at any one of 5 peri-urban primary health care clinics and had tested HIV negative in the previous 8 weeks. Participants were reassured that their identities would be treated as confidential

All 446 women gave written informed consent to complete a behavioural questionnaire and provide 1 self administered vaginal swab. Participants completed an interviewer administered questionnaire and were guided to self administer a vaginal swab in a sterile manner (Van de Wijgert, Altini, Jones, de Kock, Young, Williamson, et al., 2006). The questionnaire was translated into isiXhosa by bilingual researchers and checked for linguistic appropriateness, comprehension, and cultural relevance, and then back translated from isiXhosa into English to ensure accuracy and meaning of constructs. The questionnaires were computer based (ACASI) and administered by trained, isiXhosa speaking, black female interviewers. This assessment procedure took about an hour to complete. Participants were given R20 (approx. \$2.74) for completing the assessment procedures. Those who tested positive for any one STI were referred to a contracted medical practitioner in their respective areas, who supervised the uptake single dose prescriptions of Azithromycin (1 g) for CT, Ciprofloxacin (500 mg) for NG or Metronidazole $(2 \mathrm{~g})$ for TV infection (Pepin, \& Mabey, 2003). The study protocol was approved by the Ethics 
Committee of the South African Medical Association (SAMA) prior to implementation.

\section{STI outcomes}

All participants' vaginal swabs were tested for CT, NG, and TV. Tests for CT and NG were conducted using the COBAS Amplicor CT/NG PCR based assay (Roche Molecular Diagnostics) (Crotchfelt, Welsh, Debonville, Rosenstraus, \& Quinn, 1997). The PCR test for TV was done using a PCR with the primers set TVK3/TVK7 (Crucitti, Van Dyck, Tehe, Abdellati, Vuylsteke, Buve, et al. 2003). STI results were coded 0 for a negative result and 1 for a positive result.

The variable 'Minimum of 1 STI' was created from the STI test results and denotes frequency of infection with at least $1 \mathrm{STI}$ (coded $\mathrm{Yes}=1$ and No $=$ $0)$.

\section{Questionnaire Instrument}

The questions included in this report are as follows:

STI history was assessed with the question "Have you ever had an STI?" (Coded Yes $=1$ and No $=0$ ). Sex at last vaginal intercourse: "The last time you had vaginal sex with your main partner, did you use a condom?" (Coded Yes = 1 and No $=0$ ). Number of sex partners: "In the past 6 months, how many men have you had vaginal sex with?"

Pregnancy status: "Are you currently pregnant?" (Coded Yes = 1 and No or don't know $=0$ ). Frequency of sex in past months: "In the last 30 days, how many times have you had vaginal sex?" Frequency of condom use in past month: "Of the number of times that you had sex in the last 30 days, how many times did you use a condom?" Rate of condom use was determined by dividing frequency of condom use in past month by frequency of sex in past months. Request for condom use: "During the past 3 months, did you ask your main sexual partner to use a condom?" (Coded Yes $=1$ and No $=0)$. Frequency of 
requests for condom use: "If yes, how many times did you ask your main sexual partner to use a condom?" Frequency of request to apply condom on partner: "During the past 3 months, how many times did you ask your main sexual partner if you should put the condom on him?" Living with main sex partner: "Do you live with your main sexual partner?" (Coded Yes = 1 and No = $0)$. Inter-partner violence was assessed with the question "Has you main sexual partner or any other partner ever kicked you, bit you, dragged you, or beat you up?" (Coded Yes $=1$ and No $=0$ ).

\section{Data analysis}

Frequencies and percentages or means and standard deviations (SD) were used to describe categorical or continuous variables respectively. Logistic regression was used to evaluate univariate relationships with pregnancy status. Those variables that had a significant univariate relationship with pregnancy status were included in the multivariate regression model. The relationships of these measures with pregnancy status were modelled in a multivariate logistic regression model. Significance level was set at the 5\% level for all analyses. All analyses were conducted in SPSS version 15 (SPSS Inc., Chicago, IL). 


\section{Results}

\section{Demographic profile}

The mean age of participants was 23 years old. The majority $(88.42 \%)$ had entered secondary school and only $25.84 \%$ had at least a grade 12 level of education (Table 1). Most women were unemployed $(75.28 \%$ ) and financially dependent on a male partner $(30.11 \%)$, parents or grandparents (26.97\%), other members of their families or friends $(12.36 \%)$.

Comparison between pregnant women and non-pregnant women on reported sexual behaviour and exposure to inter-partner violence (IPV) Univariate logistic models.

Univariate test of independence between pregnancy status and STI prevalence and questionnaire variable indicated that being pregnant was significantly associated with a higher frequency of vaginal sex, lower rate of condom use in the past 30 days, lower likelihood of using a condom at last intercourse, a lower reported number of partners in past 6 months (Table 2). Pregnant women were significantly less likely to have asked a partner to use a condom in the past 3 months and those who did, requested condom use less frequently. However non pregnant women were significantly more likely to have been physically abused by a partner in the past and less likely to report a history of STI. The overall sample STI prevalence was $29.1 \%, 35.2 \%$, and $12.6 \%$ for CT, TV and NG respectively. There was no significant difference in the prevalence of $C T, N G$ or TV, between pregnant and non pregnant women. 
Table 1. Demographic Profile of Study Participants

\begin{tabular}{lc}
\hline & Total (\%) \\
\hline Age (years), mean (SD) & $23.37(4.21)$ \\
Highest level of education, $n(\%)$ & \\
Primary School & $51(11.56)$ \\
Secondary School & $276(62.59)$ \\
Matric (Grade 12) & $102(23.13)$ \\
Tertiary & $12(2.72)$ \\
Employment status, $n(\%)$ & \\
Employed & \\
Unemployed & $96(21.92)$ \\
Self employed & $335(76.48)$ \\
& $7(1.60)$ \\
Main source of income, $n(\%)$ & \\
Job & \\
Child grant & \\
Disability grant & $77(17.30)$ \\
Sexual partner & $42(9.44)$ \\
Parents or grandparents & $8(1.80)$ \\
Family members or friends & $120(26.97)$ \\
Other & $134(30.11)$ \\
& $55(12.36)$ \\
& $9(2.02)$
\end{tabular}

Note. Reported percentages are based on the total number of respondents for which a score was available. 
Table 2. Participants' sexual behaviour, condom use and STI prevalence by pregnancy status with univariate tests of independence.

\begin{tabular}{|c|c|c|c|}
\hline & Pregnant & Non pregnant & OR $(95 \% \mathrm{Cl})$ \\
\hline Age (years), mean (SD) & $23.34(4.26)$ & $23.78(6.80)$ & $0.99(0.95 ; 1.02)$ \\
\hline$\%$ condom use, past 30 days, mean (SD) & $16.22(32.29)$ & $43.06(46.81)$ & $0.21(0.12 ; 0.37)$ \\
\hline $\begin{array}{l}N^{\circ} \text { sex partners in past } 6 \text { months, mean } \\
\text { (SD) }\end{array}$ & $1.03(0.21)$ & $1.11(0.43)$ & $0.41(0.21 ; 0.83)$ \\
\hline Condom use at last sex, $n(\%)$ & $34(13.65)$ & $62(31.47)$ & $0.34(0.22 ; 0.55)$ \\
\hline CT Positive, n (\%) & $75(30.99)$ & $50(26.74)$ & $1.23(0.81 ; 1.88)$ \\
\hline TV Positive, $n(\%)$ & $91(37.60)$ & $60(32.09)$ & $1.28(0.85 ; 1.91)$ \\
\hline NG Positive, $n(\%)$ & $24(9.92))$ & $30(16.04)$ & $0.58(0.32 ; 1.02)$ \\
\hline $\operatorname{Min} 1 \mathrm{STI}, \mathrm{n}(\%)$ & $136(56.20)$ & $101(54.01)$ & $1.09(0.74 ; 1.60)$ \\
\hline History of STI, n (\%) & $186(74.70)$ & $129(66.15)$ & $1.51(1.00 ; 2.28)$ \\
\hline $\begin{array}{l}\text { Asked partner to use condom, past } 3 \\
\text { months, } n(\%)\end{array}$ & $76(30.52)$ & $106(53.81)$ & $0.38(0.26 ; 0.56)$ \\
\hline $\begin{array}{l}N^{\circ} \text { of requests to apply condom on } \\
\text { partner, past } 3 \text { months, mean (SD) }\end{array}$ & $0.55(1.45)$ & $1.06(2.30)$ & $0.86(0.77 ; 0.96)$ \\
\hline Physical abuse history, $n(\%)$ & $22(8.80)$ & $31(15.74)$ & $0.52(0.29 ; 0.93)$ \\
\hline
\end{tabular}

Multivariate logistic model.

Variables that were significant in the univariate models were entered in the multivariate model. This model revealed that pregnant participants were significantly less likely to have asked partners to use condoms and had a lower rate of condom use. Pregnant participants were also more likely to report a STI although this was not significant. Non-pregnant women reported significantly higher average number- of sex partners in the past 6 months and were significantly more likely to report having been physically abused by a partner (Table 3). 
Table 3. Results of Multivariate model of Sexual Behaviour, Condom Use Rate and STI Prevalence by Pregnancy status

\begin{tabular}{lccc}
\hline & B coefficient & $P$ & OR $(95.0 \%$ C.I. $)$ \\
\hline Number of partners & -0.94 & .03 & $0.39(0.17 ; 0.89)$ \\
Number of requests to apply condom on & -0.07 & .30 & $0.94(0.82 ; 1.06)$ \\
partner & & & \\
Physical abuse history & -0.96 & .01 & $0.38(0.19 ; 0.78)$ \\
STI history & 0.46 & .08 & $1.59(0.95 ; 2.66)$ \\
Condom use rate & -1.11 & .01 & $0.32(0.15 ; 0.74)$ \\
Asked partner to use condoms & -0.65 & .03 & $0.52(0.29 ; 0.95)$ \\
Condom use at last sex & 0.03 & .95 & $1.02(0.46 ; 2.30)$ \\
\hline B. Regression coefficient & & & \\
$P \quad$ p value & & & \\
O.R. Odds Ratio & & & \\
C.I. Confidence Interval & & &
\end{tabular}

\section{Discussion}

The results of this study indicate that HIV negative and pregnant VCT clinic attendees are at higher risk for STI as compared to their non pregnant counterparts. However this risk does not appear to be due to multi-partner related behaviour on their part, but rather a failure in negotiating condom use, resulting in a lower rate of condom use and a higher risk of contracting a STI. Non-pregnant HIV negative women may be more likely to negotiate condom use; however the higher risk of physical abuse by their partners probably limits their ability to actually implement condom use in their relationships.

This is the first report of a comparison of sexual risk behaviour and STI profiles between HIV negative pregnant and non pregnant women in South Africa. HIV prevalence in South Africa is driven by the high incidence among young HIV negative women and is often discovered during antenatal care at 
which point an unborn child is also at risk of HIV. The results also reiterate the fact that pregnancy among HIV negative women is not a low risk period as pregnant women seem less likely to adopt protective sexual behaviours. Similar studies were conducted among adolescent girls in Connecticut and among women attending clinics in Brooklyn, USA and found that pregnant women were at higher risk of Chlamydia trachomatis infection, and used condoms less consistently than non pregnant women. (Ickovics, Niccolai, Lewis, Kershaw, \& Ethier, 2003; Wilson, Minkoff, McCalla, Petterkin, \& Jaccard, 1996).

The success rate of VCT in promoting protective behaviours among HIV negative individuals is reportedly lower than among HIV positive individuals (Weinhardt, Michael, Johnson, \& Bickham, 1999). Therefore continuous, postVCT counselling and follow up of HIV negative women is imperative so as to reinforce HIV prevention messages and to provide support for the various barriers to the adoption of safe sex options that they encounter in their relationships. Pregnant women often establish a continuing relationship with health care services even after delivery. This is an opportunity that could be utilized to implement HIV prevention interventions with the aim of imparting and improving communication, negotiation and correct condom use skills that these women desperately need in order to successfully adopt protective behaviours in their relationships.

This study is important as it also highlights the vulnerability of HIV negative non pregnant young black women in South Africa. The results indicate that non pregnant women had, on average, more sexual partner and were more likely to have experienced partner abuse. A possible explanation may be that non pregnant women engaging in risky sexual behaviours are bolder in negotiating condom use. The resistance of partners to use condoms and the risk of physical abuse compound these women's risk to HIV and STI. 
A relationship between suggestion of condom use by women, multiple partner behaviour among women and domestic violence has been previously reported (Jewkes, Levin, \& Penn-Kekana, 2003). Furthermore domestic violence has been previously shown to increase women's risk to HIV by reducing their ability to use condoms consistently (Dunkle et al, 2004).

In South Africa much more focus has been placed on HIV prevention among HIV positive pregnant women. More efforts are needed to establish risk reduction and support programs to which HIV negative pregnant and non pregnant women could be referred to after VCT.

Although the use of contraceptives or women's desire to conceive were not explored in this study, the result do suggest that it is necessary to reinforce the promotion of condom use among women attending family planning clinics as the only available method to protect against HIV infection and the importance of testing both partners for HIV when pregnancy is a desirable outcome.

It would have been very informative to have examined the effect of women's desire for pregnancy and issues of trust in the primary relationship; however these variables were not explored. The interpretations of these results are limited to the population from which the participants were recruited and further research is needed into different populations of women in South Africa.

In conclusion, the results of this study highlight the differing STI risk profile and intervention needs of pregnant and non pregnant VCT attendees in South Africa. There is a need for developing targeted interventions among women VCT attendees. The results suggest factors to be taken into consideration when developing intervention targeting HIV negative, specifically women VCT attendees in South Africa. 


\section{References}

Cartoux, M., Meda, N., Van de Perre, P., Newell, M.L., de Vincenzi, I., Dabis, F., et al. (1998). Acceptability of voluntary HIV testing by pregnant women in developing countries: international survey. AIDS, 12, 2489-2493.

Crotchfelt, K.A., Welsh, L.E., Debonville, D., Rosenstraus, M., \& Quinn, T. (1997). Detection of Neisseria gonorrhea and Chlamydia trachomatis in genitourinary specimen from men and women by co-amplification PCR assay. Joumal of Clinical Microbiology, 35, 1536-1540.

Crucitti, T., Van Dyck, E., Tehe, A., Abdellati, S., Vuylsteke, B., Buve, A., et al. (2003). Comparison of culture and different PCR assays for detection of Trichomonas vaginalis in self collected vaginal swabs specimen. Sexually Transmitted Infection, 79, 393-398.

Department of Health of South Africa. (2006). National HIV and syphilis antenatal seroprevalence survey in South Africa 2005. Pretoria: Department of Health

Dorrington, R.E., Johnson, L.F., Bradshaw, D., \& Daniel, T. (2006). The Demographic impact of HIVIAIDS in South Africa. National and Provincial indicators for 2006: Centre for Actuarial Research, South Africa Medical Research Council and Actuarial Society of South Africa.

Dunkle, K.L., Jewkes, R.K., Brown, H.C., Gray, G.E., McIntryre, J.A., \& Harlow, S.D. (2004). Gender-based violence, relationship power, and risk of HIV infection in women attending antenatal clinics in South Africa. Lancet, 363, 1415-21.

Garcia-Calleja, J.M., Gouws, E., \& Ghys, P.D. (2006). National population based HIV prevalence surveys in Sub-Saharan Africa: results and implications for HIV and AIDS estimates. Sexually Transmitted Infections, 82, iii64-iii70. Downloaded from www.sti.bmi.com on 16 May 2008

Gilbert, L. \& Walker, L. (2002). Treading the path of least resistance: HIVIAIDS and social inequalities: a South African case study. Social Science a Medicine, 54, 1093-1110.

Ickovics, J.R., Niccolai, L.M., Lewis, J.B., Kershaw, T.S., \& Ethier, K.A. (2003). High postpartum rates of sexually transmitted infections among teens: pregnancy as a window of opportunity for prevention. Sexually Transmitted Infections, 79, 469-473. 
Jewkes, R.K., Levin, J.B., \& Penn-Kekana, L.A. (2003). Gender inequalities, intimate partner violence and HIV preventive practices: findings of a South African cross-sectional study. Social Science \& Medicine, 56, 125-134.

Mola, O.D., Mercer, M.A., Asghar, R.J., Gimbel-Sherr, K.H., Gimbel-Sherr, S., Micek, M.A., \& Gloyd, S.S. (2006). Condom use after voluntary counselling and testing in central Mozambique. Tropical Medicine and International Health, 11, 176-181.

Pepin, J. \& Mabey, D. (2003). Sexually transmitted infections in Africa: single dose treatment is now affordable. Sexually Transmitted Infections, 79, 432-434.

Shaikh, N, \& Adendorff, T. (2000). Health Status Report. Health Status and Health Service Evaluation Report 1999-2000. Department of Health, Western Cape.

Shaikh, N., Abdullah, F., Lombard, C.J., Smit, L., Bradshaw, D., \& Makubalo, L. (2006). Masking through averages - intraprovincial heterogeneity in HIV prevalence within the Western Cape. South African Medical Journal, 96, 539-543.

Shisana, O., Rehle, T., Simbayi, L.C., Parker, W., Zuma, K., Bhana, A., et al. (2005). South African National HIV prevalence, HIV incidence, Behaviour and communication survey, 2005. Cape Town: HSRC Press.

Van de Wijgert, J., Altini, L., Jones, H., de Kock, A., Young, T., Williamson, A-L., et al. (2006). Two methods of self sampling compared to clinician sampling to detect reproductive tract infections in Gugulethu, South Africa. Sexually Transmitted Infections, 33, 516-523

Weinhardt, L.S., Michael, P., Johnson, B.T., \& Bickham N.L. (1999). Effects of HIV counseling and testing on sexual risk behavior: a meta-analytic review of published research, 1985-1997. American Joumal of Public Health, 89, 1397-1405.

Wilson, T.E, Minkoff, H., McCalla, S., Petterkin, C., \& Jaccard, J. (1996). The relationship between pregnancy and sexual risk taking. American Journal of Obstetrics and Gynecology, 174, 1033-1036. 


\section{Chapter 5}

\section{SISTA South Africa: The Adaptation of an}

\section{Efficacious HIV Prevention Trial Conducted with}

\section{African-American Women for isiXhosa Speaking}

\section{South African Women}

Published as: Dorina Saleh-Onoya, Nikia D Braxton, Sibusiso Sifunda, Priscilla Reddy, Robert Ruiter, Bart van den Borne, Tiffany Pennick Walters, Delia Lang, Gina M Wingood. (2008). SISTA South Africa: The Adaptation of an Efficacious HIV Prevention Trial Conducted with African-American Women for isiXhosa Speaking South African Women. Journal of Social Aspects of HIV and AIDS Research Alliance, 5, 186-191. 


\section{Introduction}

Globally, at the end of 2004, nearly 37.8 million people were living with HIV. Of these, nearly 25 million were living in South Africa (Day \& Gray, 2005; Dorrington, Bradshaw, Johnson, \& Budlender, 2004). More than $70 \%$ of women and girls infected with HIV live in sub-Saharan Africa, where adult women are 1.3 times more likely than males to be infected (UNAIDSMHO, 2004). Moreover, heterosexual transmission is the dominant mode of transmission among women living with HIV in South Africa (UNAIDS/WHO, 2004). In 2006 it was estimated that in South Africa, the HIV prevalence rate of women between the ages of 15 and 49 was $20.2 \%$ relative to $16.6 \%$ among men of the same age category (Dorrington, Johnson, Bradshaw \& Daniels, 2006). Thus, conducting HIV prevention trials with young South African women is critically important. The vulnerability of young women is exacerbated by limited options for preventing HIV infection and the complex gender dynamics that affect women's ability to negotiate condom use (Eng \& Butler, 1997; Wingood \& DiClemente, 2000).

Although available HIV treatments offer hope for individuals living with HIV, behavioural interventions with a skills-training component shown to reduce HIV risk-behaviours remain one of the most powerful tools in curbing the HIV epidemic (South African Department of Health, 2006; Herbst et al., 2005; Johnson, Carey, Marsh, Levin, \& Scott-Sheldon, 2003). Much work has been done in South Africa to create awareness of HIV and AIDS prevention through multi-media campaigns (eg. LoveLife) and school based life skills interventions. However, very few behavioural interventions targeted to specific vulnerable populations have been tested and even fewer that have shown efficacy in reducing HIV incidence and STI prevalence. (Harrison, Smit, \& Myer, 2000; James, Reddy, Ruiter, McCauley, van de Borne, 2006; Pettifor et al 2005). "Stepping Stones", one of the first few behavioural interventions to 
have been tested in a randomized controlled trial for effectiveness in South Africa did not result in a significant reduction of STI prevalence or improvement of condom use behaviour among intervention participants (Jewkes et al, 2008).

Although evidence consistently indicates that women, particularly black, low income women in South African bear the brunt of the epidemic, the development of efficacious behavioural interventions for this vulnerable group has lagged behind (Reddy, Meyer-Weitz, van den Borne \& Kok, 1999; Collinge, 2005; McKleroy, 2006). One mechanism of expediting the development process is the adaptation of HIV interventions that have documented efficacy for local vulnerable populations.

Adaptation, defined as "the degree to which an innovation is changed or modified by a user in the process of its adoption and implementation" (Rogers, 1995 , p. 174), can include deletions or additions, modifications of existing components, changes in the manner or intensity of components or cultural modifications required by local circumstances (CSAP, 2001; McKleroy, 2006). Adaptation of an evidence-based intervention is often considered a distortion of the intervention, because efficacy of the adapted intervention is rarely examined. However adapting a compatible intervention can reduce the costs of designing a new program, enhance the research capacity of the local scientists adapting the program, increase community ownership of the program and build the capacity of local community members (Rogers, 1995; Reddy, Taylor \& Sifunda, 2002).

The American Centres for Disease Control (CDC) and prevention's behavioural intervention project has identified several effective behavioural interventions and has packaged them for diffusion in the US (www.effectiveinterventions.org).

The SISTA (Sisters Informing other Sisters about Topics on AIDS) is listed among the best evidence interventions targeting low income African 
American women and since 2002 it has been disseminated by the CDC to community-based organizations and AIDS service organizations to every state in the United States (Collins, 2006; Prather, 2006; Wingood \& DiClemente, 2006).

The SISTA intervention was selected for adaptation because it was developed for a population that is similar to South African women in terms of socio economic, demographic factors and gender related determinants of HIV risk and protective behaviours (Levy \& Richards, 1992; Falan \& Lucas, 1998; Hade, Smith, Moore, \& Holmberg 2001). SISTA is a 5-session, group-led HIV prevention intervention for African-American women 18-29 years of age based on Social Cognitive Theory (Bandura, 1994) and the Theory of Gender and Power (Wingood \& DiClemente, 2000).

Session 1 focuses on ethnic and gender pride, encourages women to reflect on the positive aspects of their gender and cultural heritage, and builds a sense of personal worth for the women. Session 2 provides information regarding behaviours that place African-American women at risk of contracting an STI and strategies to protect themselves. Session 3 focuses on the enhancement of distinguishing passive, aggressive and assertive communication styles and women are taught effective safer sex negotiation skills. Session 4 emphasizes fostering positive norms towards consistent condom use and proper condom use skills. Session 5 emphasizes behavioral self-management and coping skills in challenging situations (i.e. with a partner who is not supportive of condom use).

Resuits of a randomized controlled trial demonstrated that compared to the control condition, women in the SISTA intervention demonstrated increased consistent condom use (adjusted Odds ratio $[O R]=2.10 ; 95 \%$ confidence interval [Cl]: 1.03 to 4.15$)$, greater sexual self control $(O R=1.90$, $95 \% \mathrm{Cl}: 1.00$ to 3.60 ), greater sexual communication (OR $=4.10,95 \% \mathrm{Cl}$ : 
1.67 to 10.01 ), greater sexual assertiveness (OR $=1.80,95 \% \mathrm{Cl}: 1.01$ to 3.20 ) and increased partner adoption of norms supporting consistent condom use $(\mathrm{OR}=2.1,95 \% \mathrm{Cl}: 1.08$ to 3.87$)$ among an African-American group of women living in the US (DiClemente \& Wingood, 1995).

The aim of this paper is to describe the process of adapting the SISTA intervention for black isiXhosa speaking women in the Western Cape Province of South Africa. The adaptation process was conducted in a collaborative process between behavioural scientists from the Medical Research Council, Cape Town, South Africa and behavioural scientists from Emory University, Atlanta, USA.

\section{Methods}

The adaptation process consisted of several phases. These phases include: (1) development of a framework for collaboration between South African and U.S. researchers, (2) conducting qualitative research to gain a greater understanding of the determinants of HIV risk for South African Xhosa women, (3) meeting with key South African stake holders, (4) pre-testing of the original intervention with Xhosa participants, (5) adapting and translating the intervention, and (6) conducting a pre-test of the adapted intervention. These phases are described in greater detail below.

\section{Phase I: Collaborations undertaken to adapt the SISTA intervention}

The South African research team included isiXhosa and English speaking researchers, this greatly facilitated the adaptation process. A detailed plan to map out the collaboration and adaptation process was developed. These included plans for: (a) adapting the HIV intervention. curricula, (b) developing culturally appropriate health education materials, (c) 
training local health educators in the adapted HIV intervention, and (d) translating the HIV intervention into the local language (isiXhosa).

South African researchers endeavoured to fully understand the original intervention and the context within which the intervention was implemented. This was accomplished by close interaction with US researchers, observation of the implementation of the SISTA intervention with African American women, and evaluation of publications illustrating the theoretical framework underlying the intervention and the efficacy of the SISTA intervention. Furthermore the South African research team in collaboration with the U.S. research team held meetings to create a plan for the adaptation and translation process.

Phase II: Qualitative research to understand determinants of HIV risk for South African Xhosa women, and reviewing the literature

Focus group discussions aimed to gather information on determinants of sexual behaviour, the context as well as the appropriateness, and desirability of the constructs of the theory of gender and power underlying the intervention. This information was then infused into the adaptation process both in terms of content and methodology.

Participants

The focus group participants were eleven 18 to 35 year old isiXhosa speaking women who tested HIV negative at a Voluntary Counselling and Testing (VCT) clinic in a peri-urban area on the outskirts of Cape Town.

Participants provided consent to participate in focus group discussions. The discussions were facilitated by bilingual (English and isiXhosa) researchers. This team provided the participants with the opportunity to explain sensitive and complex issues in isiXhosa where necessary. The study protocol was approved by the Ethics Committee at the South African Medical Association (SAMA) prior to implementation.

Outcomes of focus group discussions 
All the participants agreed on the need for a health education intervention targeting HIV negative isiXhosa speaking women. They expressed that although they received information from the local media campaigns, the style of delivery and even the content "left people with many questions". They explained that "women in stable relationships are often exposed to HIV by their partners and that the nature of these relationships created obstacles to preventive behaviour such as condom use". The women requested information on how to deal with men who refused to use condoms, on how to encourage men to seek counselling and testing for HIV and treatment for STI. They also asked for training in communication skills especially in negotiating safe sex, including regular condom use and seeking STI treatment. The focus group participants also expressed feelings conflicted or ambivalent about "how they were living their lives" because they were "deviating from their culture" e.g. "by living with a boyfriend". Xhosa women are traditionally expected to abstain from premarital sex. They also indicated that they are aware that these behaviours and situations place them at risk for disease and abuse in general.

The study investigators believed that cultural pride should be nurtured and integrated into the HIV prevention program. During the focus group participants felt that traditional beadwork was a craft that exemplified cultural pride and it was decided that this should be implemented into the HIV prevention program.

\section{Phase III. Meeting with key stakeholders}

Prior to adapting the SISTA intervention, meetings were held with local stakeholders, including interested community members, clinic directors and nurses who work with isiXhosa women at risk of HIV, to obtain their input in designing an HIV prevention intervention for the target population. Some of the stakeholders were identified as potential collaborators, for activities such as participant recruitment, identification of intervention facilitators and locations 
where participants could receive treatment for a sexually transmitted infection for the ensuing pilot and trial of the adapted intervention.

\section{Phase IV: Pre-testing of the SISTA intervention for African American} women

Focus group participants were requested to assist a pre-test of the American version of the SISTA intervention and asked to provide input for adapting the intervention to make it more relevant to their peers. Their comments were then used as background for the modifications made throughout the intervention

Phase V. Adapting SISTA to enhance its relevance for isiXhosa Women in South Africa

Adaptations made throughout the SISTA intervention

After the pre-test of the original intervention, the theory based core elements of the original program were found to be pertinent to the South African context and therefore they were retained. The term core elements refers to those components that are critical features of an intervention's intent and design and that are thought to be responsible for its effectiveness (www.effectiveinterventions.org).

Several concepts were added to the intervention that more effectively and accurately captured African society as being more collective and communal. For example, the intervention was framed in terms of words such as "we", "us" and "our", as opposed to "l", "me", or "my" wherever possible. Additionally, it was agreed that more time in the curriculum must be allowed for discussions and exploration. Names, terms, and regional slang common in South Africa were incorporated into the curriculum. While the name SISTA was retained, an isiXhosa motto of "Bahlokom' abafazi kwamililizwe!" meaning "Women will rise up so that our nation gets healed!" was added. This motto was read at the beginning of every session and was followed by detailed 
discussions of how this motto could apply to reducing women's HIV vulnerability.

Cultural adaptation included replacing the poetry written by AfricanAmerican women with poetry by isiXhosa women to foster a sense of selfesteem and self worth and, creating beadwork as a stimulus for discussions about protective aspects of their culture and sharing of individual experiences. Finally, during the focus groups, it emerged that participants were unlikely to commit to five 3 hour sessions over a 5 week period because of competing activities. They expressed that participants could lose interest midway and not complete the program. To ensure retention of participants through the entire intervention, the original 5, 2-hour sessions intervention was condensed into three 3-hour sessions.

The intervention was then translated into isiXhosa by the South African researchers for implementation. A description of the 3-session HIV prevention intervention is described below.

The adapted SISTA intervention

Session 1 still focuses on ethnic and gender pride, encourages women to reflect on the positive aspects of their gender and cultural heritage, and builds their self esteem. Poetry by isiXhosa women was introduced to stimulate discussion about gender and cultural pride, the strengths of isiXhosa women role models as well as the challenges of being an isiXhosa woman. Much of the discussion of the challenges reflected on the role of apartheid in disempowering isiXhosa women. Participants also discussed personal and community values that could facilitate the adoption of safer sexual practices. HIVIAIDS educational brochures were distributed and discussed.

Session 2 provides information regarding personal behaviours and realities in the communities that increase women's risks of STI infection. Participants were taught correct male condom application and care, assertive 
communication, and condom use negotiation skills.. Session 3 sought to improve participants' assertive negotiation of safe sex and condom use skills with a sexual partner, to identify ways to encourage a partner to get tested for STI and HIV and get treated for STI, and finally to recognize signs of an unhealthy relationship and methods of safely resolving relationship problems. The skill development components of each session involved modelling of the skill by health educators followed by practice and role playing by participants to reinforce skills. All workshops ended with traditional Xhosa songs, as well as creating traditional bead jewellery (bracelets, necklaces and rings).

\section{Phase VI. Pre-test of the adapted intervention}

Training of facilitators to implement the intervention

A key phase of adapting an evidence-based intervention is training staff to implement the intervention with fidelity. Therefore, for 1-month, African American health educators implemented a training program at the MRC to train the South African facilitators. A train-the-trainers strategy was utilized to train the facilitators. Facilitators were Black South African women who spoke and read isiXhosa fluently, had completed their secondary education and were selected based on their demonstrated communication skills and enthusiasm for the project, and prior experience working in the field of HIV prevention. The master Trainers conducted a thorough training that consisted of facilitation techniques, basic STI and HIV knowledge, and a demonstration of each activity within the curriculum. The trainees then performed mock intervention sessions with staff members as their participants to practice and reinforce their skills. While this initial month of training was conducted in English, this small group of trained South African facilitators were then responsible for training a larger group of facilitators in isiXhosa. This larger group of facilitators pretested the SISTA HIV intervention.

Pre-test of the adapted SISTA intervention 
The pre-test in this context describes a qualitative evaluation of the adapted intervention with the pilot participants following the implementation of the adapted intervention. The complete description of the pilot will be presented in subsequent publications.

Participants were eleven 18 to 35 year old isiXhosa speaking women who tested HIV negative at a VCT clinic in a peri-urban area on the outskirts of Cape Town. They had provided informed consent to participate in the pilot of the adapted SISTA intervention which included completing a baseline survey, providing 1 self collected vaginal swab and completing intervention sessions. In this report we only describe the response of participants to the intervention.

The trained South African facilitators delivered the adapted intervention in isiXhosa in order to assess the intervention for face and construct validity. Following the intervention workshops, participants were requested to comment on the adapted SISTA intervention.

Results

There was an overwhelming response of satisfaction with the program as well as identification with the various vignettes that were used during the role play activities. The visual material which included posters and handouts were described as relevant and sensitive, and received general approval from the group.

In terms of comprehension, the participants expressed approval of the sensitive way in which complex messages were explained in their native language. The translation of the intervention into isiXhosa was hailed as important and the participants indicated that this provided them with terminology that they could use in their daily communications with their male partners. They felt that all the health education messages were infused with elements of their real life situations. They expressed appreciation for the cultural sensitivity that was integrated into all aspects of the intervention. 
Finally, questions in response to the learning and teaching methodology indicated that they enjoyed the intervention because it comprised multiple methods of participatory teaching and learning. For example, in depth group discussions, role plays, one to one sharing, writing, and listening to music.

\section{Discussion}

The final adapted intervention retained the core elements of the original SISTA intervention but adapted the intervention with respect to cultural elements and prevailing themes increasing vulnerability to HIV among South African isiXhosa women. Furthermore participants in a pre-test with the adapted intervention expressed that the message was relevant to them.

In order to ensure that cultural elements of the local population were properly integrated in the adapted intervention while maintaining the core of the intervention it was imperative to create close and respective interinstitutional collaborations. This resulted in the capacity development of both partners in the collaboration. The young South African researchers benefited in this association by gaining critical understanding of the theoretical and contextual background of the original program as well as methods for translating theory into an intervention while all researchers gained new understanding of determinants of protective behaviour among South African women and practical experience in adapting an intervention to the South African setting.

Culturally sensitive collaborations between international institutions and South African researchers are critical as these are more likely to result in continued mutual capacity development where necessary, appropriate cultural translation and adaptation of interventions, and community ownership of newly adapted programs (Reddy, Taylor \& Sifunda, 2002). Hopefully these would 
result in accelerated development of interventions for vulnerable populations in South Africa

We followed a structured process similar to the ADAPT-IT model that specifies 8 important phases that have been used in the adaptation of interventions to different populations (Wingood \& DiClemente, 2008). A structured process of adapting evidence-based interventions increases the consistency in terms of how these interventions are discussed and a transparent way in which decisions about to which elements are added or removed are made. This in turn will facilitate future evaluation and continued improvement of the adapted interventions.

We hope that this adaptation process would be informative to researchers seeking to adapt interventions in South Africa. It is important to note that the specific modifications of the SISTA interventions described in this paper were specifically suited to young Xhosa women in the Western Cape Province and may not be appropriate for women in different contexts. Furthermore we only describe face validity outcomes of the adapted intervention, further evaluations are necessary to determine its efficacy in improving determinants of protective sexual behaviour among this population. To this end the efficacy of this adapted SISTA intervention is currently being evaluated in a randomized controlled trial in the Western Cape Province of South Africa. 


\section{References}

Bandura, A. (1994). Social cognitive theory and exercise of control over HIV infection.ln R.J. DiClemente, J. Peterson (Eds), Preventing AIDS: Theories and methods of behavioral interventions, 25-59. New York NY: Plenum publishing Corp.

Centres for Substance Abuse Prevention (CSAP). 2001. Finding the balance: Program fidelity and adaptation in substance abuse prevention.

Collinge, J. (2005). Confronting HIV and AIDS through Mass Media and Community Action. In P. ljumba, \& P. Barron (Eds.), South African Health review 2005, Chapter 15, $202-$ 223. Durban Health Systems Trust.

Collins, C., Harshbarger, C., Sawyer, R., \& Hamdallah, M. (2006). the diffusion of effective behavioral interventions project: Development, implementation, and lessons learned. . AIDS Education and Prevention, 18 (Supplement A), 5-20.

Day, C. \& Gray, A. (2005). Health and related indicators. In P. ljumba, \& P. Barron (Eds.), South African Health review 2005, Chapter 17, 248-367. Durban Health Systems Trust.

DiClemente, R.J. \& Wingood, G.M. (1995). A randomized controlled trial of an HIV sexual risk reduction intervention for young African American women. JAMA 274, 12711276.

Dorrington, R.E., Johnson, L., Bradshaw, D., \& Daniel, T.J. (2006). The Demographic Impact of HIVIAIDS in South Africa. National and provincial indicators for 2006. Cape Town: Centre for Actuarial Research, South African Medical Research Council and Actuarial Society of South Africa

Dorrington, R.E., Bradshaw, D., Johnson, L., \& Budlender, D. (2004). The Demographic Impact of HIVIAIDS in South Africa. National indicators for 2004. Cape Town: Centre for Actuarial Research, South African Medical Research Council and Actuarial Society of South Africa.

Eng, T.R., Butler, W.T., ed. (1997). The Hidden Epidemic: Confronting Sexually Transmitted Diseases. Washington, DC: National Academy Press.

Falan, P. \& Lucas, R. (1998). South African labor markets: Adjustments and inequalities. The World Bank Southern Africa Discussion document. Retrieved November 2006 from www.essa.org.za 
Hade, S.L., Smith, D.K., Moore, J.S., \& Holmberg, S.D. (2001). HIV infection in women in the United States: Status at the millennium. JAMA, 285, 1186-1192.

Harrison, A., Smit, J.A., \& Myer, L. (2000). Prevention of HIV and AIDS in South Africa a review of behaviour change interventions, evidence and options for the future. South African Journal of Science, 96, 285-290.

Herbst, J.H., Sherba, R.T., Crepaz, N., DeLuca, J.B., Zohrabyan, L., \& Stall, R.D. (2005). A meta-analytic review of HIV behavioral interventions for reducing sexual risk behavior of men who have sex with men. AIDS, 34, 228-241.

James, S., Reddy, P., Ruiter, R.A.C., McCauley, A., \& van den Borne, B. (2006). The impact of an HIV and AIDS life skills program on secondary school students in Kwazulu-Natal, South Africa. AIDS Education and Prevention, 18, 281-294.

Jewkes, R., Nduna, M., Levin, J., Jama, N., Dunkle, K., Puren, A., \& Duvvury, N. (2008). Africa: cluster randomised controlled trial and HSV-2 and sexual behaviour in rural South Impact of Stepping Stones on incidence of HIV. British Medical Journal, 337, 506-517. Downloaded from bmj.com on 9 September 2008

Johnson, B., Carey, M., Marsh, K., Levin, K., \& Scott-Sheldon, L. (2003). Interventions to reduce sexual risk for human immunodeficiency virus in adolescents, 1985-2000. Archives of Pediatrics and Adolescent Medicine, 157, 381-388.

Levy, F. \& Richard, M. J. (1992). US earnings levels and earning inequalities. A review of recent trends and proposed explanations. Journal of economic literature, American economic association, 30, 1373-1380.

McKleroy, V.S., Galbraith, J.S., Cummings, B., Jones, P., Harshbarger, C., Collins, C. et Al. (2006). Adapting evidence-based interventions for new settings and target populations. AIDS Education and Prevention, 18 (Supplement A), 59-73.

Pettifor, A.E., Kleinschmidt, I., Levin, J., Rees, H.V., MacPhail, C., Madikizela-Hlongwa, L., et al. (2005). A community-based study to examine the effect of a youth HIV prevention intervention on young people aged 15-24 in South Africa: results of the baseline survey. Tropical Medicine and International Health, 10, 971-980.

Prather, C., Fuller, T.R., King, W., Brown, M., Moering, M., Little, S. et al. (2006). Diffusing an HIV prevention interventions for African-American women: Integrating Afrocentric components into the SISTA diffusion strategy. AIDS Education and Prevention, 18 (Supplement A), 149-160. 
Reddy, P., Meyer-Weitz, A., van den Borne, B., \& Kok G. (1999). STD-related knowledge, beliefs and attitudes of Xhosa-speaking patients attending STD primary health-care clinics in South Africa. International Journal of STD \& AIDS, 10, 392-400.

Reddy, P., Taylor, S.E., \& Sifunda, S. (2002). Research capacity building and collaboration between South African and American partners: the adaptation of an intervention model for HIVIAIDS prevention in corrections research. AIDS Education and Prevention, 14, 92-102.

Rogers, E.M. (1995). Diffusion of innovations $\left(4^{\text {th }}\right.$ ed.) New York: The Free Press. South African Department of Health. (2006). Broad frame-work for HIV \& AIDS and STI strategic plan for south Africa 2007-2011. South African Department of Health, Pretoria., retrieved on December 2006 from www.doh.gov.za

UNAIDS. (2004). Report on the global AIDS epidemic. Geneva, Joint United Nation Programme on HIVIAIDS. World Health Organization. Retrieved July 18, 2007 from www.unaids.com.

Wingood, G.M. \& DiClemente, R.J. (2000). Application of the Theory of Gender and Power to Examine HIV-Related Exposures, Risk Factors, and Effective Interventions for Women. Health Education \& Behavior, 27, 539-565.

Wingood, G.M. \& DiClemente, R.J. (2006). Enhancing Adoption of Evidence- Based HIV Interventions: Promotion of a Suite of HIV Prevention Interventions for African American Women. AIDS Education and Prevention, 18 (Supplement A), 161-170. Wingood, G.M. \& DiClemente, R.J. (2008). The ADAPT-ITT Model, a novel method of adapting evidence-based HIV interventions. Journal of Acquired Immune Deficiency Syndrome, 47, S40-S46. 


\section{Chapter 6}

\section{Facilitators and barriers to recruitment and retention of HIV negative black South African women to behavioural HIV prevention programs}

Submitted as: Dorina Saleh-Onoya, Priscilla Reddy, Sibusiso Sifunda, Gina Wingood, Bart van den Borne, Robert A.C. Ruiter. SISTA South Africa: Facilitators and barriers to recruitment and retention of HIV negative black South African women to behavioural HIV prevention programs 


\section{Introduction}

While the HIV epidemic appears to be stabilizing, its dimensions remain staggering. Sub-Saharan Africa remains the region most heavily affected by HIV, accounting for $67 \%$ of all people living with HIV and for $75 \%$ of AIDS deaths in 2007, with women being at much higher risk of infection than men (UNAIDSWHO, 2008). In 2006 it was estimated that in South Africa, where complex gender dynamics limit women's ability to negotiate condom use and adopt protective behaviour, the HIV prevalence for women between the ages of 15 and 49 was $20.2 \%$, compared to $16.6 \%$ among men of the same age category (Dorrington, Johnson, Bradshaw \& Daniels, 2006; Eng \& Butler, 1997; Wingood \& DiClemente, 2000).

Behavioural interventions, with skills-training components, have been shown to reduce HIV risk-behaviour and remain one of the most powerful tools in curbing the HIV epidemic (Albarracín et al., 2005; Harrison, Smit, \& Myers, 2000; Herbst et al., 2005; Lyles et al., 2007). Although the number of HIV prevention behavioural interventions in South Africa is growing, culturally tailored and group-specific behavioural interventions are limited and more work is needed in order to curb the progression of the epidemic.

Recruitment and retention of participants present a challenge for medical and behavioural intervention trials. Although some research has been done to understand potential barriers to community participation in vaccine trials and uptake of HIV related health services, very little has been done to understand barriers for participation in behavioural HIV prevention programs, especially among women who test HIV negative at VCT clinics (Smit et al., 2006; Cummings et al., 2006; Albarraci'n, Durantini, Earl, Gunnoe, \& Leeper, 2008). Publications of the recruitment processes of randomised controlled trials, particularly in the South African context, are scarce. A recent study found that only 28 percent of trials report enough recruitment data to calculate the 
proportion of participants who actually enrol in the trials. (Gross, Mallory, Heiat, \& Krumholz, 2002). This is of significance, as, if only a small proportion of potential participants eventually participate in a study, the concern would be that participants may differ from non participants and therefore are not representative of the source population. Furthermore research on selective exposure suggests that people have the tendency to seek interventions that confirm and validate their point of view and therefore participants of HIV prevention interventions may be people who are either already inclined to using condom or use condoms (Albarracín et al., 2008). Therefore research on recruitment and retentions are important to support the development of recruitment strategies to ensure that interventions reach the populations for which they were intended.

Recruitment process information also provides an important framework to help interested parties interpret the results of the study and important sources of knowledge about prevailing recruitment and retention challenges and opportunities that could facilitate the implementation of new programs and the development of strategies for the potential scale up of efficacious interventions.

The process of adapting the SISTA (Sisters Informing other Sisters about Topics on AIDS) intervention, a peer-led HIV prevention intervention that was created for young African American women, to young black women in the Western Cape Province of South Africa has been previously described (SalehOnoya et al., 2008). The evaluation of the adapted SISTA intervention in the Western Cape Province is currently being finalised. The aim of this paper is to provide an understanding of the barriers to participation in a behavioural HIV prevention program among black HIV negative women in general and to describe the process and challenges of recruiting and retaining participants into the SISTA South Africa program in particular. 


\section{SISTA recruitment and retention process}

\section{Setting}

The SISTA study was conducted in peri-urban areas of the Western Cape Province of South Africa. This is a wealthy and highly urbanised province with $87 \%$ of its population living in the Cape metropolis. There are acute differences in health provision, health status and HIV prevalence that also depend on racial, socioeconomic and geographic locations. The highest rates of HIV infection and prevalence are among black people who represent only $21 \%$ of the population. This is more pronounced among women living in poor urban informal settlements (referred to as townships) (Shaikh, \& Adendorf, 2000; Shaikh et al., 2006).

\section{Recruitment Process}

Participants were recruited into the study over a 2 year period, namely from January 2006 to December 2007. Women were eligible to participate if they were single, black, isiXhosa speaking, between 18 and 35 years of age, sought voluntary counselling and testing (VCT) services at any one of 5 periurban primary health care clinics (PHC), and had tested HIV negative in the previous 8 weeks.

In order to recruit from the VCT clinics it was necessary to have access to the VCT register to identify women who tested HIV negative. Permission to access the VCT registers was obtained from the PHC head nurse and facility manager under the assumption that VCT centres operate as part of local PHC clinics and as such HIV counsellors were managed by the clinic managers. The initial strategy was that a study recruiter in collaboration with the HIV counsellor would generate a list of names and available contact details of HIV negative women from the VCT register who met the study eligibility criteria. However contrary to the initial assumption, it was later discovered that 
although VCT clinics were situated adjacent to the PHC clinics the counsellors were often funded and managed by local non-governmental organisations (NGO) and not by the PHC. Therefore authorisation to access the VCT clinic register had to be obtained from the NGOs.

Several meetings were held with VCT counsellors and their superiors in order to negotiate access to the register. A referral system was agreed upon, where the HIV counsellor received from the SISTA study written information on participant eligibility criteria and a referral form on which VCT clients could update their contact details and consent to being contacted by the study recruiters. VCT counsellors would then refer the VCT client to the study recruiter who would either recruit her at the clinic or make an appointment for a home visit at a time suitable to the VCT client. Once a month, the study coordinator would check that all VCT clients in the register who met the study inclusion criteria were also referred to the recruiters. This was a good system, and to further ensure its success it was important that VCT counsellors viewed the study as an important extension of the HIV counselling process. As the VCT counsellors participated in this strategy on a completely voluntary basis, the relationship between the study recruiters and the VCT counsellors required careful management to ensure their continued participation in the recruitment process.

Potential participants were subsequently visited by recruiters at the address given on the referral form or the VCT register and screened for eligibility. Sometimes a telephone number was available and this was used to make appointments to visit potential participants. However often incorrect or the lack of telephone numbers resulted in recruiters having to make home visits in the morning and the evening to increase their chances of finding potential participants at home. Eligible women were invited to participate. Those who accepted and signed a consent form were provided with an 
invitation card containing details of the appointment. The first appointment was for assessment which comprised of a computerised survey and the collection of a self administered vaginal swab. Ethical approval for the SISTA study was obtained from the South African Medical Association (SAMA).

This strategy was successful when a correct address was given on the HIV register and the potential candidate was successfully contacted at her home. However some VCT clients provided incorrect physical addresses and telephone numbers to the VCT counsellors. The recruiters walked to each address and this often meant that they would walk long distances trying to find addresses that either did not exist or were incorrect. Furthermore houses in informal settlements and townships are not always arranged in a numerical order, thus increasing the difficulties in contacting potential participants and limiting recruitment.

\section{Retention process}

Potential participants who consented were invited to participate in the study. Appointments were confirmed telephonically on the day before and reminder calls were made on the morning of day of the appointment. The study site was located at community halls centrally located in the townships, within walking distance from the homes of potential participants. However less than half of them honoured the appointment and when called to inquire about the reasons for not coming, some had switched off their phones or indicated being unavailable to participate. We then resorted to offering transportation from their homes and back. Those who accepted this arrangement were collected from their homes and taken to the study site and dropped off after the baseline assessment session. This was done for every session thereafter.

This approach yielded 1088 referrals at all 5 VCT clinics. Of these 857 $(78.70 \%)$ were eligible and consented to participate in the study, 49 (4.50\%) were not eligible because of their age, $8(0.73 \%)$ did not speak isiXhosa, 
$104(9.55 \%)$ were married, $24(2.20 \%)$ were moving from the community, $15(1.38 \%)$ had not had sex in the previous six months, $31(2.85 \%)$ were not interested.

Of the 857 who consented 446 (52.04\%) attended baseline assessment. After baseline assessment participants were invited to attend 3 or 2 once weekly workshops for the intervention and comparison groups respectively. They were given a second invitation card with dates for the workshops. Randomisation occurred just before the first workshop. Participants were assessed again 6 months after the completion of the workshops. Of the 446 who attended baseline assessment $344(77.13 \%)$ were randomised and attended at least 1 workshop. Of those who were randomised $240(69.77 \%)$ completed the 6 month assessment. The recruitment and retention flow diagram is depicted in Figure 1. 
Figure 1. Diagram of participant recruitment and retention in the program

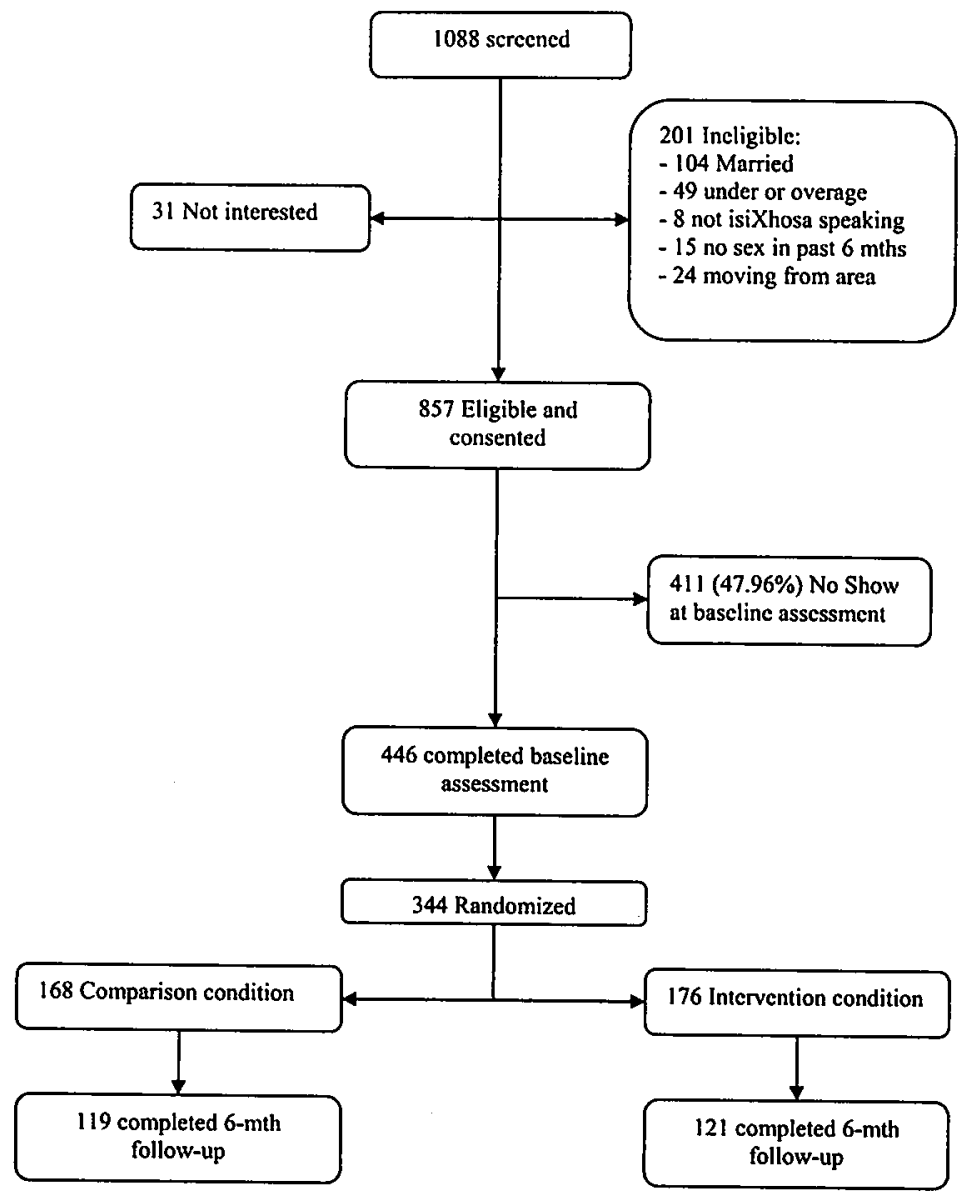




\section{Barriers and facilitators of participation}

\section{Methods}

In order to understand the barriers and facilitators of participation of HIV negative women in HIV prevention programs, focus group discussions were conducted at 3 different study sites (Hermanus, Grabouw and Strand). Participants were women who had met the eligibility criteria of the SISTA study and had provided informed consent to participate in the SISTA program but did not attend any of the activities. At each site 1 focus group discussion was conducted. In total 21 women participated in the focus groups that were conducted by 2 trained facilitators in isiXhosa. Focus group participants were not compensated however refreshments were provided during the discussions. The focus groups discussions were completed in approximately 1 hour and 30 minutes.

Transportation to and from the study site was provided. The discussions covered issues relating to experiences with STI, awareness of STI and HIV, awareness of and attitude towards behavioural HIV prevention programs, and finally barriers and facilitators to participation in HIV prevention programs.

\section{Results}

Experience with STI

Participants were asked about their past experiences with STI and issues of susceptibility to HIV. All the participants indicated having experienced a STl at least once even though some did not initially recognise their symptoms as STI. Some had sought treatment from a pharmacist who recommended an over the counter drug without counselling the women. Those who sought treatment at PHC clinics expressed that after getting treated at the clinic they understood that STI were transmitted through sexual contact. Some even indicated an attempt to use condoms afterwards. It was alarming to note that even after being counselled at the PHC clinic, there were still many 
misunderstandings about STI and their mode of transmission. Some understood that STI were transmitted through sexual contact and that an unfaithful partner poses a risk of contracting a STI. However they seemed to separate the risk of contracting STI from the risk of contracting HIV. There was no mention of the associated risk of HIV in STI episodes.

"Someone at the clinic told me that you get STI from your boyfriend when he has slept with a dirty person and since you are not dirty your body gets itchy."

Awareness of the HIV epidemic

Most of the women were aware of HIV and heard about HIV through family members or close friend. Most women knew of at least one close person infected or affected by HIV. They expressed uncertainty about HIV transmission, symptoms, co-infection with TB and how to help and support HIV positive individuals.

The women were aware of some of the ways in which HIV is transmitted although many had incorrect perceptions. Some thought that HIV is transmitted through hugging, coughing or sharing a toothbrush.

"Whether you are in love or involved with a person or not, you can get it (HIV) by sharing a toothbrush."

"I did not know how it is was transmitted. In 2006 when I was pregnant, the clinic nurses explained it to me. My aunt used to say that we must not sleep with boys as there was a disease called gonorrhoea going around" Awareness and attitude concerning HIV prevention programs

Participants were aware of HIV prevention programs in the communities such as Siyanqoba, Ubuntu-bethu, and Lovelife. However none of the women indicated ever participating in them. They indicated that they "liked" HIV programs and felt that these programs were important because "they teach people about HIV'. 
"I like the programs because they teach how to live with HIV. If you have children you can still live long to bring up your children and you can say no to sex without a condom and say to your boyfriend openly that I do not know what you do when I am not there."

"This thing is right, to hear teaching about HIV because there are perceptions that if kiss someone with HIV you will get it. If I see someone kissing a HIV positive person I will say that that person also has it. It's not like that you cannot get it by kissing. If people teach you then you will know how you get it."

The women expressed that the programs are especially good for HIV positive women as they help them to accept their status and therefore live long and productive lives. Their responses to the questions about HIV prevention programs indicated that they thought that the programs were mainly aimed at HIV positive people. They recounted stories about HIV positive people whom they felt could have richly benefited from these programs and because they could not bring themselves to attend these programs and accept their status, their condition worsened and they died as a result. The general attitude was that of concern and pity for HIV positive individuals. Most indicated being willing to support members of their families who test HIV positive and recounted efforts to get family members or friends tested for HIV. They expressed being keen to participating and interested in listening to the content of the programs as they felt that they have very little information and would have liked to find out more.

\section{Barriers to participation in HIV prevention programs}

Four main categories of barriers were identified:

1. HIV programs are for HIV positive people.

Some women expressed the need to attend HIV prevention programs in order to correctly teach other members of their families. However the tendency 
was to think that those programs are for HIV positive people and if HIV negative women were to attend it would be to equip themselves to better help and support HIV positive individuals.

"Maybe I am just lying to myself because those programs are for HIV positive people. I am negative and I don't know how to talk to HIV positive people."

When questioned about how they felt about personally participating in HIV prevention programs participants, participants expressed difficulties in joining as they feared the responses of HIV positive people to having a HIV negative person teach them about how to take care of themselves.

"I would have difficulties teaching a HIV positive person because they would think that I am laughing at her because of her status."

"It's a problem when a person is positive, when you are trying to talk to these people. I have experienced this from my cousin, they are very cheeky and do not want to listen to anyone because they think that before talking to her you talk about her outside."

"I like these programs but many people I know and who know me are living with HIV and they will come and confront me because they think I will be mocking them and making them a laughing stock by telling everybody their business."

There was some expressed interest in the programs to gain information for personal protection from HIV. However participants indicated that their desire to obtain information to prevent HIV was reduced after testing HIV negative.

"If I were positive I would join all these programs but because I am HIV negative I just don't care. I feel this way after testing. Before testing I just had faith that I was negative."

2. HIV Stigma 
HIV stigma seems to play an important barrier to participation in HIV programs. The women expressed fear that if they were seen to participate they would be labelled as being HIV positive and members of the community would gossip about them. In the SISTA study in particular, transportation, with a car marked "Health", to the study site was provided and they felt that people associated the car with HIV and assumed that the women being picked up were HIV positive and that the car was taking them to the clinic to get treatment.

"People are shy because when that car that is written health on it comes to pick her up people will think that she is positive even if she knows that she is negative she still feels afraid that people will talk about her."

"If they see you in the (Health Promotion Car) car they label you as HIV positive. There is nothing that they can do, they will just look at you like so and talk behind your back. They will not physically hurt you, just gossip."

3. Economic and domestic activities

Some of the women expressed interest in participating in the program but could not attend because of competing economic or domestic chores that left them little time to participate. Some of the women had economic activities such as a job or a little business to take care of or had to watch children and therefore could not spare the time to attend HIV prevention programs.

"It is not that I do not want to go but I am always at the stand and I can't just leave the business unattended. The business is my life."

"I am not afraid of anyone, my husband is unemployed so I am always busy either looking after the children or something else to find money."

4. Lack of clarity about the purpose and content of programs

Some women indicated being scared to attend the SISTA study in particular because they were not sure about the purpose and the content of the 
program. They felt uncertain about how they would have been treated in the program and how the activities were conducted.

"There were girls telling them that it was going to be a teaching about AIDS and I was scared so / didn't want to attend."

Participants indicated that after attending the focus group they were less afraid to participate as they now had much more positive ideas of the content of HIV prevention programs and were more inclined to attend.

\section{Facilitators to participation}

Participants expressed that many programs in the communities erected temporary structures within the communities and information materials about the program were not disseminated for long enough to ensure better understanding of the HIV prevention program. They felt that the stigma could be alleviated by establishing a permanent program site (other than the VCT and $\mathrm{PHC}$ ) from where workshops could be conducted in a formal fashion and where information about the program could be disseminated to the community to reduce misunderstandings, where people could come and ask questions about the program.

"If you had opened a type of school where what we do there would have been clear, where people could ask questions about HIV and the school."

Participants who were employed when the SISTA study was conducted indicated that it would have been easier for them to attend if they were approached through their employer.

\section{Discussion}

This is one of the first papers to present recruitment process information of a controlled, experimental trial of a behavioural intervention in South Africa. This information highlights the importance of understanding the structure of organisations that may participate or impact on the recruitment process. 
Furthermore it is important to be flexible as initial assumptions about the setting and the recruitment may have to be revisited and recruitment approaches adjusted accordingly.

VCT clinics are entry points in the system of HIV education and care in South Africa and the SISTA recruitment process highlight the possibility for successfully referring HIV negative individuals from VCT clinics to small group HIV prevention programs. Once the referral system was set up a relatively high number of HIV negative women were successfully recruited however a secondary set of factors impacted on the attendance of the potential participants in the program.

The main barriers to participation in HIV prevention programs were the perception that HIV related programs are for HIV positive people, uncertainties about the purpose and content of HIV programs, HIV stigma and competing economic (job) or domestic activities or chores. The results suggest that anticipated perceived difficulties in interacting with HIV positive individuals could be a deterrent for women who think that HIV related programs are for HIV positive people. Furthermore HIV stigma affects the desire of HIV negative women to participate in any HIV-related community program because of fear of being labelled and treated as HIV positive. The fear of being identified as being at risk of HIV has been cited as a deterrent from participation in HIV prevention program (Rutledge, Roffman, Picciano, Kalichman, \& Berghuis, 2002). It has been shown, among women in Bostwana, that participation in PMTCT (Prevention of mother to child transmission) programs was hindered by the fear of HIV testing. Women were afraid of knowing their HIV status because they feared the potential stigma, stress and depression associated to being HIV positive (Kebaabetswe, 2007). HIV stigma in Africa and South Africa is of great concern because it negatively affects attendance of HIV related services and programs such as VCT, treatment, infant formula distributions and 
therefore limits their efficacy (Kebaabetswe, 2007; Population Council and Health Systems Trust. 2006). Furthermore high illiteracy rates in some communities limit the ability of many to access adequate information about HIV and AIDS and HIV programs and services (Rankin, Brennan, Schell, Laviwa, \& Rankin, 2005; Population Council and Health Systems Trust, 2006).

A study conducted in Ethiopia also found that domestic workload, lack of education, limited awareness about the purpose of the program and cultural norms that discourages sexual discussions prevented women from participating in HIV prevention programs (Cumming et al., 2006).

In a context where much more focus has been placed on HIV treatment and not enough on behavioural interventions among HIV negative women, the perception that HIV programs are for HIV positive people is understandable. It is necessary to include the wider community in the discussions about HIV and AIDS and even treatment and care of HIV positive people. The results indicate that more efforts are needed to reduce HIV stigma in South African communities. This could be achieved by devising appropriate methods for the dissemination of information in townships and informal settlements. In South Africa the dissemination of HIV related information is often associated to clinical care or VCT service which do not allow for group discussions. A way of impacting on stigma could be by establishing continuous programs that encourage group discussions about HIV (Brown, Macintyre, \& Trujillo, 2003).

This study was necessary to shed some light on the high drop-out rate in not only the SISTA program but possibly in other HIV prevention programs as well in South Africa. In retrospect more attention to branding and marketing the SISTA study to the community and potential participants by ensuring that enough information about the content and activities of the study were disseminated may have alleviated some of the uncertainties of potential participants. Because barriers to participation may be different for women with 
different social, economic and cultural background, the generalisation of these results to other settings than HIV negative isiXhosa speaking women in periurban areas of the Western Cape seems to be limited.

\section{Conclusion}

Behavioural interventions have to reach the target at risk populations and the adequate attendance of HIV prevention programs is necessary for their success. The great need for behavioural HIV intervention for women in South Africa demands a better understanding of barriers and facilitators to participation in order to develop successful recruitment strategies. The results of this study provide important information to this end; however more detailed studies into the psychosocial determinants of participation in HIV intervention programmes are needed to adequately inform strategies to reduce hindrances to participation. 


\section{References}

Albarracín, D., Durantini, M.R., Earl, A., Gunnoe, J.B., \& Leeper, J. (2008). Beyond the most willing audiences: a meta-intervention to increase exposure to HIV-prevention programs by vulnerable populations. Health Psychology, 27, 638-644.

Albarracín, D., Gillette, J.C., Earl, A.N., Glasman, L.R., Durantini, M.R., \& Ho, M.H. (2005).

A test of major assumptions about behavior change: a comprehensive look the effects of passive and active HIV-prevention interventions since the beginning of the epidemic. Psychological Bulletin, 131, 856-897

Brown, L., Macintyre, K., \& Trujilio, L. (2003). Interventions to reduce HIVIAIDS stigma: what have we learned? AIDS Education and Prevention, 15, 49-69.

Cummings, B., Mengistu, M., Negash, W., Bekele, A. \& Ghile, T. (2006). Barriers to and facilitators for female participation in an HIV prevention project in Rural Ethiopia: Findings from a qualitative evaluation. Culture, Health \& Sexuality, 8, 251-266.

Dorrington, R., Johnson, L., Bradshaw, D., \& Daniel, T.J. (2006). Demographic impact of HIV and AIDS in South Africa, National and Provincial Indicators for 2006. Retrieved on 26 of November 2007 from www.doh.gov.za

Eng. T.R. \& Butler, W.T. (Eds) (1997). The hidden epidemic: Confronting sexually transmitted diseases. Washington, DC: National Academy Press.

Gross, G.P., Mallory, R., Heiat, A., \& Krumholz, H.M. (2002) Reporting the Recruitment Process in Clinical Trials: Who Are These Patients and How Did They Get There? Annals of Internal Medicine, 137, 10-16.

Harrison, A., Smit, J.A., \& Myer, L. (2000). Prevention of HIVIAIDS in South Africa: a review of behaviour change interventions, evidence and options for the future. South African Journal of Science, 96, 285-290.

Herbst, J.H., Sherba, R.T., Crepaz, N., DeLuca, J.B., Zohrabyan, L., \& Stall, R.D. (2005). A meta-analytic review of HIV behavioral interventions for reducing sexual risk behavior of men who have sex with men. AIDS, 34, 228-241.

Kebaabetswe, P.M. (2007). Barriers to participation in the prevention of mother-to-child HIV transmission program in Gaborone, Botswana a qualitative approach. AIDS Care, 19, 355-360.

Lyles, C.M., Kay, L.S., Crepaz, N., Herbst, J.H., Passin, W.F., Kim, A.S., et al (2007). Bestevidence interventions: findings from a systematic review of HIV behavioral 
interventions for US populations at high risk, 2000-2004. American Journal of Public Health, 97, 133-143.

Population Council and Health Systems Trust. 2006. "Understanding barriers to community participation in HIV and AIDS services," Summary Report. Johannesburg: Population Council.

Rankin, W.W., Brennan, S., Schell, E., Laviwa, J., \& Rankin, S.H. (2005). The stigma of being HIV-positive in Africa. PLOS Medicine, 2, 702-704.

Rutledge, S.E., Roffman, R.A., Picciano, J.F., Kalichman, S.C., \& Berghuis, J.P. (2002). HIV Prevention and Attrition: Challenges and Opportunities. AIDS and Behavior, 6, 69-83. Saleh-Onoya, D., Braxton, N.D., Sifunda, S., Reddy, P., Ruiter, R.A.C., van den Borne, B. et al. (2008). SISTA South Africa: The adaptation of an efficacious HIV prevention trial conducted with African-American women for isiXhosa-speaking South African women. SAHARA journal, 5, 186-191.

Shaikh, N., Abdullah, F., Lombard, C.J., Smith, L., Bradshaw, D., \& Makubalo, L. (2006).

Masking through averages - intraprovincial heterogeneity in HIV prevalence within the Western Cape. South African Medical Journal, 96, 539-543.

Shaikh, N., \& Adendorff, T. (2000). Health Status Report. Health Status and Health Service Evaluation Report 1999-2000. Western Cape Department of Health, 2000.

Smit, J., Middelkoop, K., Myer, L., Seedat, S., Bekker, L-G., \& Stein, D.J. (2006). Willingness to participate in HIV vaccine research in a peri-urban South African community. International Journal of STD \& AIDS, 17, 176-179.

UNAIDS. (2008). 2008 report on the global AIDS epidemic. UNAIDS. Retrieved July 18, 2007 from www.unaids.com

Wingood, G.M., \& DiClemente, R.J. (2000). Application of the Theory of Gender and Power to Examine HIV-Related Exposures, Risk Factors, and Effective Interventions for Women. Health Education \& Behavior, 27, 539-565. 


\section{Chapter 7}

\section{Psychosocial Correlates of Condom Use Frequency among isiXhosa Speaking Women Living with HIV}

in the Western Cape Province of South Africa: a Preliminary Study

Submitted as: Dorina Saleh-Onoya, Priscilla S. Reddy, Sibusiso Sifunda, Gina Wingood, Bart van den Borne, Robert A.C. Ruiter. Psychosocial Correlates of Condom Use Frequency among isiXhosa Speaking Women Living with HIV in the Western Cape Province of South Africa: a Preliminary Study. 


\section{Introduction}

The impact of the HIV epidemic in sub-Saharan Africa continues to grow and young women are at much higher risk of acquiring HIV compared to their male counterparts (UNAIDS, 2004). A population survey in South Africa in 2004 reported that in general, the prevalence of HIV was $15.5 \%$ among young women compared to $4.8 \%$ among men (Pettifor et al., 2005). Similarly high HIV prevalence levels have been observed elsewhere in sub-Saharan Africa among young women reporting one lifetime partner and few sexual contacts (Auvert et al., 2001; Glynn et al., 2001).

Although increasing, condom use among South African women is generally low. A survey conducted in 2003 revealed that $40 \%$ of sexually active women reported ever using a condom and $30 \%$ reported using a condom at last intercourse (Department of Health of South Africa, 1998). Data on condom use among South African women living with HIV are scarce. It has been reported that over $70 \%$ of people living with HIV in the USA continue to have unprotected sex after finding out their HIV status (Kline \& VanLandingham, 1994). In a recent study among HIV positive patients in South Africa, $47 \%$ of female and $42 \%$ of male participants reported having used condoms at last sex (Olley, et al., 2005). It is therefore imperative that interventions to improve condom use among HIV positive women are developed on the basis of appropriate theories and a thorough understanding of the correlates of consistent condom use.

Determinants of condom use have been identified among heterosexual HIV naive individuals and include: positive attitudes toward condoms and condom use, behavioural intentions, communication about condoms, self efficacy for condom use, and STI history (Reddy et al., 2000; Sheeran et al., 1999; Sifunda et al., 2007). In addition, a recent study found that HIV naïve South African women aged 20-24 were less likely to use condoms if they were 
married, knew their HIV status, did not use a condom on their first intercourse, and had sex as a result of partner's insistence (Hendriksen et al., 2007).

Relatively fewer studies have been conducted to identify correlates of condom use among HIV positive women, most of them conducted among HIV positive women in the USA. The psychosocial determinants of condom use among HIV positive women in the USA include: knowledge about HIV transmission and HIV related health risks, negative attitude to condom use, low self-efficacy for condom use, low perceived behavioural control over condom use, difficulties with negotiation of safer sex practices, and perceiving barriers to condom use were found to be important predictors of unsafe sexual behaviours among HIV positive women in the USA (Bedimo et al., 1998; Crepaz \& Marks, 2002). To our knowledge only one study has been conducted to identify determinants of unprotected sex among HIV positive individuals in South Africa (Olley et al., 2005). The results of this study indicated that shorter duration of illness and coping styles characterized by denial and substance abuse were significantly associated with unprotected sex among HIV positive patients.

Considering the urgency of reducing HIV transmission, further research on psychosocial determinants of condom use behaviour among HIV positive women in South Africa is of great importance. Determinants of condom use among American HIV positive women may apply to South African women, but there is no current model on how they would apply to a South African population. The structuring of known determinants of condom use into a framework of proximal and distal determinants facilitates their translation into targeted health education interventions for this population of women.

in this paper we report the results of a preliminary study in which the objectives were to examine psychosocial correlates of condom use frequency among isiXhosa speaking women living with HIV in peri-urban areas of 
Western Cape Province and propose a framework of determinants of condom use frequency to inform intervention development processes.

\section{Method}

\section{Participants}

The data for this report were drawn from baseline measures of a pilot study to test the efficacy of a sexual HIV transmission risk-reduction and social networking intervention among black, isiXhosa speaking women living with HIV in South Africa (Saleh-Onoya et al., 2009).

From June through to August 2003, 143 women from treatment sites or clinic based support groups of five primary care clinics in the Western Cape Province, South Africa were screened. Women were eligible to participate if they were between 18 and 50 years old at the time of enrolment, black, isiXhosa speaking, living with HIV infection, and had sex in the prior 12 months. Twenty-three women were ineligible as they had not had sex in the previous 12 months, leaving 120 (83.9\%) women in the sample.

Study Design and Procedure

All 120 women provided written informed consent to participate in all assessment procedures. Participants received additional information about sterile methods for self-collecting a vaginal swab (Van de Wijgert et al., 2006), completed an interviewer administered questionnaire, and provided one selfcollected vaginal swab specimen. Participants were allowed to opt out if unable to provide a swab ( $n=2$ at baseline), however they were not excluded from the sample. The questionnaire was translated into isiXhosa by bilingual researchers and checked for linguistic appropriateness, comprehension, and cultural relevance, and then back translated from isiXhosa into English to ensure accuracy and meaning of constructs. The interviews were administered by trained, isiXhosa speaking, black female interviewers who read the 
questions to the participants and noted the responses on paper. The interview took 1 to 2 hours to complete. Participants were compensated R20 (approx. 3 $\$)$.

\section{Assessment Instrument}

The following measures were assessed in the questionnaire: condom use frequency, self-efficacy for negotiating condom use, assertive negotiation of condom use, abusive partner response to request for condom use, selfefficacy for correct condom use, personal attitude to condom use, perceived attitude of partner towards condom use, perceived control of life, self-esteem, problem-oriented coping, self-controlled way of coping, and seeking social support. Detailed descriptions of the questionnaire variables are presented in Table 1.

\section{Data Analysis}

Frequencies and percentages were used to describe the condom use behaviour variable. The condom frequency variable was treated as a continuous variable because it demonstrated parametric parameters. 
Table 1. Description of questionnaire variables

\begin{tabular}{|c|c|c|c|}
\hline Variable & $\begin{array}{l}\mathrm{N} \text { of Items } \\
\text { (Alpha) }\end{array}$ & Example of questions & Coding \\
\hline $\begin{array}{l}\text { Condom use } \\
\text { frequency }\end{array}$ & $\begin{array}{l}1 \text { (treated } \\
\text { as } \\
\text { continuous) }\end{array}$ & $\begin{array}{l}\text { "In the past } 6 \text { months, how } \\
\text { often did you use a condom } \\
\text { during sex with your main } \\
\text { partner?" }\end{array}$ & $\begin{array}{l}0=\text { never, } 1 \text { = inconsistently, } \\
2=\text { always. }\end{array}$ \\
\hline $\begin{array}{l}\text { Self-efficacy for } \\
\text { negotiating } \\
\text { condom use }\end{array}$ & $\begin{array}{l}4 \text { items } \\
(\alpha=.85)\end{array}$ & $\begin{array}{l}\text { "How confident are you that } \\
\text { you could convince your } \\
\text { partner to use a condom } \\
\text { even if he did not want to?" }\end{array}$ & $\begin{array}{l}0=\text { not at all confident to } 2= \\
\text { very confident; higher average } \\
\text { scores indicate higher levels of } \\
\text { self-efficacy. }\end{array}$ \\
\hline $\begin{array}{l}\text { Assertive } \\
\text { negotiation of } \\
\text { condom use }\end{array}$ & $\begin{array}{l}6 \text { items } \\
(\alpha=.86)\end{array}$ & $\begin{array}{l}\text { "Have you ever asked your } \\
\text { partner to wait while you get } \\
\text { a condom?" }\end{array}$ & $\begin{array}{l}0=\text { no and } 1=\text { yes; higher total } \\
\text { scores indicate more assertive } \\
\text { negotiation. (Range: } 0-6 \text { ). }\end{array}$ \\
\hline $\begin{array}{l}\text { Abusive partner } \\
\text { response to } \\
\text { request for } \\
\text { condom use }\end{array}$ & $\begin{array}{l}5 \text { items } \\
(\alpha=.92)\end{array}$ & $\begin{array}{l}\text { "In the past month, when } \\
\text { you asked your partner to } \\
\text { use condoms, how often did } \\
\text { he threaten to hit you?" }\end{array}$ & $\begin{array}{l}0=\text { never to } 3=\text { always. Higher } \\
\text { average scores indicate higher } \\
\text { frequency. }\end{array}$ \\
\hline $\begin{array}{l}\text { Self-efficacy for } \\
\text { correct condom } \\
\text { use }\end{array}$ & $\begin{array}{l}9 \text { items } \\
(\alpha=.95)\end{array}$ & $\begin{array}{l}\text { "Even if you've never used } \\
\text { condoms before, how } \\
\text { confident or sure are that } \\
\text { you could unroll a condom } \\
\text { down correctly on the first } \\
\text { try?" }\end{array}$ & $\begin{array}{l}0=\text { not at all confident to } 2= \\
\text { very confident; Higher average } \\
\text { scores represented higher } \\
\text { levels of self efficacy. }\end{array}$ \\
\hline $\begin{array}{l}\text { Personal attitude } \\
\text { to condom use }\end{array}$ & $\begin{array}{l}8 \text { items } \\
\langle\alpha=.96)\end{array}$ & $\begin{array}{l}\text { "I can never find a condom } \\
\text { right before sex". }\end{array}$ & $\begin{array}{l}0=\text { strongly disagree to } 3= \\
\text { strongly agree; higher average } \\
\text { scores represented more } \\
\text { positive attitudes to condom } \\
\text { use. }\end{array}$ \\
\hline $\begin{array}{l}\text { Perceived } \\
\text { partner's attitude } \\
\text { towards condom }\end{array}$ & $\begin{array}{l}4 \text { items } \\
(\alpha=.89)\end{array}$ & $\begin{array}{l}\text { "If I asked my partner to use } \\
\text { a condom, he would think I } \\
\text { didn't trust him." }\end{array}$ & $\begin{array}{l}0=\text { strongly disagree to } 3= \\
\text { strongly agree; higher average } \\
\text { scores indicate more positive }\end{array}$ \\
\hline
\end{tabular}


attitudes towards condom use.

Perceived control 5 items "In the past month, how of life $(\alpha=.64)$

often have you felt that others were running your life?"

Self-esteem

6 items ( $\alpha=.79$ )

Problem-oriented coping

3 items $(\alpha=.80)$

"In dealing with your problems, how often in the past month have you just concentrated on what you had to do next?"

Self-controlled way of coping

5 items $(\alpha=.76)$

"In dealing with your problems, how often in the past month have you tried to keep your feelings to yourself?"

Seeking social 4 items $(\alpha=.82)$
"In dealing with your problems, how often in the past month have you talked to someone about your feelings?"
$1=$ never to 5 = always; higher average scores indicate higher levels of control

$0=$ strongly disagree to 3 = strongly agree; higher average scores indicate higher self-esteem.

$0=$ not at all to $3=$ most of the time; higher average scores represented higher levels of positive coping.

$0=$ not at all to $3=$ most of the time; higher average scores represented higher levels of positive coping.

$0=$ not at all to $3=$ most of the time; higher average scores represented higher levels of positive coping.

Univariate association between the questionnaire variables under study and condom use frequency during vaginal sex with main partner were determined using correlation analysis. To determine their independent contribution, those correlates showing significant univariate associations with 
condom use frequency were entered in a multivariate regression model hierarchically while noting the cumulative explained variance $\left(R^{2}\right)$ change and $F$ change for each variable added to the model. Variables were removed from the model when their contribution was not significant. Significant correlates in the multivariate model were treated as proximal determinants of condom use frequency. It is possible that the relationships between condom use frequency and those variables that were significant in the univariate analyses but not in the multivariate model of condom use frequency are mediated by the proximal correlates, and are therefore distal correlates of condom use frequency. In order to map out these mediatory relationships to condom use frequency, further explorative analyses were conducted.

According to Baron and Kenny (1986), mediation can be said to occur when four conditions are satisfied: (1) variation in the independent mediator measure (e.g., assertive negotiation of condom use) accounts for significant variance in the dependent measure (Condom use frequency); (2) variation in the independent measure accounts for significant variance in the mediator; (3) variation in the mediator accounts for variance in the dependent measure while controlling for the influence of the independent measure; and (4) the significant effect of the independent measure on the dependent measure is significantly reduced after controlling for the effects of the mediator. Conditions 2 and 3 together imply condition 4 (MacKinnon \& Fairchild, 2009; MacKinnon, Lockwood, Hoffman, West, \& Sheets, 2002). We further used the Sobel's Z-test to determine whether the reduction in the strength of the original effect of distal variables on condom use frequency, following the inclusion of the mediator, significantly differed from zero, thus indicating mediation (Kenny, Kashy, \& Bolger, 1998).

Significance level was set at the $5 \%$ level $(\alpha=.05)$ for all analyses. Collinearity between the independent variable was tested with measures of 
variance inflation factor (VIF), tolerance (Tol), condition number, condition indices and Eigenvalues for each variable entered into each model. On the basis of these methods we found no collinearity problems on any of the regression models.

\section{Results}

Table 2 provides an overview of the demographic characteristics and sexual behaviours of the study sample. The mean age of participants was 29 years (Range 18 to 45). More women lived with their parents or other relatives than with a partner or spouse, and almost a quarter of the women lived alone at the time of the study. Most women reported being single, and the majority was unemployed. The majority of respondents had sex with a main partner in the past month. Among 111 women who provided data on the frequency of condom use in past 6 months, $48(43 \%)$ never used condoms, $29(26 \%)$ used condoms inconsistently and $34(31 \%)$ always used condoms.

\section{Proximal Correlates of condom use frequency}

All scales were computed as described in Table 1 to create psychosocial variables that were used to determine correlates of condom use frequency. The inter-item correlation, mean and standard deviation of each variable, are presented in Table 3. Significant correlations with condom use frequency were found for self-efficacy for negotiating condom use, assertive negotiation of condom use, self-esteem, self-efficacy for condom use, perceived control of life, and perceived partner's attitude to condom use. These univariate associations were then tested in a hierarchical multivariate linear regression model to test their independent contributions. 
Table 2. Demographic characteristics and sexual behaviours of study participants

\begin{tabular}{|c|c|c|}
\hline Variables & & Frequency $(\%)$ \\
\hline Age, Mean (SD) & Categories & $29(5.95)$ \\
\hline \multirow[t]{4}{*}{ Highest level of education } & Primary school & $52(43.3)$ \\
\hline & High school & $57(47.5)$ \\
\hline & Tertiary (tech/college) & $1(0.80)$ \\
\hline & No formal schooling & $10(8.30)$ \\
\hline \multirow[t]{5}{*}{ Lives } & Alone & $2(24.80)$ \\
\hline & With parents or other relative & $50(42.74)$ \\
\hline & Spouse, boyfriend or partner & $35(29.91)$ \\
\hline & A friend & $1(0.85)$ \\
\hline & Other (specify) & $2(1.71)$ \\
\hline \multirow[t]{4}{*}{ Marital status } & Single, never married & $84(70.59)$ \\
\hline & Married & $28(23.53)$ \\
\hline & Divorced or separated & $6(5.04)$ \\
\hline & Widowed & $1(0.84)$ \\
\hline \multirow[t]{3}{*}{ Employment status } & Working full time & $5(4.24)$ \\
\hline & Working part time & $14(11.86)$ \\
\hline & Unemployed & $99(83.90)$ \\
\hline Sex with main partner in past 1 & & $87(73.11)$ \\
\hline \multicolumn{3}{|l|}{ month } \\
\hline Condom use (last time) & & $46(63.01)$ \\
\hline Condom use frequency in past & Never & $48(43.20)$ \\
\hline \multirow[t]{2}{*}{6 month } & Inconsistent & $29(26.10)$ \\
\hline & Always & $34(30.60)$ \\
\hline
\end{tabular}




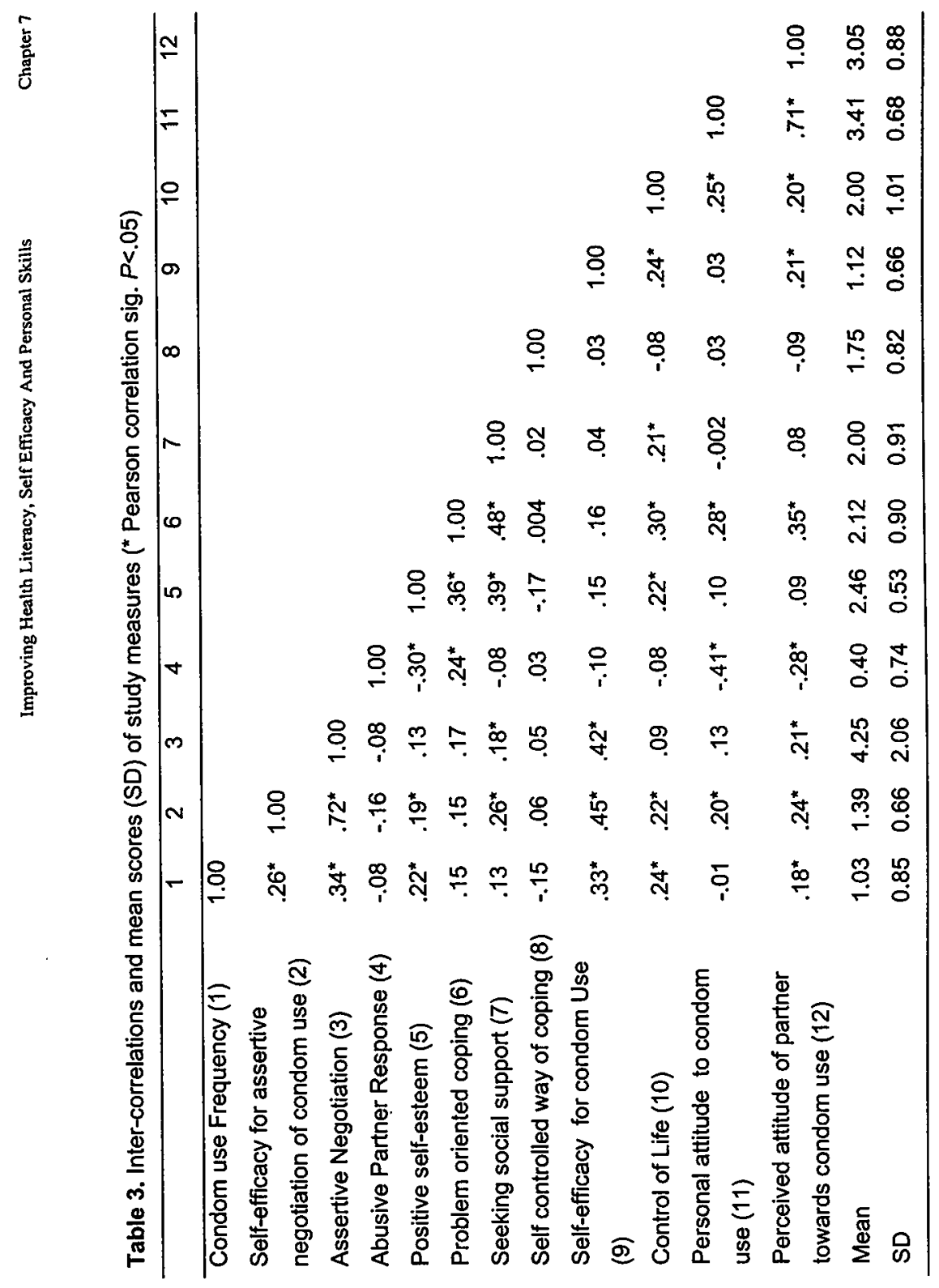


Table 4 shows adjusted regression coefficients (betas), Fs, cumulative explained variance $\left(R^{2}\right), R^{2}$ change statistics for individual variables in this model and collinearity statistics. Assertive negotiation of condom use accounted for $14 \%$ of the variance in frequency of condom use. The addition of self-efficacy for condom use in the model improved the $R^{2}$ by $4 \%$ while adding self-esteem accounted for an additional $3 \%$ and perceived partner's attitude to condom use added $1 \%$ to the $R^{2}$. The final model explained $23 \%$ of the variance in condom use frequency with assertive negotiation for condom use, self-esteem, and self-efficacy for condom use remaining significant in the model. These variables were then considered as proximal correlates of condom use frequency. 
巳̆

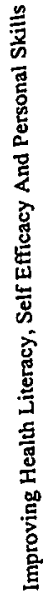

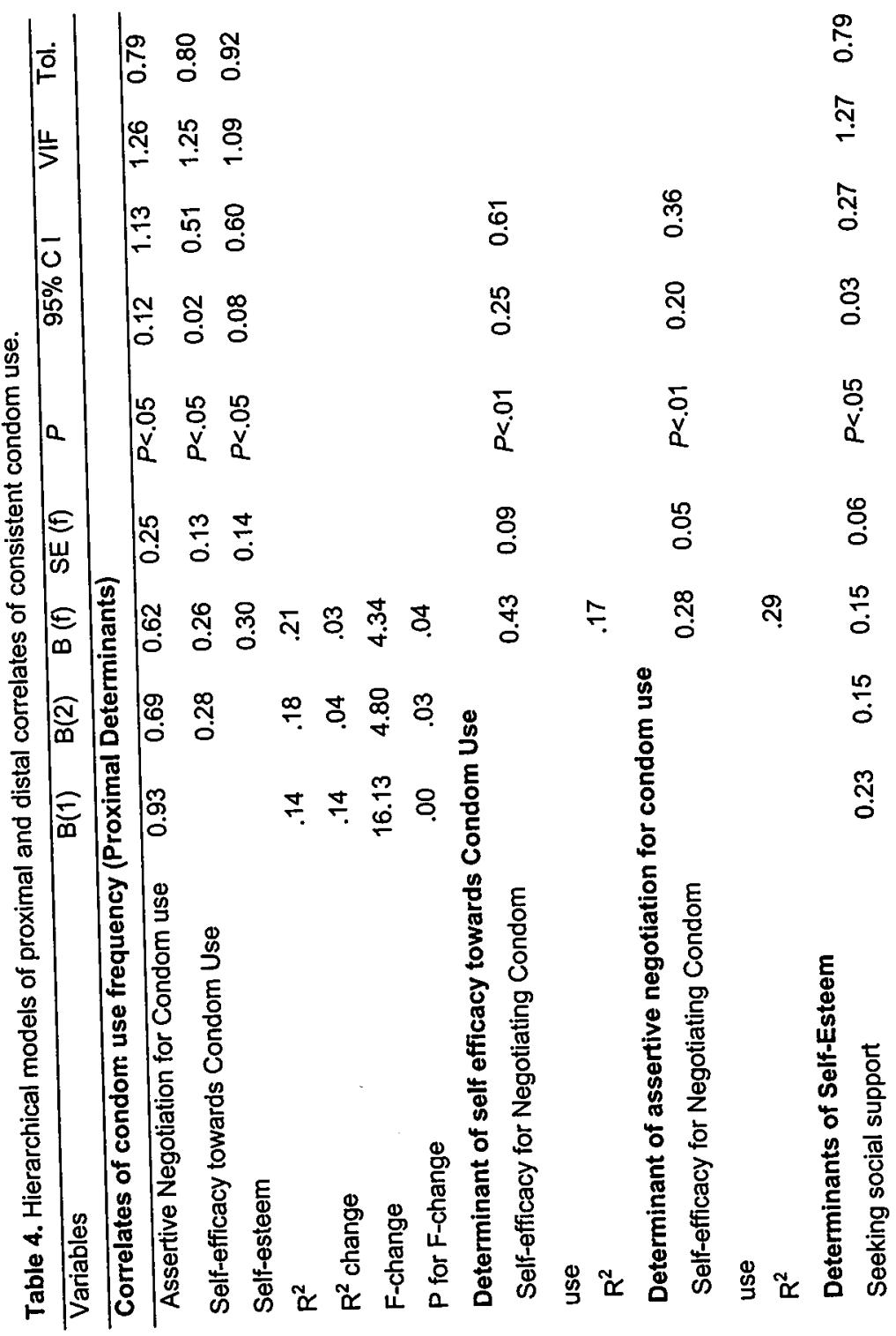


京

$N$
0

둘

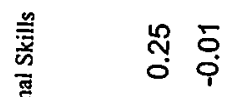

홍

总总

웅 :

วั0

웅 웅 웅

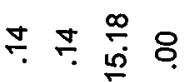

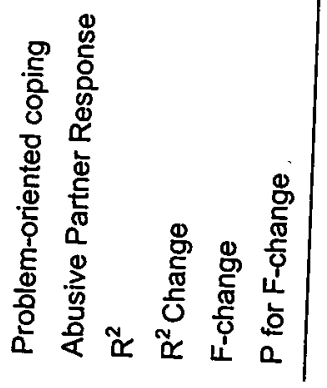




\section{Distal correlates of condom use frequency}

Determinants of assertive negotiation of condom use

Only self-efficacy for negotiating condom use was a significant predictor of assertive negotiation of condom use and explained $33 \%$ of its variance. Seventy percent of the direct effect of self-efficacy for negotiating condom use was mediated by assertive negotiation of condom use. This mediation effect was statistically significant, Sobel's $Z=2.46, p<.05$.

Determinants of self efficacy for condom use

Only self-efficacy for negotiating condom use was a significant predictor of self- efficacy for condom use and explained $18 \%$ of the variance. Forty-two percent of the direct effect of self-efficacy for negotiating condom use was mediated by self- efficacy for condom use. This mediation effect was statistically significant, Sobel's $Z=$ $2.85, \mathrm{p}<.05$.

Determinants of self-esteem

Significant determinants of self-esteem were seeking social support, problem-oriented coping, and abusive partner response to requests for condom use. These variables explained $14 \%, 5 \%$ and $4 \%$ of the $R^{2}$ respectively. Abusive partner response to requests for condom use was negatively related to positive self-esteem. The final model explained $23 \%$ of the total variance. However none of these variables met the criteria for being distal correlates of condom use frequency (criteria for. mediation) as they were not significantly correlated to condom use frequency.

The proposed framework of proximal and distal correlates of condom use frequency is presented in Figure 1. 
Figure 1. Proposed framework of relationships among distal and proximal correlate of condom use frequency

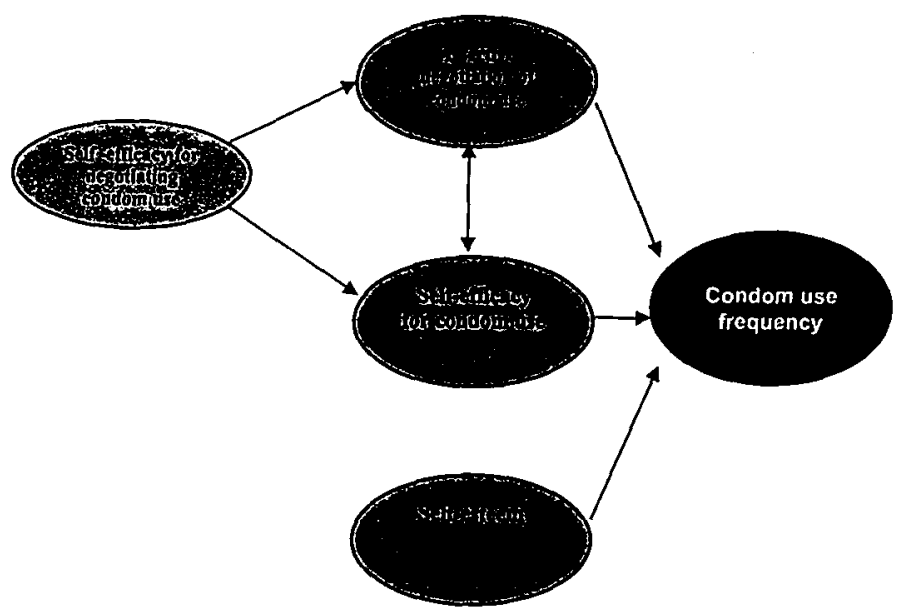

\section{Discussion}

The results of this study indicate that the majority of HIV positive Xhosa women, who know their status, are sexually active and over half of them either use condoms inconsistently or not at all.

The determinants described in this paper have been previously described as predictors of condom use among a variety of populations (Bedimo et al. 1998; Kline and van Landingham 1994; Marks, Burris, and Peterman 1999; Reddy et al. 2000; Sheeran et al. 1999; Wingood and DiClemente 1998, 2000). However this is one of the first studies to examine these variables' relationships with condom use frequency among HIV positive black women in South 
Africa and propose a framework that suggests how they could influence the frequency of condom use in this population.

Assertive negotiation of condom use, self-efficacy for condom use and self-esteem constitute stronger and proximal predictors of condom use frequency. The association of condom use frequency with self-efficacy for negotiating condom use was mediated by assertive negotiation of condom use and self-efficacy for condom use. Although problem-oriented coping, history of abusive partner response to requests for condom use and seeking social support to cope were significant determinants of self-esteem they did not meet the criteria for mediation.

The proposed framework suggests that social support components are important to changing condom use frequency to the extent that they improve the self-esteem of the women and that in order to positively affect the frequency of condom use it is important to combine these determinants with skill-based components such as self-efficacy for assertive negotiation of condom use. The framework provides potential evidence to support the importance of elements of the theory of planned behaviour and the social cognitive theory, particularly the elements of perceived behavioural control and behavioural skill (Ajzen, 2002; Albarracin et al., 2005). The data does not provide enough evidence to indicate that attitude and subjective norms about condom use have a strong impact on the consistency of condom use among HIV positive black South African women. This pattern of relationships is also consistent with the larger domain of attitude-behaviour research that suggests that skill-based belief systems such as self-efficacy components are necessary 
determinants of protective action (Godin, \& Kok, 1996; Ruiter et al., 2001).

Public health professionals often struggle with the issue of identifying the set of core determinants to address in an intervention to promote condom use. Bartholomew, Parcel, Kok and Gottlieb (2006) proposed the Intervention Mapping approach which specifies methods for planning, developing and implementing health promotion programs. The proposed framework essentially suggests core theoretical constructs for an eventual intervention for HIV positive women in South Africa within the Intervention Mapping process and the structuring of determinants into proximal and distal allows for organising intervention component so as to address specific objectives.

While the findings are preliminary and should be validated in a more robust study with a larger sample study, the data suggests that future interventionist aiming to increase condom use among black HIV positive women in South Africa could consider including components aimed to increase the condom negotiation skills, selfesteem and self-efficacy for condom use. Increasing the negotiations skills of the women can be done through communication training with role play to allow women to gain skills and experience in negotiating for condom use. Condom use skills training should aim to increase participant's condom application skills and knowledge of the feature of condoms that make them efficacious in preventing HIV transmission (Albarracín et al., 2005, Albarracin, Durantini, \& Earl, 2006). While the ability of HIV positive women to gain and maintain social support to cope and negative experiences in negotiating 
condom use were not associated to condom use in this study, they may impact on self-esteem. It could therefore be beneficial to include activities that boost these coping mechanisms. This could be done through group discussions and role plays to allow participants to share and discuss specific experiences and practical solutions to problems. Role plays would demonstrate the use of assertive communication in dealing with partners' negative responses to requests for condom use.

The interpretability of the study results and the strength of the framework are limited by the small study sample, particularly because of the range of variables examined in the study. A multi-collinearity problem was not found in the regression model however a larger sample size would have strengthened the results. The outcome variable has three risk levels (never, inconsistently and always using condoms) and a range of risk levels are encompassed within the 'inconsistently' level therefore a variables measuring the rate of condom use would have allowed for the examination of correlates of condom use frequency within the range of risks between 'always' and 'never'. The questionnaires were interviewer administered and this allows for potential problems associated to the giving of socially desirable answers to questions about condom use and potential significant associations due to shared method variance. The impact of social desirability factors on the condom use frequency cannot be ruled out. However the effects of shared method variance are less likely because all predictor variables included in the analyses were measured with more than one item. Furthermore these are 
preliminary results and further research is needed to validate the proposed framework.

In conclusion, although this is one of the first studies to comprehensively examine psychosocial correlates of condom use frequency among HIV positive women in South Africa, the deferminants for condom use frequency are similar to previously described determinants of condom use among women in other populations of women. The proposed model of proximal and distal determinants of condom use is an attempt to inform and strengthen the process of developing robust interventions for women living with HIV in South Africa. 


\section{References}

Ajzen, I. (2002). Perceived behavioural control, self efficacy, locus of control and the theory of planned behaviour. Journal of Applied Social Psychology, 32, 665- 683.

Albarraci'n, D., Gillette, J.C., Earl, A.N., Glasman, L.R., Durantini, M.R., \& Ho, M.H. (2005). A test of major assumptions about behavior change: a comprehensive look at the effects of passive and active HIV-prevention interventions since the beginning of the epidemic. Psychological Bulletin, $131,856-897$

Albarracín, D., Durantini, M.R., \& Earl, A. (2006). Empirical and Theoretical Conclusions of an Analysis of Outcomes of HIV-Prevention Interventions. Current Directions in Psychological Science, 15, 73-78.

Auvert, B., Ballard, R., Campbell, C., Caraël, M., Carton, M., Fehler, G., et al. (2001). HIV infection among youth in a South African mining town is associated with herpes simplex virus-2 seropositivity and sexual behavior. AIDS, 15, 885-898.

Baron, R.M., \& Kenny, D.A. (1986). The moderator-mediator variable distinction in social psychological research: conceptual, strategic, and statistical considerations. Journal of Personality and Social Psychology, 51, 11731182.

Bartholomew, L. K., Parcel, G. S., Kok, G., \& Gottlieb, N. H. (2006). Planning health promotion programs: An Intervention Mapping approach. San Francisco, CA: Jossey-Bass.

Bedimo, A.L., Bennett, M., Kissinger, P., \& Clark, R.A. (1998). Understanding barriers to condom usage among HIV-infected African American women. Journal Of The Association of Nurses in Aids Care, 9, 48-58.

Crepaz, N., \& Marks, G. (2002). Towards an understanding of sexual risk behavior in people liying with HIV: A review of social, psychological, and medical findings. AIDS, 16, 135-149. 
Department of Health, Medical Research Council, \& OrcMacro. (2007). South African demographic and health survey 2003. Pretoria: Department of Health.. Retrieved July 18, 2007, from www.doh.gov.za.

Folkman, S., Lazarus, R.S., Dunkel-Schetter, C., DeLongis, A., \& Gruen, R.J. (1986). Dynamics of a stressful encounter: Cognitive appraisal, coping, and encounter outcomes. Journal of Personality and Social Psychology, 50, 992-1003.

Glynn, J., Carael, M., Auvert, B., Kahindo, M., Chege, J., Musonda, R., et al. (2001). Why do young women have a much higher prevalence of HIV than young men? A study in Kisumu, Kenya and Ndola, Zambia. AIDS, 15, S51-S60.

Godin, G., \& Kok, G.J. (1996). The theory of planned behavior: A review of its applications to health-related behaviors. American Journal of Health Promotion, 11, 87-98.

Hendriksen, E.S., Pettifor, A., Lee, S.J., Coates, T.J., \& Rees, H.V. (2007). Predictors of condom use among young adults in South Africa: The reproductive health and HIV research unit national youth survey. Research and Practice, 97, 1241-1248.

Kalichman, S.C., Rompa, D., Cage, M., Difonzo, K., \& Simpson, D. (2001). Effectiveness of an intervention to reduce HIV transmission risks in HIVpositive people. American Journal of Preventive Medicine, 21, 84-92.

Kenny, D.A., Kashy, D.A., \& Bolger, N. (1998). Data analysis in social psychology. In D. Gilbert, S. Fiske, \& G. Lindzey (Eds.), The handbook of social psychology (Vol. 1, $4^{\text {th }}$ ed., pp 233-265). Boston, MA: McGraw-Hill.

Kline, A., \& VanLandingham, M. (1994). HIV infected women and sexual risk reduction: the relevance of exisisting models of behavior change. AIDS Education and Prevention, 6, 390-402.

Marks, G., Burris, S., \& Peterman, T.A. (1999). Reducing sexual transmission of HIV from those who know they are infected: the need for personal and collective responsibility. AIDS, 13, 297-306. 
MacKinnon, D.P., Lockwood, C.M., Hoffman, J.M., West, S.G., \& Sheets, V. (2002). A comparison of methods to test the significance of the mediated effect. Psychological methods, 7, 83-104.

Mackinnon, D.P., \& Fairchild, A. (2009). Current directions in mediation analysis. Current Direction in Psychological Science, 18, 16-20.

Olley, B.O., Seedat, S., Gxamza, F., Reuter, H., \& Stein, D.J. (2005). Determinants of unprotected sex among HIV positive patients in South Africa. AIDS Care, 17, 1-9.

Pettifor, A., Rees, H., Kleinschmidt, I., Steffenson, A., MacPhail, C., HlongwaMadikizela, L., et al. (2005). Young people's sexual health in South Africa: HIV prevalence and sexual behaviors from a nationally representative household survey. AIDS, 19, 1525-1534.

Reddy, P., Meyer-Weitz, A., Van den Borne, B., \& Kok, G. (2000). Determinants of condom-use behavior among STD clinic attenders in South Africa. International Journal of STD \& AIDS, 11, 521- 530.

Ruiter, R.A.C., Abrahams, C., \& Kok, G. (2001). Scary warning and rational precautions: A review of the psychology of fear appeals. Psychology and Health, 16, 613-630.

Saleh-Onoya, D., Reddy, P.S., Ruiter, R.A.C., Sifunda, S., Wingood, G., \& van den Borne, B. (2009). Condom use promotion among isiXhosa speaking women living with HIV in the Western Cape province, South Africa: a pilot study. AIDS Care, 21, 817.

Sheeran, P., Abraham, C., \& Orbell, S. (1999). Psychosocial correlates of heterosexual condom use: A meta-analysis. Psychological Bulletin, 125, 90-132.

Sifunda, S., Reddy, S.P., Braithwaite, R.B., Stephens, T., Bhengu, S., Ruiter, R.A.C., et al. (2007). Psychosocial determinants of risky sexual behavior amongst South African prison inmates. Manuscript submitted for publication. 
UNAIDS. (2004). Report on the global AIDS epidemic. Geneva, Joint United Nation Programme on HIVIAIDS. World Health Organization. Retrieved July 18, 2007 from www.unaids.com.

Van de Wijgert, J., Altini, L., Jones, H., de Kock, A., Young, T., Williamson, A-L., et al. (2006). Two methods of self sampling compared to clinician sampling to detect reproductive tract infections in Gugulethu, South Africa. Sexually Transmitted Infections, 33, 516-523.

Wingood, G.M., \& Diclemente, R.J. (1998). Gender-related correlates and predictors of consistent condom use among young adult African American women: a prospective analysis. International Journal of STD \& AIDS, 9, 139-145.

Wingood, G.M., \& Diclemente, R.J. (2000). Application of the theory of gender and power to examine HIV-related exposures, risk factors, and effective interventions for women. Health Education and Behavior, 27, 539-565. 


\section{Chapter 8}

\section{Condom Use Promotion among isiXhosa Speaking Women Living with HIV in the Western Cape Province, South Africa: A Pilot Study}

Published as: Dorina Saleh-Onoya, Priscilla S. Reddy, Robert A.C. Ruiter, Sibusiso Sifunda, Gina Wingood, Bart van den Borne. (2009). Condom Use Promotion among isiXhosa Speaking Women Living with HIV in the Western Cape Province, South Africa: A Pilot Study. AIDS Care, 21, 817. 


\section{Introduction}

The HIV prevalence among women aged between 15 and 49 in the Western Cape Province was estimated at $10.8 \%$ in 2006 , the lowest in South Africa. However, HIV positive women in this province are more likely to be black and of Xhosa decent (Dorrington, Johnson, Bradshaw, Daniel, 2006). In the large black communities of Khayelitsha and Gugulethu in Cape Town, the 2004 prevalence of HIV was estimated at $33 \%$ and $29.1 \%$ respectively (Shaikh, Abdullah, Lombard, Smit, Bradshaw, \& Makubalo, 2006). Over 50\% of HIV positive black Xhosa women in the Western Cape continue to have unprotected sex following diagnosis (Saleh-Onoya, Reddy, Ruiter, Sifunda, Wingood, \& van den Borne, under review).

Condom use negotiation by women in mostly male dominated relationships is not always successful and may result in inter-partner violence (Pettifor, Measham, Rees, \& Padian, 2004; Gilbert \& Walker, 2002; Wood \& Jewkes, 2001; Wood, Maforah, \& Jewkes, 1998). Interventions among HIV positive African American women targeting transmission risk behaviours are increasingly being reported (Johnson, Carey, Chaudoir, \& Reid, 2006; Lyles, Kay, Crepaz, Herbst, Passin, Kim, et al, 2007). Although many HIV-related interventions have been implemented in sub Saharan Africa, relatively few interventions have specifically aimed at the promotion of condom use among people living with HIV and particularly women living with HIV (Foss, Hossain, Vickerman, \& Watts, 2007).

It has been suggested that strong social support and positive coping may reduce transmission risk behaviours among HIV-positive women in SouthAfrica (Gaede, Majeke, Modeste, Naidoo, Titus, \& Uys 2006). We have previously demonstrated that personal and partner-related attitudes towards condom use, assertive negotiation skills of condom use, and positive selfesteem are proximal determinants of condom use frequency among HIV- 
positive Xhosa women in South Africa (Saleh-Onoya et al., under review). Previous research supports the relationship between condom use and selfefficacy for condom use as well as assertive communication for condom use among African American women of unknown HIV status (Wingood \& DiClemente, 2000), STI clinic attendees in South Africa (Reddy et al, 2000), and African American women living with HIV (Bedimo et al., 1998).

The assumption here is that an adapted version of the WiLLOW intervention may have success in motivating Xhosa women living with HIV in South Africa to use condoms. The WiLLOW intervention is a coping and risk behaviour reduction intervention first developed for African American HIVpositive women (Wingood, DiClemente, Mikhail, Lang, McCree, Davies et al., 2004). The intervention addresses issues of social support, self-esteem, HIV and STI knowledge, and self-efficacy and skills towards correct condom use and condom use negotiation. It was demonstrated to be efficacious in reducing unprotected vaginal intercourse and incidence of Chlamydia Trachomatis and Neisseria Gonorrhea, and in changing psychosocial determinants of condom use (Wingood et al., 2004).

We aimed to pilot a version of the WiLLOW intervention adapted to black, isiXhosa speaking, HIV-positive women in the Western Cape, South Africa. The objective was to compare the effectiveness of this intervention with a control condition that reiterated HIV-related motivating messages that HIVpositive individuals are generally exposed to in South Africa. The main outcome measures at 3-months follow-up were frequency of condom use, psychosocial determinants of condom use, and the incidence of Chlamydia trachomatis (CT), Neisseria gonorrhoea (NG), Trichomonas vaginalis (TV) infections, and bacteria vaginosis (BV). 


\section{Method}

\section{Participants}

Between June and August 2003, 143 women from five primary care clinics in the Western Cape Province, South Africa were screened. Women were eligible to participate if they were between 18 and 50 years old, black, isiXhosa speaking, living with HIV infection, and had sex in the prior 12 months. Twenty-three women were ineligible as they had not had sex in the previous 12 months, leaving 120 women in the sample.

Study design and procedure

All 120 women provided written informed consent to participate in all assessment procedures. During both baseline and follow up assessments, participants received additional information about sterile methods for selfcollecting a vaginal swab (Van de Wijgert, Altini, Jones, de Kock, Young, Williamson et al, 2006), completed an interviewer administered questionnaire, and provided one self-collected vaginal swab specimen. Participants were allowed to opt out if unable to provide a swab ( $n=2$ at baseline and $n=5$ at follow up), however they were not excluded from the sample. The questionnaire was translated into isiXhosa by bilingual researchers and then back translated from isiXhosa into English to ensure accuracy and meaning of constructs. The interviews were administered by trained, isiXhosa speaking, black female interviewers who read the questions to the participants and noted responses on paper. They were not blind to the conditions at follow-up assessment. Each assessment procedure took 1 to 2 hours to complete and participants were compensated R20 (approx. $3 \$$ ).

At each of the five participating primary care clinics, participants were randomized to the intervention or control condition after baseline assessment by picking a marble from an opaque bag containing marbles of two different colours (Terrell, 1999). Across participating clinics, 54 women were 
randomised to the intervention condition and 66 to the control condition. This distribution of participants is illustrated in Figure 1.

Participants who tested positive for any one STI were referred to their local clinic for free treatment. Treatment adherence was not checked. Participants were assessed again 3 months after completing either the intervention or control activities. The follow-up STI results were considered as estimates of STI incidence during the 3 month after the workshops.

Both conditions were initiated simultaneously. Each group session comprised of 8 to 10 participants and was implemented by a black, isiXhosa speaking, female health educator and a black isiXhosa speaking HIV positive woman co-facilitator. Contamination was minimised by holding the intervention and control conditions sessions on different days of the week.

The study protocol was approved by the Ethics Committee at the South African Medical Association (SAMA) prior to implementation. 
Figure 1. Flow diagram depicting the study design and flow of participants in the program

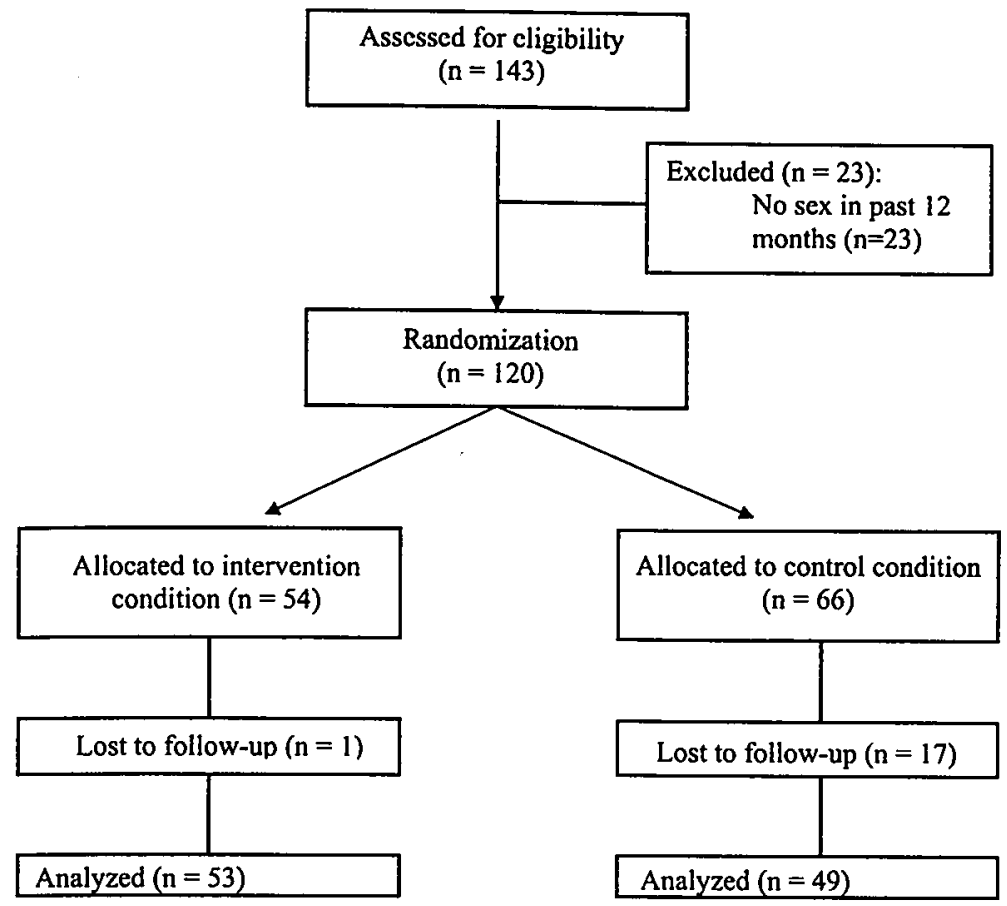

\section{Experimental conditions}

\section{Intervention activities}

The intervention condition consisted of four 4-hour sessions of sexual risk reduction and coping training, implemented over 4 consecutive Saturdays. Session 1 focused on enhancing ethnic and gender pride, and self-esteem. The group discussed ways of expanding support networks and maintaining social support. In session 2 participants discussed different communication styles and potential outcomes of each option. Role plays were used to demonstrate and reinforce assertive communication skills. Session 3 focused 
on reinforcing HIV and STI infection and re-infection knowledge, and highlighted personal HIV risk associated to unsafe sexual behaviour. Participants discussed and role-played strategies for negotiating condom use with sex partners. They learnt skills for correct condom use by observing demonstrations by health educators and practicing condom application on penis models. In session 4 participants differentiated healthy and unhealthy relationships, and discussed abuse in relationships (emotional, sexual, or physical) and methods for safely resolving relationship problems. Most intervention activities were adopted from the original WiLLOW programme and with the help of focus group discussions adapted to create culturally appropriate activities for the local context.

Control activities

The control condition consisted of one 4 hour session focusing on reiterating motivational messages about developing a positive outlook on life despite the challenges of living with HIV.

\section{Outcome variables}

At both baseline and 3-month follow-up, participants were asked for their date of birth, address and identification number which were linked to their study ID number. The study ID numbers were used to match participants' data across time. The baseline questionnaire collected demographic information, such as education and living conditions, using appropriate answer scales. Other questionnaire measures were taken at time points and were based on scales with two, three or four response options. ${ }^{1}$ Scores on sets of items that shared the same number of response options and showed sufficient internal reliability at baseline (Cronbach's alpha $>.65$ ) were averaged to create a single measure.

STI prevalence and incidence. 
Vaginal swabs were tested for CT, NG, TV and BV. Tests for CT and NG were conducted using the COBAS® Amplicor CT/NG polymerase chain reaction (PCR) based assay (Roche Molecular Diagnostics; Crotchfelt, Welsh, Debonville, Rosenstraus, \& Quinn, 1997). The PCR test for TV was done using a PCR with the primers set TVK3/TVK7 (Crucitti, Van Dyck, Tehe, Abdellati, Vuylsteke, Buve, et al, 2003). For the BV test, the swabs were cultured on $5 \%$ blood agar, eosin methylene blue agar and Saboraud (Sabdex) dextrose agar. The plates were evaluated following $24-48 \mathrm{~h}$ incubation at $37^{\circ} \mathrm{C}$ in microaerophilic conditions. Nugent criteria was used to diagnose BV (Tokyol, Aktepe, Cevrioslu, Alt ${ }_{2}$ ndis, \& Dilek, 2004). STI results were coded 0 for a negative result and 1 for a positive result.

Sexual behaviour

Condom use at last sex was assessed with the question "The last time you had vaginal sex with your spouse or steady partner, did you use a condom?" ( 1 = yes, $0=$ no).

Condom use frequency was assessed with one item inquiring about the frequency of condom use in the past month with answer options $0=$ never, $1=$ inconsistently, and 2 = always.

Psychosocial determinants of condom use.

Knowledge about HIV transmission and prevention methods was evaluated with 10 false-true items (e.g., "If both partners are HIV positive it's OK to have unprotected sex"). These items were coded such that a score of 1 indicated a correct answer and a score of 0 an incorrect answer. The scores were summed to create HIV knowledge (range: 0-10).

Attitude towards condom use was assessed with twelve items with 4point scales, ranging from $1=$ strongly agree to $4=$ strongly disagree. Two factors were extracted from a principal axis factoring analysis with direct oblimin rotation: 8 items were combined to measure personal attitude to 
condom use (e.g., "Condoms spoil the mood") and 4 items measured perceived partner's attitude towards condom use (e.g., "If I asked my partner to use a condom, he would think I didn't trust him"). Higher scores indicate a more positive attitude towards condom use.

Self-efficacy for negotiating condom use was assessed using four items with 3-point scales, ranging from $0=$ not at all confident to $2=$ very confident, exploring participants' perceived ability to assertively communicate their desire to use a condom with a partner (e.g., "How confident are you that you could convince your partner to use a condom even if he did not want to?").

Self-efficacy for correct condom use was assessed with nine items with 3-point scales, ranging from $0=$ not at all confident to $2=$ very confident, probing the perceived ability for correct condom use (e.g., "Even if you've never used condoms before, how confident or sure are that you could unroll a condom down correctly on the first try?").

Control in relationships was measured with one item: "In the past month how often have you felt that you were in control of your sex life?" This question was coded from $0=$ never to $3=$ always.

Self esteem was measured with six items assessing participant's positive feelings about their personal worth (e.g., "I feel that I'm able to do things as well as most other people"). Answer options ranged from $0=$ strongly disagreè to 3 = strongly agree with higher scores indicating more positive self-esteem.

Coping with HIV positive status was assessed using three subscales of the coping scale developed by Folkman, Lazarus, Dunkel-Schetter, Delongis and Gruen (1986). All items used 4-point coding $(0=$ not at all to $3=$ most of the time) and were coded such that higher scores represent more successful coping. Planful problem solving way of coping was measured with 3 items describing practical methods for coping (e.g., "In dealing with your problems, how often in the past month have you just concentrated on what you had to do 
next?"). Self controlling way of coping was measured with 5 items (e.g., "In dealing with your problems, how often in the past month have you tried to keep your feelings to yourself?"). Seeking social support to cope was measured with 4 items (e.g., "In dealing with your problems, how often in the past month have you talked to someone about your feelings?").

\section{Data analysis}

Comparisons between intervention (coded as 1) and control group (coded as 0 ) at baseline were made using chi-squared tests for discrete variables and independent samples $t$ tests for continuous variables. Fisher's exact test was used for discrete variable when expected frequencies were less than 5. For continuous variables, analysis of covariance (ANCOVA) was used to determine the intervention effect on condom use frequency and its psychosocial determinants after 3 months while controlling for baseline measures. Logistic regression analysis was used to compare STI incidences and condom use at last sexual intercourse between the intervention and control conditions at 3-month follow-up while controlling for baseline measures. Significance level was set at the $5 \%$ for all analyses. All analyses were conducted in SPSS version 15 (SPSS Inc., Chicago, IL).

\section{Results}

\section{Demographic Characteristics}

The demographic characteristics of the intervention group did not significantly differ from the control group (Table 1). Participants were on average 29 years old. Most women had at least primary school education, few attained secondary school and even fewer entered tertiary education. Most women lived either alone, or with a family member and were unmarried although in a relationship. The majority of the participants were unempioyed. 
Table 1. Demographic Profile of Women in the Control and Intervention Conditions and Tests of Significance for Baseline Differences ${ }^{a}$

\begin{tabular}{|c|c|c|c|}
\hline \multirow[b]{2}{*}{ Demographic characteristics } & \multicolumn{2}{|c|}{ Experimental condition } & \multirow[b]{2}{*}{$p$} \\
\hline & $\begin{array}{l}\text { Control } \\
(n=49)\end{array}$ & $\begin{array}{c}\text { Intervention } \\
(n=53)\end{array}$ & \\
\hline Age in years $(M, S D)$ & $28.37(6.25)$ & $30.62(5.82)$ & .06 \\
\hline Level of education $(n, \%)$ & & & .31 \\
\hline Primary school & $7(14 \%)$ & $12(23 \%)$ & \\
\hline Standard 6 & $16(33 \%)$ & $8(15 \%)$ & \\
\hline Standard 8 & $16(33 \%)$ & $17(33 \%)$ & \\
\hline Matric & $6(12 \%)$ & $12(23 \%)$ & \\
\hline Tertiary & $1(2 \%)$ & $2(4 \%)$ & \\
\hline No formal schooling & $2(4 \%)$ & $1(2 \%)$ & \\
\hline Other & $1(2 \%)$ & $0(0 \%)$ & \\
\hline Living condition ( $n, \%)$ & & & .50 \\
\hline Alone & $15(31 \%)$ & $17(32 \%)$ & \\
\hline With parents or relatives & $22(45 \%)$ & $22(42 \%)$ & \\
\hline With spouse or partners & $10(20 \%)$ & $13(25 \%)$ & \\
\hline With friend & $2(4 \%)$ & $0(0 \%)$ & \\
\hline Other & $0(0 \%)$ & $1(2 \%)$ & \\
\hline Marital status (n, \%) & & & .87 \\
\hline Single, not married & $33(67 \%)$ & $35(66 \%)$ & \\
\hline Married & $12(24 \%)$ & $15(28 \%)$ & \\
\hline Divorced or separated & $2(4 \%)$ & $2(4 \%)$ & \\
\hline Widowed & $1(2 \%)$ & $1(2 \%)$ & \\
\hline Other & $1(2 \%)$ & $0(0 \%)$ & \\
\hline Steady relationship (n, \%) & & & .61 \\
\hline No & $8(19 \%)$ & $11(23 \%)$ & \\
\hline Yes & $35(81 \%)$ & $37(77 \%)$ & \\
\hline Employment status $(n, \%)$ & & - & .46 \\
\hline Working fulltime & $2(4 \%)$ & $1(2 \%)$ & \\
\hline
\end{tabular}


Working part time

Unemployed

Self-employed
$2(4 \%)$

$44(90 \%)$

$1(2 \%)$
$5(9 \%)$

$47(89 \%)$

$0(0 \%)$

${ }^{9}$ Reported p-values are based on chi-square tests, except for age in years (independent samples $t$-test).

Note. Reported percentages are based on the total number of respondents for which a score was available.

\section{STI Prevalence and Incidence}

At baseline, the prevalence of CT, NG, TV and BV were $13 \%, 11 \%, 14 \%$ and $53 \%$ respectively, and $68 \%$ of the participants had at least one STI (Table 2). Chi-square tests showed no significant differences in the prevalence of BV, NG and CT at baseline between the intervention and control conditions. However participants in the control group had a higher prevalence in TV at baseline compared to the intervention group $(p=.02)$. At 3 month follow-up, the incidence for CT, NG, TV and BV were $27 \%, 17 \%, 16 \%$, and $42 \%$ respectively, and $68 \%$ of the participants had at least one STI. Logistic regression analyses showed significantly higher incidences of CT, NG and TV in the control condition than in the intervention condition. No significant difference was found for BV incidence.

Table 2. Odds Ratios (OR) and $95 \%$ Confidence Intervals ( $\mathrm{Cl}$ ) Comparing Intervention Condition vs. Control Condition on Baseline Prevalence and 3-month Follow-up Incidence of Bacteria Vaginosis (BV), and Chlamydia Trachomatis (CT), Neisseria Gonorrhoea (NG) and Chlamydia Trachomatis (CT) infections

\begin{tabular}{|c|c|c|c|c|c|c|}
\hline \multirow[b]{2}{*}{ STI } & \multicolumn{2}{|c|}{ Baseline (n, \%) } & \multirow[b]{2}{*}{ OR $(95 \% \mathrm{CI})$} & \multicolumn{2}{|c|}{ Follow-up $(n, \%)$} & \multirow[b]{2}{*}{ OR $(95 \% \mathrm{Cl})$} \\
\hline & $\begin{array}{l}\text { Control } \\
(n=49)\end{array}$ & $\begin{array}{l}\text { Intervention } \\
(n=51)\end{array}$ & & $\begin{array}{l}\text { Control } \\
(n=48)\end{array}$ & $\begin{array}{l}\text { Intervention } \\
(n=49)\end{array}$ & \\
\hline BV & $23(47 \%)$ & $30(59 \%)$ & $1.61(0.73,3.56)$ & $18(38 \%)$ & $22(45 \%)$ & $1.23(0.53,2.85)$ \\
\hline TV & $11(22 \%)$ & $3(6 \%)$ & $0.21(0.06,0.82)$ & $13(27 \%)$ & $3(6 \%)$ & $0.06(0.01,0.46)$ \\
\hline NG & $7(14 \%)$ & $4(8 \%)$ & $0.51(0.14,1.87)$ & $14(29 \%)$ & $2(4 \%)$ & $0.10(0.02,0.49)$ \\
\hline CT & $3(6 \%)$ & $10(20 \%)$ & $3.74(0.96,14.53)$ & $19(40 \%)$ & $7(14 \%)$ & $0.21(0.07,0.59)$ \\
\hline
\end{tabular}

Note. Reported percentages are based on the total number of respondents for which a score was available. OR $(95 \% \mathrm{Cl})$ are based on chi-square analysis at baseline and logistic regression at follow-up while controlling for baseline. 


\section{Condom Use}

A higher proportion of intervention participants indicated using a condom at last sex, at baseline, whereas the reverse was true for the follow up assessment (Table 3). The results of a logistic regression analysis showed no significant intervention effect on condom use at last sex at follow-up (OR= $0.48,95 \% \mathrm{Cl}: 0.09,2.54, p=.39)$. Furthermore, a general increase in the frequency of condom use at 3 months follow up was found. Eighty-two percent of the respondents at follow-up reported always using condoms versus $33 \%$ at baseline. However, an ANCOVA model showed no significant difference between the intervention and control conditions on this measure (Table 4). 
Table 3. Frequencies (Percentages) of Condom Use at Last Sex and Condom Use Frequency in Control and Intervention Conditions at Baseline and 3-Month Follow-up.

\begin{tabular}{llllll}
\hline & & $\begin{array}{l}\text { Control } \\
\text { Baseline }\end{array}$ & $\begin{array}{l}\text { Intervention } \\
\text { Baseline }\end{array}$ & $\begin{array}{l}\text { Control } \\
\text { Follow-up }\end{array}$ & $\begin{array}{l}\text { Intervention } \\
\text { Follow-up }\end{array}$ \\
\hline $\begin{array}{l}\text { Condom use at last } \\
\text { sex }\end{array}$ & Yes & $16(48 \%)$ & $22(76 \%)$ & $26(81 \%)$ & $25(71 \%)$ \\
$\begin{array}{l}\text { Condom use } \\
\text { frequency }\end{array}$ & Never & $19(40 \%)$ & $10(24 \%)$ & $3(12 \%)$ & $7(24 \%)$ \\
& $\begin{array}{l}\text { Inconsistent } \\
\text { Always }\end{array}$ & $13(28 \%)$ & $17(42 \%)$ & $3(12 \%)$ & $5(17 \%)$ \\
& $15(32 \%)$ & $14(34 \%)$ & $20(76 \%)$ & $17(59 \%)$ \\
\hline
\end{tabular}

Note. Reported percentages are based on the total number of respondents for which a score was available. OR $(95 \% \mathrm{Cl})$ are based on chi-square analysis at baseline and logistic regression at follow-up while controlling for baseline. Condom use at last sex: $n$ baseline (control) $=33 ; n$ baseline (intervention) $=29 ; n$ follow up (control) $=32 ; n$ follow up (intervention) $=35$. Condom use frequency: $n$ baseline $($ control $)=47 ; n$ baseline (intervention $)=41 ; n$ follow up (control) $=26 ; n$ follow up (intervention) $=29$

\section{Psychosocial Determinants of Condom Use}

Only positive self esteem was significantly higher in the intervention condition compared with the control condition. Effect size estimates of Cohen's $d$ suggest relatively small effects between the two conditions on the other psychosocial measures (Table 4). 


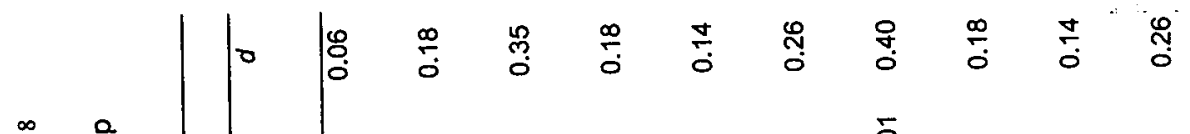

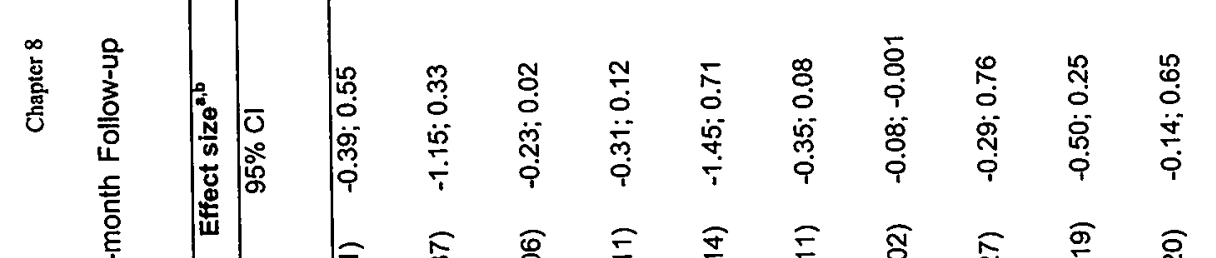
일

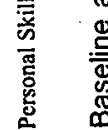

(1) i

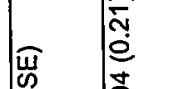

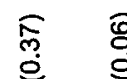

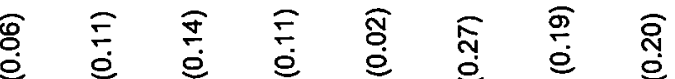

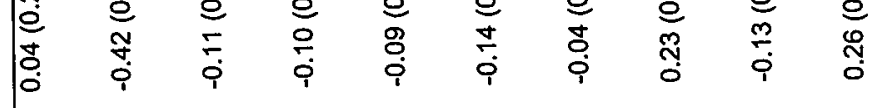

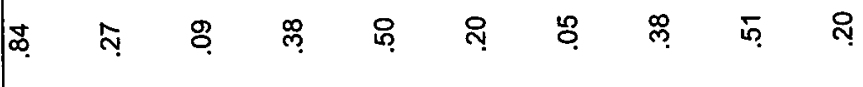

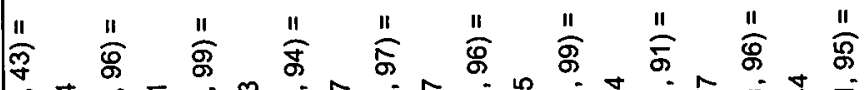
芒 它

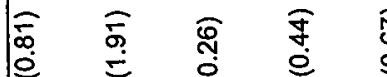

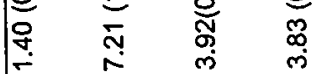

离

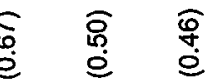

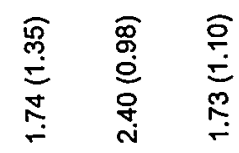

क

ฮิ

웅

웅

ิิ

กิ

$\stackrel{0}{\circ} \quad$

0

잉

离

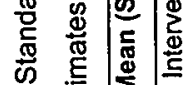

응

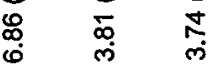

草

官.

ก

के

స్ సু

至营

売

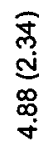

要

要

\%

高

露

危

ㅎํㅇ

离 离

ळ ธิ 㺿 学

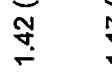

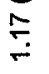
i ริ ฐู ๘

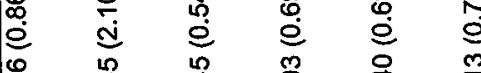
हิ 愛

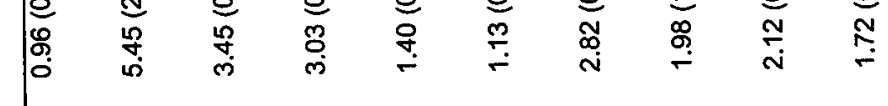

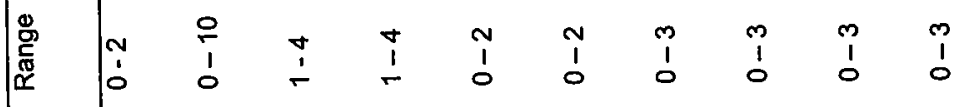

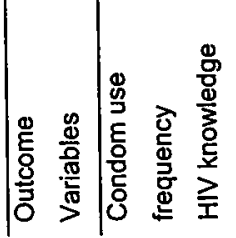

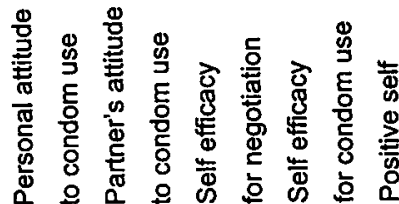

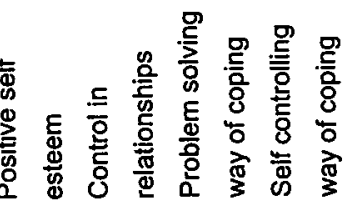




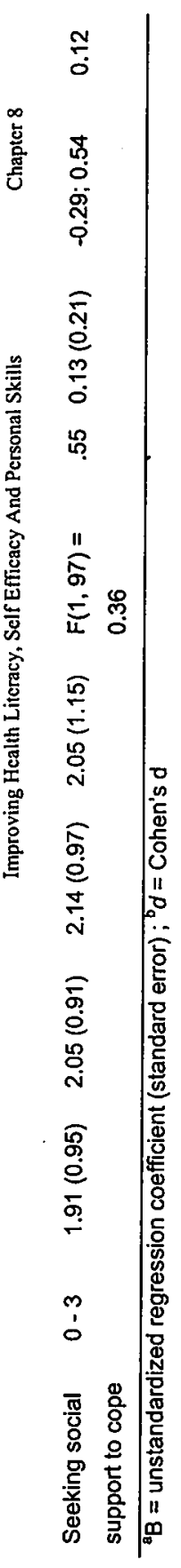




\section{Discussion}

This is one of the first reports of behavioural risk reduction interventions among HIV-positive women in Sub-Saharan Africa. The results of this pilot are encouraging as they indicate that adapting previously successful interventions for a population with similar determinants of condom use could produce potentially successful risk reduction interventions for black HIV-positive women in South Africa.

The follow-up incidence of CT, NG and TV in the intervention condition was significantly lower, even after adjusting for baseline prevalence. There was no difference in the incidence of BV. The self-esteem was significantly higher in the intervention condition. The majority of participants in both study conditions reported always using condoms with no significant difference between the intervention and control condition at follow-up.

Additional analyses revealed that the STI incidence outcomes were not mediated by self-esteem. The STI incidence reduction could have resulted from differential STI treatment adherence in the two groups, possibly implying that although condom use behaviour was not significantly different; the intervention had a positive effect on STI treatment adherence.

Baseline prevalence for CT, NG, TV and BV were similar to estimated STI prevalence among women of unspecified HIV status attending primary care clinics in Gugulethu, South Africa (Van de Wijgert, Altini, Jones, de Kock, Young, Williamson et al, 2006; Johnson, Coetzee, \& Dorrington, 2005). However, the incidences of CT, NG and TV in the control condition at follow-up were much higher than the baseline prevalence estimates in this condition. It is possible that because these women have regular contact with health care facilities, they receive STI treatments more promptly, hence the low baseline prevalence, and that the incidence in the control condition represents a truer estimate STI prevalence among HIV positive Xhosa women. The intervention 
effects on the incidence of $C T$ and NG were also reported in the original WiLLOW intervention (Wingood et al, 2004).

These results cannot be generalised to other settings as this was a pilot with a small sample size. This intervention should be tested for effectiveness in a larger sample. Interviewers were not blinded to the condition at the 3-months follow-up assessment which may have distorted or even enhanced the selfreported measures. The relatively small effect size estimates suggest that the intervention could be strengthened to change important psychosocial determinants of condom use behaviour. However, the STI incidence reduction during the study period highlights the necessity and feasibility of developing and testing successful interventions to increase protective behaviours among HIV-positive women in South Africa. 


\section{References}

Bedimo, A.L., Bennett, M., Kissinger, P., \& Clark, R.A. (1998). Understanding barriers to condom usage among HIV-infected African American women. Journal of The Association of Nurses in Aids Care, 9, 48-58.

Crotchfelt, K.A., Welsh, L.E., Debonville, D., Rosenstraus, M., \& Quinn, T.C. (1997). Detection of Neisseria gonorrhoeae and Chlamydia trachomatis in genitourinary specimens from men and women by a co-amplification PCR assay. Joumal of Clinical Microbiology, 35, 1536-1540.

Crucitti, T., Van Dyck, E., Tehe, A., Abdellati, S., Vuylsteke, B., Buve, A., \& Laga, M. (2003). Comparison of culture and different PCR assays for detection of Trichomonas vaginalis in self collected vaginal swabs specimen. Sexually Transmitted Infection, 79, 393-398.

Dorrington, R., Johnson, L., Bradshaw, D., \& Daniel, T.J. (2006). Demographic impact of HIV and AIDS in South Africa: National and Provincial Indicators for 2006. Retrieved on 26 of November 2007 from www.doh.gov.za.

Folkman, S., Lazarus, R.S., Dunkel-Schetter, C., DeLongis, A., \& Gruen, R.J. (1986). Dynamics of a stressful encounter: Cognitive appraisal, coping, and encounter outcomes. Joumal of Personality and Social Psychology, 50, 992-1003.

Foss, A.M., Hossain, M., Vickerman, P.T., \& Watts, C.H. (2007). A systematic review of published evidence on intervention impact on condom use in Sub-Saharan Africa and Asia. Sexually Transmitted Infections, 83, 510-516.

Gaede, B.M., Majeke, S.J., Modeste, R.R.M., Naidoo, J.R., Titus, M.J., \& Uys, L.R. (2006). Social support and health behavior in women living with HIV in KwaZulu-Natal. Journal of Social Aspects of HIVIAIDS, 3, 362-368.

Gilbert, L., \& Walker, L. (2002). Treading the path of least resistance: HIVIAIDS and social inequalities, a South African case study. Social Science and Medicine, 54, 10931110.

Johnson, B.T., Carey, M.P., Chaudoir, S.R., \& Reid, A.E. (2006). Sexual risk reduction for persons living with HIV: Research synthesis of randomized controlled trials 19932004. Journal of Acquired Immune Defficiency Syndrome, 41, 642-650.

Johnson, L.F., Coetzee, D.J., \& Dorrington, R.E. (2005). Sentinel surveillance of sexually transmitted infections in South Africa. Sexually Transmitted infections, 81, 287-293. 
Lyles, C.M., Kay, L.S., Crepaz, N., Herbst, J.H., Passin, W.F., Kim, A.S., et al (2007). BestEvidence Interventions: Findings From a Systematic Review of HIV Behavioral Interventions for US Populations at High Risk, 2000-2004. American Journal of Public Health, 97, 133-143.

Pettifor, A.E., Measham, D.M., Rees, H.V., \& Padian, N.S. (2004). Sexual power and HIV risk, South Africa. Emerging infectious diseases, 10, 1996-2003.

Reddy, P., Meyer-Weitz, A., Van den Borne, B., \& Kok, G. (2000). Determinants of condom-use behavior among STD clinic attenders in South Africa. International Journal of STD \& AIDS, 11, 521- 530.

Saleh-Onoya, D., Reddy, P., Ruiter, R., Sifunda, S., Wingood, G., \& van den Borne, B. (under review). Correlates of Condom Use Frequency Among Isixhosa Speaking Women Living with HIV in The Western Cape Province, South Africa: A Framework for Intervention Development.

Shaikh, N., Abdullah, F., Lombard, C.J., Smit, L., Bradshaw, D., Makubalo, L. (2006). Masking through averages - intraprovincial heterogeneity in HIV prevalence within the Western Cape. South African Medical Journal, 96, 539-543.

Terrel, G.R. (1999). Mathematical statistics: A unified introduction. New York: Springer.

Tokyol, Ç., Aktepe, O.C., Cevriošlu, A.S., Altındis, M., \& Dilek, F.H. (2004). Bacterial vaginosis: Control of Pap smear and microbiological test results. Modern Pathology, $17,857-860$.

Van de Wijgert, J., Altini, L., Jones, H., de Kock, A., Young, T., Williamson, A-L., et al. (2006). Two methods of self sampling compared to clinician sampling to detect reproductive tract infections in Gugulethu, South Africa. Sexually Transmitted Infections, 33, 516-523.

Wingood, G.M., \& DiClemente, R.J. (2000). Application of the theory of gender and power to examine HIV related exposures, risk factors and effective interventions for women. Health Education and Behavior, 27, 539-565.

Wingood, G.M., DiClemente, R.J., Mikhail, I., Lang, D.L., McCree, D.H., Davies, S.L., et al. (2004). A Randomized Controlled Trial to Reduce HIV Transmission Risk Behaviors and Sexually Transmitted Diseases among Women Living With HIV: The WILLOW Program. Journal of Acquired Immune Deficiency Syndrome, 37, S58-S67. 
Wood, K. \& Jewkes, R. (2001). 'Dangerous love': Reflectional on violence among Xhosa township youth. In R. Morrel (Ed.), Changing men in southern Africa (pp. 317-336). Pietermaritzburg: University of Natal Press.

Wood, K., Maforah, F., \& Jewkes, R. (1998). "He forces me to love him": Putting violence on adolescent sexual health agendas. Social Science and Medicine, 47, 233-242. 
Chapter 9

General Discussion and recommendations for future research 
At the outset of the research reported in this thesis, data on psychosocial determinants of condom use specific to HIV-positive and HIV-negative black South African women were largely unavailable. Black women in South Africa constitute the largest population at risk of acquiring and transmitting HIV in South Africa. While it was recognised that much work has been done to mitigate the impact of HIV infection among women, particularly pregnant women, not enough work has been done in terms of developing and evaluating targeted, group specific, HIV prevention behavioural interventions among black women who have taken the first step in the prevention of HIV. Women who have tested and received their HIV test results. Therefore further research to generate information on the psychosocial determinants of condom use among HIV negative and HIV positive black women in South Africa was needed in order to inform the eventual intervention development processes.

The objectives of the research presented in this thesis were firstly to examine determinants of condom use among HIV positive and HIV negative isiXhosa speaking women separately. Secondly, to present the processes for adapting the SISTA program - a five-session, peer-led HIV prevention intervention for African-American women, 18-29 years of age. The intervention was adapted for black South African isiXhosa speaking women and evaluated in a randomised controlled trial recruiting HIV negative isiXhosa speaking women. Thirdly, we aimed to present the effects of the pilot test of the adapted WiLLOW intervention - a coping and risk behaviour reduction intervention first developed for African American HIV-positive women (Wingood et al., 2004). The intervention addresses issues of social support, self-esteem, HIV and STI knowledge, and self-efficacy and skills towards correct condom use and condom use negotiation among HIV positive isiXhosa speaking women. 


\section{Psychosocial determinants of condom use among HIV-negative isiXhosa speaking women}

The studies conducted among HIV-negative isiXhosa speaking women are unique in that they are among the first studies in the South African context to research uniquely black women who tested HIV negative at a VCT centre and are aware of this status. We focused on three factors that have been shown to impact on the decision of women in South Africa to use condoms: transactional sexual behaviours, dry sex and pregnancy. We examined the psychosocial factors that affect condom use among women who reported transactional sex. We further examined condom use and its psychosocial determinants among women who indicated preferring dry sex. Finally, considering that pregnant women are the most accessible population for research in behavioural risk of HIV, we looked at whether there is a significant difference between pregnant and non-pregnant HIV-negative women in terms of condom use, sexual behaviours, STI risk, and psychosocial determinants of condom use.

\section{Preference for dry sex and condom use}

It has been suggested that dry sex behaviour may increase the risk of STI and HIV among women possibly through abrasion of the vaginal wall and possible inflammatory effects of substances inserted into the vagina (Brown et al., 1993; Runganga and Kasule, 1995; Kun, 1998; McClelland et al., 2006). Furthermore, dry sex behaviour may be incompatible with condom use.

In the study presented in chapter 2 we aimed to assess whether a preference for dry sex among isiXhosa speaking women in the Western Cape is associated to the rate of condom use. The results did not indicate an association between the preference of dry sex among HIV-negative isiXhosa 
speaking women with condom use and high risk sexual behaviour. However, the results pointed to a strong association between women's preference of dry sex practices and the perceived preferences of their main partners relative to the practice. The results highlight the influence of perceived preferences of male partners on the reported sexual practices of women and the necessity for further research into the effect of partner-related and relationship characteristics on the adoption of protective measures in heterosexual relationships of HIV-negative isiXhosa speaking women.

It seemed intuitive that dry sex behaviour and condom use are mutually exclusive. This was not evident in the results, possibly suggesting that dry sex behaviour among women who prefer it is not frequent enough to significantly reduce the rate of condom use. We did not collect data on the frequency of actual dry sex behaviour and the frequency of condom use in conjunction with dry sex. This would have provided a more accurate measure of the impact of dry sex behaviour on the uptake of condom use. The women's preference for dry sex, a potentially painful practice for women, appears to be motivated by the desire of women to please their partner and is not necessarily associated to fear of violence from partners. This suggests that it is important to understand the dynamics within non-violent sexual partnerships that may influence HIV related risk behaviour among young black South African women in order to increase their uptake of condoms.

\section{Transactional sexual behaviour and condom use}

Previous research indicates that transactional sex behaviour is common among young women in South Africa. Transactional sexual behaviour has also been cited as one of the underlying factors for the rapid spread of the HIV epidemic in South Africa. While participation in transactional sex occurs as a result of the economic marginalisation of women in South Africa, it has been found that young women are increasingly engaging in transactional 
relationships for consumption purposes (Luke, 2003; Chatterji, Murray, London and Anglewicz, 2004; Dunkle, 2007; Luke, 2003; Manganja, 2007; Poulin, 2007; Swidler and Watkins, 2007; Hunter, 2002; Leclerc-Madlala, 2004). However, participation in transactional sexual relations exposes women to potentially violent coercions into having unprotected sex and reduces their ability to argue against the non-use of condoms, resulting in women forgoing of condom use in order to satisfy a partner. Hence transactional sexual behaviour increases the risk of HIV and STI among women.

The results of chapter 3 did not indicate a significant difference between the HIV knowledge of women who reported no risk behaviour, those who reported high risk behaviour compared to those who reported participating in transactional sex. This is consistent with the literature that indicates that although HIV knowledge is important for behaviour change, it is a weak predictor of safe sex behaviour (Sheeran et al., 1999; Albarracin et al., 2005; Albarracin, Durantini, \& Earl, 2006). We expected to find that women who reported transactional sex would have a higher than average number of sexual partners. However this was not evident, possibly because the data was based on self-reported sexual behaviour. It is possible that because of the stigma attached to transactional sex some women may have been reluctant to admit that their relationships were transactional in nature. Furthermore, the number of partners may have been underreported.

Whether transactional sex behaviour occurs as a result of poverty or consumption related factors, this behaviour is related to the insufficiency of personal income. The results of chapter 3 suggest that women who are forthcoming about their participation in transactional sex may be more proactive in using condoms with their main partners compared to those women who report high risk sexual behaviours or no risk behaviour, sometimes at the risk of intimate partner violence. Therefore, interventions 
aimed at reducing transactional sex behaviour have to address the economic vulnerabilities and the risk of intimate partner violence. While the perception of HIV risk was not measured in the study the results may indicate an openness to condom use promotion among women who are forthcoming about their risk behaviour. This openness and potential willingness of women who admit to participating in transactional sex to use condoms may in turn indicate a potential receptiveness to behavioural interventions aimed at increasing their self-efficacy and skills in condom use negotiation and to use condoms among this population of women.

\section{Comparing STI/HIV risk of HIV-negative women by pregnancy status}

Considering the fact that the risk of pregnancy may be related to the risk of STI and HIV because they both result through unprotected sex, a greater focus in the research of determinants of protective behaviours and intervention strategies among young HIV-negative, non-pregnant South African women is needed. The results of chapter 4 reiterate the fact that the period of pregnancy is a high risk period for infection with STI. Pregnant isiXhosa speaking women were less communicative about condom use and they used condom less frequently than non-pregnant women. It is possible that their pregnancy was the result of this failure to negotiate and use condoms.

Although non-pregnant women had a higher rate of condoms use, they had on average more sexual partners and their attempts to use condoms may have been hampered by the risk of physical violence from their partners. Additional analyses (presented in Appendix A) indicated that pregnant consistent condom users were more likely to have used a condom at the last sexual intercourse compared to pregnant inconsistent condom users. Similar results were found among non-pregnant women.

Among inconsistent condom users it was found that being pregnant was significantly associated to a higher likelihood of being unemployed rather than 
having a part-time job, having on average a lower number of sexual partners than non-pregnant women, and a higher likelihood of testing positive for CT. Pregnant women had significantly lower negative perceptions about partner's attitude to testing for STI, were less likely to have asked a partner to use a condom and less likely to have reported intimate partner violence.

There was no significant difference between pregnant and non pregnant consistent condom users. The number of consistent condom users was substantially lower than that of inconsistent condom users. This absence of a difference between these two groups may be related to the low statistical power of this analysis. However the differences found between pregnant and non-pregnant inconsistent condom users mirror those found in a similar analysis for the whole sample.

The results of this study make a case for HIV behavioural interventions among both young pregnant and non pregnant women because while the determinants of their risk to HIV are slightly different, their risk to HIV infection remains similarly high. The reported number pregnant, consistent condom users raises concerns about the truthfulness of participants when responding to question about condom use. Additional questions about desire for pregnancy and family planning could have clarified this outcome.

Taken together the results of chapters 2, 3 and 4 highlight the need for a greater focus of HIV-prevention efforts among young, HIV-negative isiXhosa speaking women. In all three studies which focused on different subcategories of HIV-negative isiXhosa speaking women, we found that inconsistent users of condoms were less likely to communicate with their partner about condom use than participants who indicated higher condom use.

Americans and Europeans generally believe in direct and verbal communication and tend to see nonverbal communication as ancillary to verbal communication. Interventions aiming to increase negotiation skills often 
advocate the use of assertive negotiation or direct verbal communication styles (Giri, 2006; Cruz, 2001). These studies are based on the accumulated literature on the association between direct assertive communication methods and condom use among women in mainly American and European societies (Noar, Carlyle, \& Cole, 2006; Quina, Harlow, Morokoff, Burkholder, \& Deiter, 2000). However communication styles have been shown to differ between cultures (Giri, 2006). It has been shown that in Asian, Latina and African cultures nonverbal and sometimes indirect communication may be used to convey important messages. For example, prolonged eye contact that is common and acceptable in Western societies may be considered rude, threatening, and disrespectful in Asian and Latina cultures (Giri, 2006; Cruz, 2001). Although the results of chapters 2,3 and 4 showed higher condom use among women who used assertive communication, it appears that these women did this at the risk of intimate partner violence. Inter-partner violence has been repeatedly associated with reduced condom use among South African women (Pettifor, Measham, Rees, \& Padian, 2004; Gilbert \& Walker, 2002; Wood \& Jewkes, 2001; Wood, Maforah, \& Jewkes, 1998; Dunkle et al 2007). It is possible that the communication styles currently promoted among black women, who are most likely poor and have low relationship power, could be inappropriate resulting in resistance from the male partner and a low rate of condom use (Yep, 1998; La France, 1997; Carli, 1990; Eagly, 1995). Lam, Mak, Lindsay, and Russell (2004) found that although direct verbal (e.g., to threaten, plead, or use health reasons to convince partner) and direct nonverbal (e.g., opening a condom in front of partner) strategies were more frequently used in condom use negotiation among university students in the USA, condom users also employed indirect verbal (eg. deception, flattery, dropping hints) and indirect nonverbal (placing condoms or safe sex pamphlet in open view - pillow or dresser) strategies to negotiate condom use. 
Moreover, Asians used indirect verbal strategies more than Whites. Women used indirect nonverbal strategies more than men. Unfortunately there is limited information on communication styles and the negotiation strategies currently used successfully by black South African women. It may be that a communication style that is compatible with the prevailing culture and considers the relationship characteristics of black South African women may result in more successful negotiation of condom use and reduced experience of intimate partner violence.

Interventions to reduce intimate partner violence, conducted among women usually include a form of poverty alleviation and a microfinance component (Gupta, Parkhurst, Ogden, Aggleton, \& Mahal, 2008). Economic interventions are intended to give young women alternatives to transactional sex as a means for obtaining money and reduce the incidence of intimate partner violence experience among women. However, very few microfinance interventions are associated with HIV-prevention behavioural interventions. Moreover, few studies have evaluated the impact of microfinance interventions on risky sexual behaviour and condom use among women. A microfinance intervention conducted among poor women in Limpopo province, South Africa, resulted in increases in women's ability to challenge the acceptability of violence, expect and receive better treatment from partners, leave abusive relationships, and raised awareness about intimate partner violence and a decrease in reported intimate partner violence (Kim et al., 2007). However, no measure of condom use or rate of unprotected sex was included. A structural intervention that included a microfinance component with gender and HIVtraining components among poor women in the Limpopo province resulted in $55 \%$ decrease in reported experience of intimate partner violence. There was no impact on reported multiple partner behaviour or condom use and reported rate of unprotected sex with a non-primary partner across the total sample 
(Pronyk et al., 2006). Among women aged 14-35, the results of this study showed significant increases in communication about sex or HIV in the homes of intervention participants, higher uptake of VCT services, and modestly lower levels of unprotected sexual experiences. Microfinance interventions combined with a robust behavioural intervention have the potential for reducing risk behaviour among young black South African women, but more research is needed to develop culturally appropriate behavioural interventions with activities aimed at improving culturally viable condom use negotiation and communication strategies.

Although behavioural interventions among women are necessary components of HIV-prevention efforts, on their own these interventions cannot reduce the risk of violence perpetrated by men, whatever the communication style. Dunkle and colleagues (2006) found that men who perpetrated physical violence were also more likely to have higher numbers of past year and lifetime sexual partners. Therefore there is a need for increased efforts in developing behavioural interventions among men in the aim of reducing the perpetration of intimate partner violence in response to women's request for condom use. However, behavioural interventions have to be supported by appropriate legislation and effective strategies for enforcing legislation against the perpetration of intimate partner violence.

\section{Processes for the adaptation of the SISTA intervention and the recruitment and retention of participants into the RCT}

The original version of the SISTA intervention was adapted for HIV-negative, isiXhosa speaking black women in the Western Cape Province as a means of fast tracking the development of a behavioural intervention for this population. 
This adapted intervention was then implemented and is currently being evaluated. Considering that this is one of the first behavioural interventions adapted for and implemented exclusively among HIV-negative young black female VCT attendees, we thought it wise to present the lessons learned in the adaptation of the intervention and recruitment of this population of women.

\section{Adaptation of the SISTA intervention}

There is a growing consensus that in order to ensure that all aspects of the intervention development or adaptation and implementation process are taken into consideration, a structured method for adapting interventions for the prevention of HIV infection is needed (Gandelman \& Rietmeijer, 2004; Solomon, Card, \& Malow, 2006). Several adaptation models such as the ADAPT-ITT model (Wingood, \& DiClemente, 2008) and the Intervention Mapping based adaptation model (Torterelo et al., 2005) have been proposed. Essentially the models specify key steps needed for successful adaptations of behavioural interventions including: a needs assessment step which involves the collection of data to understand the current problem and the capacity of service providers to adapt and implement the intervention successfully; the selection of the intervention to adapt on the basis of an understanding of theory-based determinants of condom use among the target population, the core components of the selected intervention and the behavioural outcome set for the adapted intervention; the gathering of information on appropriate theoretical and cultural elements to be incorporated into the intervention; and finally the adaptation and pilot testing of the adapted program (Wingood, \& DiClemente, 2008; Torterelo et al., 2005).

Currently there are very few published processes of adaptations of behavioural interventions in the Sub-Saharan context. In the adaptation of the SISTA intervention we used a 6 -step process that included establishing a 
close inter-institutional collaboration for the adaptation, conducting focus group discussions to get an understanding of determinants of condom use among HIV negative isiXhosa speaking black women, conducting a pre-test of the original SISTA intervention, and finally adapting the intervention and conducting a pre-test of the adapted SISTA intervention. The pre- of the adapted SISTA intervention was followed with focus group discussions to assess its face validity. The participants of the pre-test found the adapted SISTA intervention to be relevant to them. They found that the materials, the delivery methods and the language used in the adapted intervention were culturally sensitive and engaging.

Despite the socio-political and, to a certain extent, economic similarities between African American and black South African women, there are important socio-cultural differences between these two populations and appropriate acculturation of the intervention is needed to ensure the face validity and acceptability of the adapted intervention among South African women (Reddy, Taylor, \& Sifunda, 2002). We took particular care to infuse in the intervention cultural elements specific to women of Xhosa descent, such as songs, beadwork and poetry. Prather and colleagues (2006) found that infusing afro-centric elements such as opening and closing each session with the "Umoja circle" and activities that included historically relevant details, poetry and music, to the original SISTA intervention contributed positively to its successful national diffusion and implementation among Africa American women by community based agencies. Therefore it is important to have a thorough understanding of the original intervention, the context where it was developed, as well as the determinants of condom use and elements of the cultural identity of the local target population to ensure that the intervention is modified appropriately (Wingood \& DiClemente, 2008; Miller, 2003). 
It has been found that establishing structured inter-institutional collaborations facilitate the transfer of technology or knowledge across institutions involved in the intervention translation or adaptation process (Reddy, Taylor, \& Sifunda, 2002; Miller, 2003). In collaborations between South African institutions and institutions of developed countries, it is necessary to establish formal inter-institutional collaborations with a focus on the development of South African organisational capacity to develop and implement interventions and the ability of young South African professionals to conduct independent research through active participation at all stages of planning, intervention development, and implementation (Constello \& Zumla, 2000; Reddy, Taylor, \& Sifunda, 2002).

While the adapted SISTA intervention was received favourably by isiXhosa speaking women in the pre-test, the appropriateness of the adaptation and efficacy of the intervention will be established once its evaluation is finalised.

\section{Facilitators and barriers of participation in HIV-prevention interventions}

The recruitment and retention of participants was the main challenge encountered in the implementation of the SISTA study. The study presented in chapter 6 aimed to describe the process of recruiting HIV-negative isiXhosa speaking black women from VCT centres and retaining participants in the adapted SISTA program. We found that the referral of HIV-negative isiXhosa speaking women from VCT centres to group specific behavioural interventions is possible. Gandelman and Rietmeijer (2004) reiterated the fact that in order for the dissemination and adaptation of behavioural interventions to be successful, adapting organisations must be willing to assess their organizational and programmatic capacity to implement interventions. They should recognize that increasingly complex interventions require staff with advanced skills. The recruitment process presented in chapter 6 highlights the 
importance of understanding the available resources and establishing clear collaboration structures with participating institutions prior to the implementation of the study. Furthermore, we found that the establishment of clear guidelines and a stable collaboration with VCT centre managers and counsellors prior to the commencement of the study would have greatly facilitated the recruitment efforts.

However, difficulties were also encountered in recruiting and retaining participants in the adapted SISTA program. We therefore thought it useful to conduct focus group discussions with women who had consented but not participated in the program. The results indicated that HIV negative isiXhosa speaking women may be reticent to participate in HIV prevention behavioural program because of the perception that HIV related programs are for HIV positive people, the fear of being labelled "HIV positive" and stigmatised, the perceived lack of clarity on the purpose and content of HIV programs, and competing activities that limit available time for participation.

The qualitative component of the study in chapter 6 produced important information on the factors that affect the participation of HIV negative isiXhosa speaking women into HIV prevention behavioural interventions such as the need for appropriate marketing of the program ahead of recruitment processes. This marketing would have provided both the community and potential participant with necessary information and minimised uncertainties and misconceptions about the program.

The use of appropriate meta-interventions prior to recruitment is another way of reducing barriers to participation. Meta-interventions are standard introductions or procedures that do not impact on the target behaviour of the behavioural intervention but rather improve participation of the target population in the behavioural interventions (Albarracin et al., 2008). An example of a meta-intervention developed by Albarracin and colleagues 
(2008) is the exposure of potential participants to brochures and/or a short video about HIV before offering the opportunity to participate in a short HIV counselling session. This meta-intervention was successful at improving the participation of individuals with low intention to use condoms in the HIV counselling session.

The development of meta-interventions to improve participation of consenting HIV negative population into behavioural intervention requires detailed information on psychosocial determinants of participation. Currently information on determinants of participation of HIV negative women in HIV prevention is scare. Inadequate recruitment and retention of participants is a great concern in HIV prevention research and more efforts are needed to understand facilitators and barriers to participation so as to develop population specific meta-interventions in order to improve participation in HIV prevention programs.

While meta-interventions could reduce psychological and informational hindrances to participation in HIV prevention behavioural interventions for women, women could still be unable to attend due to competing activities (particularly jobs and schools) and time restrictions. Hence, it is necessary to associate employers and education institutions in the process of delivering interventions to women. Another option would be to incorporate within the intervention some professional training such as a short computer course. In South Africa, the labour equity act (Department of Labour, 2006) prohibits unfair discrimination or stigmatisation of a person living with HIV, however while employers are encouraged to provide some form of HIV education for their employees they are not compelled by law to do so. The onus is therefore on HIV interventionists to seek the collaboration of employers, to ensure the participation of employees in HIV prevention behavioural interventions. 


\section{Psychosocial determinants of condom use among HIV positive, isiXhosa speaking black women and a pilot test of the adapted WiLLOW intervention}

The development of behavioural interventions for HIV positive individuals in the USA has occurred over several years through repeated experimentation that resulted in accumulated knowledge about what works and what does not. However, the context, including the wider socioeconomic background and cultural assumptions, differs between locations, populations and may change over time, hence the need for adaptation of behavioural interventions (Campbell at al., 2007). Although a wealth of candidate HIV behavioural interventions are available for adaptation and implementation among women living with HIV in South African, a comprehensive understanding of contextual, cultural and psychosocial determinants of safe sexual behaviour like condom use is needed. While a significant body of literature on determinants of condom use and HIV prevention interventions among HIV-positive women in developed countries, particularly African American women, is currently available, very little research has been conducted among HIV-positive black women in South Africa. It is the recognition of the high burden of HIV disease and risk of transmission of HIV by black isiXhosa speaking women living with HIV, in the Western Cape Province, that informed the decision to adapt the WiLLOW intervention among this population of women.

In the emerging efforts to develop and implement positive prevention strategies among women in South Africa, literature on psychosocial determinants of condom use, specific to the local population, is crucial. One of the first steps in planning a behavioural intervention is a needs assessment which includes the systematic review of the literature related to the problem 
under investigation in order to understand the determinants of the targeted behaviour change (Bartholomew, Parcel, Kok, \& Gottlieb, 2006). Although the development and implementation of behavioural interventions among HIV positive individuals, particularly women, in South Africa is set to increase, the literature on psychosocial determinants of condom use among women living with HIV is currently very limited. Therefore in chapter 7 we endeavoured to contribute to this emerging field by examining psychosocial determinants of condom use frequency among HIV positive isiXhosa speaking black women in South Africa. The results suggest a two level framework of correlates with assertive negotiation of condom use, self-esteem and self-efficacy for condom use being proximal correlates of condom use while self-efficacy for negotiating condom use was found to be a more distal correlate mediated by assertive negotiation of condom use and self-efficacy for condom use. Although seeking social support, problem-oriented coping, and abusive response of the male partner to requests for condom use were determinants of self-esteem they were not included in the model as they were not associated to condom use frequency. The framework that is proposed is preliminary as it was based on a small sample of women. However, it does highlight the importance of assertive negotiation self-efficacy and skills as well as self-efficacy for condom use and self-esteem to the consistency of condom use among isiXhosa speaking HIV positive women in South Africa.

This study was followed by the pilot test of the adapted WiLLOW intervention among the same population of women. The WiLLOW intervention was selected because of the assumed similarities between HIV-positive African American women and HIV-positive black South African women. The results of chapter 7 did show some similarities in the two populations of women in terms of psychosocial determinants of condom use such as self-efficacy for condom use and assertive communication (Wingood \& DiClemente, 2000; 
Bedimo, Bennett, Kissinger, \& Clark, 1998). The results of the pilot of the adapted WiLLOW intervention in chapter 8 showed higher incidences of Chlamydia Trachomatis, Neisseria Ghonorrhoea and Trichomona Vaginalis in the control condition than in the intervention condition. There was no significant difference in condom use rate between the experimental conditions. Only positive self-esteem was significantly higher in the intervention condition compared with the control condition. The STI incidence reduction could have resulted from differential STI treatment adherence in the two groups, possibly implying that although there was no effect on condom use behaviour, the intervention had a positive effect on STI treatment adherence.

These results indicate that an adapted WiLLOW intervention has the potential for reducing the incidence of STI among HIV positive isiXhosa speaking women. However, relative to the effect of the original WiLLOW intervention among African American HIV-positive women (Wingood et al., 2004), the effects of the adapted intervention are limited.

The weaknesses in the adapted WiLLOW intervention may be related to the adaptation process, the appropriateness of the contents, the fidelity of implementation, or delivery methods of the intervention. The adaptation of a HIV behavioural intervention process requires the availability of background information about psychosocial determinants of condom use among the target population (Bartholomew, Parcel, Kok \& Gottlieb, 2006; Campbell et al., 2007). Prior to the adaptation of the WiLLOW intervention there was very little published empirical research on psychosocial determinants of condom use among isiXhosa speaking black women living with HIV to inform the adaptation process. This may have limited the tailoring of the original intervention to this population. The availability of empirical data would have ensured an evidencebased adaptation process, which in turn could have improved the intervention's efficacy among this population of women and helped to define appropriate 
outcome measures for the evaluation (Campbell et al., 2007; Wegbreit, Bertozzi, DeMaria, \& Padian, 2006).

Secondly, a greater understanding of the socio-cultural determinants of condom use such as relationship power, gender roles, communication styles and methods available to the target population to introduce condom use with minimal opposition from the male partner are needed. These are all information that will inform the skills training requirements of the target population and methods for imparting these skills in order to improve condom use behaviour.

Thirdly, a greater understanding of the context, the language and the socio-economic situation of the target population will facilitate the development of effective strategies for recruitment and retention of participants, and the application of viable methods for ensuring that the adapted intervention is implemented with fidelity.

This study was conducted within the context of primary health care centre and women were recruited with the collaboration health providers on site. This success in recruiting from this setting suggests the possibility for referring HIV positive women from health care centres to behavioural intervention programs.

\section{Methodological Limitations}

The studies presented in this thesis were conducted on two samples of women, HIV-positive and HIV-negative black isiXhosa speaking women who were recruited from primary health care clinics in the Western Cape Province. This strategy was adopted because of the convenience and ease of access to the target populations at the selected sites. We are cognisant of the fact that the resulting samples of HIV-positive and HIV-negative isiXhosa speaking 
women were not representative of the wider population of isiXhosa speaking women in the Western Cape or black South African women in general. Therefore the results of these studies can only be generalised to a relatively small population of women, isiXhosa speaking women who test HIV-negative at VCT centres, and HIV-positive isiXhosa speaking women who attend clinic based HIV services. Despite these limitations the research on these two populations of women contribute valuable empirical data to the literature on determinants of safe sex behaviour among black South African women and provide process data that will inform future adaptation and implementation of behavioural interventions in the South African context. The research in this thesis also suggests an intervention that has the potential for reducing HIV transmission risk among HIV-positive women in the South African context, provided that it is adapted and implemented appropriately. At the very least this research could inform future studies on more representative samples.

The questionnaire used to collect baseline data in the adapted SISTA study was quite comprehensive in term of measuring sexual behavioural outcomes (eg. condom use rates, condom use at last sex, multiple partner behaviour). The questionnaire included measures of relationship power, condom attitude, and condom use self-efficacy. However, measures of sexual communication and condom use negotiations were limited to 5 individual questions that measured condom use negotiation, partner resistance to condom use and 5 questions that assessed women's attitude towards communication about sexual matters. Considering that our studies are among the first studies conducted exclusively among HIV-negative isiXhosa speaking, black women in South Africa, and the importance of condom use negotiation in the adoption of condom use among women, more comprehensive measures on condom use negotiation, self-efficacy for negotiation of condom use, communication about sexual matters, HIV and STI testing, would have 
yielded important information on determinants of condom use in this population. Furthermore, future studies should clearly follow well-established explanatory models of human behaviour such as the theory of planned behaviour (Ajzen, 1991) and social cognitive theory (Bandura, 1997).

The process evaluation of the SISTA intervention was not designed at the planning stages of the SISTA study and therefore the necessary process data apart from field notes were not collected. Prompted by the low turnout of participants at baseline assessment and the difficulties encountered in retaining participant in the program we though it necessary to present a description of the process of the implementation of the recruitment and conduct a qualitative study to understand the phenomenon. A systematic study of psychosocial determinants of participation in the HIV behavioural intervention was not conducted due to funding constraints. However, we believe the study presented in chapter 6 provides important formative data that will help to define outcome variables for future quantitative studies on psychosocial determinants of participation.

The studies conducted among HIV-positive women were based on the sample for the pilot of the WiLLOW study. Although the questionnaire in this study was comprehensive and included a wide array of instruments for measuring psychosocial determinants of condom use and protective sexual behaviour, the sample size of 120 was too small to allow for high enough power to detect small associations. It is possible that some variables that showed significant univariate associations with condom use frequency became non-significant in multivariate models because of the low statistical power of the model due to the small sample size. For this reason the study results were considered as only preliminary. Furthermore, the WiLLOW pilot was conducted by another team of researchers and the analyses were conducted on data collected in 2003. Although the questionnaires were 
interviewer administered, there were many missing values in both the baseline and the follow-up questionnaire assessment data. Because of logistical reasons and considering the time of data collection it was not possible to go back to the participants and complete the data. This further reduced the effective sample size and limited our ability to adequately examine correlates of condom use.

\section{Conclusion}

HIV-positive and HIV-negative isiXhosa speaking women represent populations at two ends of the matrix as applied to HIV-prevention among women. Early HIV-prevention activities endeavours to identify HIV-negative women and attempt to prevent HIV-infections among them through population specific behavioural interventions, while at the patient care level health promotion activities should consist of providing appropriate medical care as well as behavioural intervention aiming to reduce the rate of HIV transmission. The research presented in this thesis provides important information on determinants of condom use among HIV-negative and HIV-positive isiXhosa speaking women to inform and support further research into the development of group specific behavioural intervention among these two populations of women.

In order for the development of interventions for black women in South Africa to be evidence-based in their intervention design, implementation and evaluation strategies, it is necessary to generate evidence through experimentation. To this end we presented in this thesis methodological data on intervention adaptation and implementation as well as a the effect of a pilot test of an intervention among HIV positive isiXhosa speaking women to contribute to the literature on best practices for implementation of behavioural 
interventions in the Western Cape Province of South Africa and introduce an intervention with the potential for reducing HIV transmission risk behaviour among HIV positive isiXhosa speaking black women (The adapted WiLLOW intervention). However further research is needed in the adaptation, implementation and evaluation of more behavioural interventions among HIVpositive and HIV-negative black women in South Africa.

While behavioural interventions among black women in South Africa, which are part of the health education components of the response to HIV in this population, are necessary, they have to be complemented by parallel institutional interventions such as increasing access to funding for the development and ongoing implementation of behavioural interventions among HIV-negative and HIV-positive black women; increased access to funding for the development and evaluation of structural interventions to reduce economic vulnerability of women as well as the related risk of intimate partner violence. Furthermore, it is important to consider that condom use occurs in the context of a sexual partnership. In order to be effective, condom use promotion among women has to be accompanied by behavioural interventions specific to men, to increase acceptability of condom use among men and reduce the rate of abusive and violent responses to request for condom use by women. 


\section{References}

Albarracin, D., Durantini, M.R., Earl, A., Gunnoe, J.B., \& Leeper, J. (2008). Beyond the Most Willing Audiences: A Meta-Intervention to Increase Exposure to HIV-Prevention Programs by Vulnerable Populations. Health Psychology, 27, 638-644.

Bartholomew, L.K., Parcel, G.S., Kok, G., \& Gottlieb, N.H. (2006). Planning health promotion programs: an intervention mapping approach $2^{\text {nd }}$ edition. Jossey-Bass, an imprint of Wiley, San Francisco.

Bedimo, A.L., Bennett, M., Kissinger, P., \& Clark, R.A. (1998). Understanding barriers to condom usage among HIV-infected African American women. Journal of the Association of Nurses in Aids Care, 9, 48-58.

Campbell, N.C., Murray, E., Darbyshire, J., Emery, J., Farmer, A., Griffiths, F. et al. (2007). Designing and evaluating complex interventions to improve health care. British Medical Journal, 334, 455-459.

Constello, A., \& Zumla, A. (2000). Moving to research partnerships in developing countries. British Medical Journal, 321, 827-829.

Cruz, W. (2001). Differences in nonverbal communication styles between cultures: the latino-anglo perspective. Leadership and Management in Engineering, 104, 52-53.

South African department of labour. (2006). Department of labour employment equity act, act $\mathrm{N}^{\circ} 55$ of 1998. Downloaded on the 18, July, 2009 from www.labourguide.co.za

Dunkle, K.L., Jewkes, R.K., Nduna, M., Levin, J., Jama, N., Khuzwayo, N., et al. (2006). Perpetration of partner violence and HIV risk behaviour among young men in the rural Eastern Cape, South Africa. AIDS, 20, 2107-2114.

Gandelman, A., \& Rietmeijer, C.A. (2004). Translation, adaptation, and synthesis of interventions for persons living with HIV, lessons from previous HIV prevention interventions. Journal Acquired Immune Deficiency Syndrome, 37, S126-129.

Gilbert, L., \& Walker, L. (2002). Treading the path of least resistance: HIVIAIDS and social inequalities: a South African case study. Social Science a Medicine, 54, 1093-1110.

Giri, V.N. (2006). Culture and Communication Style. Review of Communication, 6, 124 130.

Gupta, G.R., Parkhurst, J.O., Ogden, J.A., Aggleton, P., \& Mahal, A. (2008). Structural approaches to HIV prevention. The Lancet, 372, 764-775. 
Lam, A.G., Mak, A., Lindsay, P.D., \& Russell, S.T. (2004). What really works? An exploratory study of condom negotiation strategies. AIDS Education and Prevention, 16, 160-171.

Miller, R.L. (2003). Adapting an Evidence-Based Intervention: Tales of the Hustler Project. AIDS Education and Prevention, 15, 127-138.

Noar, S.M., Carlyle, K., \& Cole, C. (2006). Why communication is crucial: Meta-analysis of the relationship between safer sexual communication and condom use. Joumal of Health Communication, 11, 365-390.

Pettifor, A.E., Measham, D.M., Rees, H.V., \& Padian, N.S. (2004). Sexual Power and HIV Risk, South Africa. Emerging Infectious Diseases, 10, 1996-2004.

Prather, C., Fuller, T.R. King, W., Brown, M., Moering, M., Little, S. et al. (2006). Diffusing an HIV prevention intervention for African American women: integrating afrocentric components into the SISTA diffusion strategy. AIDS Education and Prevention, 18, 149-160.

Pronyk, P.M., Hargreaves, J.R., Kim, J.C., Morison, L.A., Phetla, G., Watts, C. et al. (2006). Effect of a structural intervention for the prevention of intimate-partner violence and HIV in rural South Africa: a cluster randomised trial. Lancet, 368, 1973-1983.

Quina, K., Harlow, L.L., Morokoff, P.J., Burkholder, G., \& Deiter, P.J. (2000). Sexual communication in relationships: when words speak louder than actions. Sex Roles, 42, 523-549.

Reddy, P., Taylor, S.E., \& Sifunda, S. (2002). Research capacity building and collaboration between South African and American partners: the adaptation of an intervention model for HIVIAIDS prevention in corrections research. AIDS Education and Prevention, 14, 92-102.

Simbayi, L.C., Kalichman, S.C., Skinner, D., Jooste, S., Cain, D., Cherry, C., et al. (2004). Theory-based HIV risk reduction counselling for sexually transmitted infection clinic patients in Cape Town, South Africa. Sexually Transmitted Diseases, 31, 727733.

Solomon, J., Card, J.J., \& Malow, R.M. (2006). Adapting Efficacious Interventions: Advancing Translational Research in HIV Prevention. Evaluation and Health Professions, 29, 162 - 194. 
Wegbreit, J., Bertozzi, S., DeMaria, L.M., \& Padian, N.S. (2006). Effectiveness of HIV prevention strategies in resource-poor countries: tailoring the intervention to the context. AIDS, 20, 1217-1235.

Wingood, G.M., \& DiClemente, R.J. (2008). The ADAPT-ITT Model a novel method of adapting evidence-based HIV interventions. Journal of Acquired Immune Deficiency Syndrome, 47, S40-S46.

Wingood, G.M., \& DiClemente, R.J. (2000). Application of the Theory of Gender and Power to Examine HIV-Related Exposures, Risk Factors, and Effective Interventions for Women. Health Education \& Behavior, 27, 539-565.

Yep, G. A. (1998). Safer sex negotiation in cross-cultural romantic dyads: An extension of Ting-Toomey's face negotiation theory. In N. L. Roth, L. K. Fuller (Eds.), Women and AIDS: Negotiating safer practices, care, and representation (pp. 81-100). New York: Harrington Park. 


\section{Summary}

Black women in South Africa bear the highest burden of HIV and the condom use among this population of women is low. There is a growing consensus that in addition to the media driven HIV-prevention programs and VCT programs, it is necessary to fast track the development and evaluation of behavioural interventions among young black women, particularly women who are aware of their HIV status. However while there is much knowledge on determinants of safe sexual behaviour and empirical evidence of efficacy of behavioural interventions among HIV-positive and HIV-negative women in highly industrialised nations, similar data on the South African population are not as readily available. Furthermore there is a shortage of empirical evidence of HIVprevention behavioural interventions among women in South Africa.

In this thesis seven studies among black isiXhosa speaking women were conducted. Five were conducted among HIV-negative women (chapters 2 to 6 ) and two among HIV positive women (chapter 7 and 8).

In chapter 2 we aimed to explore the relationship of women's preference for dry sex with condom use and the prevalence of Chlamydia Trachomatis, Neisseria Ghonorrhoea and Trichomona Vaginalis infections. The results demonstrated that women who preferred dry sex have a partner who also preferred dry sex and were more likely to report past STI episodes. The findings indicate that dry sex behaviour is not directly associated with condom use and STI (Chlamydia Trachomatis, Neisseria Ghonorrhoea and Trichomona Vaginalis) prevalence but may have been associated with relationships in which sexual preferences of the male partner were dominant.

In chapter 3 we aimed to evaluate the relationship between past participation in transactional sexual behaviour, condom use and STI prevalence. The results demonstrated that women who report participation in 
transactional sex do attempt to use condoms however this may be hindered by the risk of intimate partner violence. The results also point to possibly concealed risk to STIs and HIV among women with a history of high risk relationships who indicate no transactional sex.

In chapter 4 we aimed to compare the STI prevalence and sexual behaviour profiles between HIV negative pregnant black women who attend VCT services during antenatal care and their non pregnant counterparts. The results demonstrated that compared to the non pregnant participants, the pregnant women had a significantly lower average number of male partners in the past 6 months, had a lower rate of condom use, were significantly less likely to report a history of partner abuse and to have asked their partner to use a condom. They were more likely to test positive for at least $1 \mathrm{STI}$ and to report a STI history, however these were not statistically significant.

In chapter 5 we described an adaptation process of the SISTA (Sisters Informing other Sisters on the Topic of AIDS) intervention. SISTA is a fivesession, peer-led HIV-prevention intervention for African-American women, 1829 years of age, based on Social Cognitive Theory and the Theory of Gender and Power. The intervention was adapted for black South African isiXhosa speaking women. The study highlighted the importance of establishing a close and structured collaboration between researchers who developed the original intervention and the researchers adapting the intervention to ensure mutual knowledge and skills transfers. Furthermore the research highlighted the necessity of understanding the core contents as well as the cultural and contextual background to the development of the original intervention. It also showed the importance of understanding of psychosocial, cultural and contextual determinants condom use among local target population as well as using a structured approach in the adaptation process to ensure that appropriate adaptations are made. 
Chapter 6 presented the process of recruiting and retaining participants in the RCT of the adapted SISTA intervention. We learned that referring HIVnegative women from VCT clinic sites to small group behavioural interventions is possible however it is important to understand the available resources and establish stable collaboration structures with participating institutions prior to the implementation of the study. The second objective of the study was to understand the barriers and facilitators of participation in HIV-prevention programs among HIV-negative black women in South Africa. The findings suggest that the main barriers to participation are the assumption that HIVprevention programs are for HIV-positive women therefore HIV-negative women would not be welcome to join; fear of being tagged HIV-positive and fear of being stigmatized, and uncertainties about the purpose and content of HIV-prevention programs. Finally, women indicated that they had competing economic activities and domestic chores that hinder opportunities for participation. We further learned that marketing of the program prior to recruitment, to provide the community and potential participant with necessary information about the program is important so as to minimise uncertainties and misconceptions about the program. This study provides information that could inform the development of meta-interventions to successfully recruit participants for future HIV-prevention programs.

In chapter 7 we examined psychosocial correlates of condom use frequency among South African, isiXhosa speaking women living with HIV. The results indicated that assertive negotiation of condom use, self-esteem, and self efficacy for condom use were proximal correlates of condom use frequency, whereas self-efficacy for negotiating condom use, is a distal correlate of condom use frequency.

In Chapter 8 we reported the results of an experimental pilot study of a health education intervention aimed at enhancing coping skills and consistent 
condom use among HIV-positive women attending primary health clinics in the Western Cape province of South Africa. The results indicated that only selfesteem was significantly higher in the intervention group relative to the control group. Importantly, incidence for Chlamydia Trachomatis, Neisseria Ghonorrhoea and Trichomona Vaginalis during the study period were significantly lower in the intervention group than the control group. These results indicated that this adapted WiLLOW intervention is a strong candidate intervention to reduce STI related sexual risk behaviours among HIV-positive black women in South Africa. However, further research is needed to strengthen this intervention. 


\section{Samenvatting}

De bevolkingsgroep die het zwaarst wordt getroffen door HIV in Zuid-Afrika zijn Afrikaanse (zwarte) vrouwen. Het condoomgebruik in deze groep is laag. In Zuid-Afrika bestaat een breed scala aan HIV-preventie programma's met als doel condoomgebruik en vrijwillig testen op HIV-infectie te bevorderen. De ontwikkeling en evaluatie van gedragsinterventies onder jonge zwarte vrouwen die zich bewust zijn van hun HIV-status is echter grotendeels onderbelicht gebleven. Hoewel er veel kennis is over de determinanten van veilig vrijen en de effectiviteit van gedragsinterventies onder HIV-positieve en HIV-negatieve vrouwen in de geïndustrialiseerde wereld, zijn vergelijkbare data niet voorhanden voor vergelijkbare populaties in Zuid-Afrika.

In dit proefschrift worden zeven studies onder jonge isiXhosa-sprekende Afrikaanse vrouwen beschreven. Vijf studies werden uitgevoerd onder HIVnegatieve vrouwen (Hoofdstukken 2-6) en twee studies onder HIV-positieve vrouwen (Hoofdstuk 7-8).

In hoofdstuk 2 werd de relatie tussen enerzijds de voorkeur van vrouwen voor het hebben van $d r y$. sex en anderzijds de mate van condoomgebruik en de incidentie van sexueel overdraagbare aandoeningen (SOA's) bestudeerd. De resultaten lieten zien dat voor vrouwen die een voorkeur hadden voor $d r y$ sex het meer waarschijnlijk was dat zij een partner hadden die ook een voorkeur had voor $d r y$ sex. Bovendien was het waarschijnlijker dat zij in het verleden een SOA hadden opgelopen en op dit moment betrokken zijn in een relatie waarin de mannelijke partner dominant is. De bevindingen lieten ook zien dat het hebben van dry sex niet gerelateerd was aan condoomgebruik en het hebben van een SOA op het moment van de studie.

In Hoofdstuk 3 werd de relatie tussen deelname in het verleden aan transactionele seks (het hebben van seks in ruil voor een gunst), het gebruik 
van condooms in huidige relaties en het voorkomen van een SOA onderzocht. De resultaten lieten zien dat vrouwen die deelname aan transactionele seks rapporteerden trachten condooms te gebruiken, maar dat dit gehinderd werd door de vrees voor geweld van de sekspartner. De resultaten wijzen ook op een mogelijk verborgen verhoogd risico op SOA's en HIV onder vrouwen met een geschiedenis van risicovolle relaties maar die geen verleden van het hebben van transactionele seks rapporteerden.

In Hoofdstuk 4 werd de mate van voorkomen van SOA's en de aard van het seksuele gedrag bestudeerd onder jonge Afrikaanse HIV-negatieve vrouwen die deelnamen aan een programma van vrijwillig testen en counseling. Meer specifiek werd er een vergelijking gemaakt tussen die vrouwen die zwanger waren en die vrouwen die niet zwanger waren. Zwangere vrouwen scoorden lager op het gerapporteerde aantal mannelijke partners in de afgelopen zes maanden, de mate van consistent condoomgebruik, de mate waarin men in het verleden werd geconfronteerd met geweld van de partner en het vragen van de partner om een condoom te gebruiken.

Hoofdstuk 5 biedt een beschrijving van de wijze waarop een bestaande interventie uit de Verenigde Staten genaamd SISTA (Sisters Informing other Sisters on the Topic of AIDS) werd aangepast aan de Zuid-Afrikaanse context. SISTA is een peer-geleide interventie van vijf sessies voor Afro-Amerikaanse vrouwen van 18-29 jaar oud. De interventie werd aangepast voor gebruik onder jonge isiXhosa-sprekende Afrikaanse vrouwen in Zuid-Afrika. De studie benadrukt het belang van het hebben van een nauwe en gestructureerde samenwerking tussen onderzoekers die de originele interventie hebben ontwikkeld en de onderzoekers die de interventie aanpassen aan een nieuwe context om zo zorg te dragen voor een optimale overdracht van kennis en vaardigheden. Nieuwe gebruikers moeten verder niet alleen bekend zijn met 
de centrale inhoud van het programma maar ook met de culturele context waarbinnen het originele programma tot stand is gekomen. Bovendien benadrukt de studie het belang van een goed begrip van de psychosociale, culturele en omgevingsfactoren die van invloed zijn op condoomgebruik onder de lokale doelgroep alsmede een gestructureerde aanpak om te zorgen dat de juiste aanpassingen worden gedaan.

Hoofdstuk 6 beschrijft de wijze waarop deelnemers werden geworven en behouden voor de effectstudie van de aangepaste SISTA interventie. Dit proces liet zien dat het mogelijk is HIV-negatieve vrouwen te interesseren voor deelname aan gedragsinterventies, waarbij het echter van belang is voorafgaand aan de implementatie van de interventie zorg te dragen voor voldoende middelen en het hebben van stabiele samenwerkingsverbanden met deelnemende instanties. Een belangrijke doelstelling van deze studie was het in kaart brengen van factoren die deelname van HIV-negatieve jonge vrouwen aan HIV-preventie programma's bevorderen en hinderen. De bevindingen suggereren dat de belangrijkste factoren die deelname in de weg staan, zijn: de veronderstelling dat HIV-preventieprogramma's bedoeld zijn voor vrouwen die HIV-positief zijn, de angst om als HIV-positief bestempeld te worden en te worden gestigmatiseerd en onzekerheid over de doelstelling en inhoud van HIV-preventie programma's. Deelnemende vrouwen rapporteerden ook dat concurrerende economische activiteiten en de thuissituatie deelname in de weg kunnen staan. Goede voorlichting over de interventie voorafgaande aan de werving van deelnemers bleek waardevol om misconcepties en onzekerheden over het programma weg te nemen. De ervaringen beschreven in deze studie vormen een waardevolle informatiebron voor de ontwikkeling van meta-interventies om deelnemers te werven voor toekomstige HIVpreventie programma's. 
In hoofdstuk 7 werden de psychosociale determinanten van de frequentie van condoomgebruik onder Afrikaanse, isiXhosa-sprekende HIVpositieve vrouwen bestudeerd. De resultaten lieten zien dat assertief kunnen onderhandelen over condoomgebruik, zelfvertrouwen en vertrouwen in het succesvol kunnen gebruiken van condooms belangrijke factoren zijn die de mate van condoomgebruik bepalen, terwijl het vertrouwen in de eigen vaardigheden om succesvol te kunnen onderhandelen over condoomgebruik een meer indirecte relatie heeft met condoomgebruik.

In hoofdstuk 8 worden de resultaten beschreven van een experimentele studie naar de effecten van een interventie gericht op de bevordering van coping vaardigheden en consistent condoomgebruik onder HIV-positieve vrouwen die gezondheidsklinieken bezoeken in de provincie Western Cape in Zuid-Afrika. De resultaten laten zien dat na de interventie alleen de mate van zelfvertrouwen significant hoger scoorde in de interventiegroep dan in de controlegroep. Belangrijk was de bevinding dat SOA-infecties significant minder vaak voorkwamen in de interventiegroep dan in de controlegroep tijdens de studieperiode. Deze resultaten suggereren dat de aangepaste en geteste interventie een belangrijke kandidaat is om risicogedrag onder HIVpositieve jonge Afrikaanse vrouwen te verminderen, maar dat meer onderzoek nodig is om de interventie inhoudelijk te versterken. 


\section{Aknowledgements}

I would like to thank my Lord Jesus Christ for the opportunity, ability and carrying me through process of completing this work. Thank you professor Priscilla Reddy, Dr Robert Ruiter and Professor Bart van den Borne, I sincerely appreciate your patient guidance, teaching and support. A special thank you to the Health Promotion Research and Development unit, and all those who participated in one way or another to the project management and data collection in the SISTA and WiLLOW studies and assisted me in the completion of this thesis. To my family Eric and Gabriel, thank you for your love, patience and support during this process.

Dorina Onoya 


\section{Curriculum Vitae}

Dorina Onoya was born in Kisangani in the Haut-Zaire Province of the Democratic Republic of Congo (Formely known as Zaire). Her family emigrated to South Africa in 1991 and in 1995 she obtained her National Senior Certificate. She thereafter conpleted her undergraduate studies at University of Witwatersrand where she obtained a B.Sc(hon) degree in Medical Biochemistry. She worked in HIV research and diagnostic laboratories for 6 years. During the later 2 years of this period she studied at the University of Cape Town and obtained a Master of Public Health (Epidemiology) degree. She then joined the Health Promotion Research and Development unit of the $M R C$ as a $\mathrm{PhD}$ intern and endeavoured to complete the work presented in this thesis. She is currently a Senior Research Specialist in the Social Aspects of HIVIAIDS and Health (SAHA) unit of the Human Sciences Research Council. 


\section{Appendix A: Additional analyses for chapter 4}

\section{Abstract of Chapter 4}

CONTEXT: In South Africa more HIV prevention efforts are focused on HIV positive and particularly pregnant women compared HIV negative and non pregnant woman. The objective of this study was to compare the STI prevalence and sexual behaviours between HIV negative black women who attend HIV VCT services during antenatal care and their non pregnant counterparts.

METHODS: $\mathrm{A}$ total of 446 women (Mean age $=23.37$; $\mathrm{SD}=4.21$ ) completed an interviewer administered questionnaire. The interview assessed sexual and condom use behaviours. Participants also provided self administered vaginal swabs that were tested for Chlamydia trachomatis (CT), Neisseria gonorrhoea (NG) and Trichomonas vaginalis (NG).

RESULTS: Compared to the non pregnant participants, the pregnant VCT attendees had a significantly lower average number of male partners in the past 6 months (AOR $=0.39 ; 95 \% \mathrm{Cl}: 0.17$ to 0.89 ), had a lower rate of condom use (AOR $=0.32 ; 95 \% \mathrm{Cl}: 0.15$ to 0.74 ), were significantly less likely to report a history of partner abuse ( $A O R=0.38 ; 95 \% \mathrm{Cl}: 0.19$ to 0.78 ) and to have asked their partner to use a condom (AOR $=0.52 ; 95 \% \mathrm{Cl}: 0.29$ to 0.95 ). They were more likely to test positive for at least $1 \mathrm{STI}$ and to report a STI history, however these were not significant.

CONCLUSIONS: The data highlight the urgent need to further explore the differences in profile of determinant of STI risk black pregnant and non pregnant VCT attendees in order to develop focused HIV prevention interventions to meet their different needs.

Objectives of additional analyses 
- Compare pregnant consistent and inconsistent condom user

- Compare non-pregnant consistent and inconsistent condom user

- Compare inconsistent non-pregnant and pregnant condom user

- Compare consistent non-pregnant and pregnant condom user

Consistent condom users are those who used at all sexual encounters in the past 30 days. Inconsistent condom users are those who used condoms sometimes or not at all in the past 30 days

\section{Additional variables not described in chapter 4}

Inter-partner sexual abuse represents the question "Has your current boyfriend or husband, or any other partner, ever forced you to do something sexual that you found degrading or humiliating? (Coded Yes 1 , no 0$)$

Sexual communication scale consists of 5 items describing attitudes towards communication about sexual matters (e.g. It is okay for a woman to discuss HIVIAIDS issues with her main sexual partner; a man should be able to discuss about safe sex with his partner) (Coded fully disagree $=1$ to fully agree $=5 ; a=0.75$ )

\section{Results}

Table 1. Frequencies of pregnant and non-pregnant by condom use consistency

\begin{tabular}{|l|l|l|}
\hline & Consistent & Inconsistent \\
\hline pregnant & 25 & 176 \\
\hline Not pregnant & 50 & 84 \\
\hline
\end{tabular}


Participants were grouped by pregnancy status and by condom use consistency categories. Comparison were made within pregnancy status categories as presented in tables 2-5 (pregnant consistent verses inconsistent condom user; non-pregnant consistent verses inconsistent condom users) as well as within condom use consistency categories as presented in tables 6-7 (pregnant verses non-pregnant inconsistent condom users). The comparison between pregnant verses non-pregnant consistent condom users as univariate models indicated no significant difference between these two groups of women.

The results of multivariate logistic regression analyses indicate that among pregnant women, being a consistent condom user was significantly associated to a greater likelihood of using a condom at the last sexual intercourse. Similar results were found among non-pregnant women.

Among inconsistent condom users it was found that being pregnant was significantly associated to a higher likelihood of being unemployed rather than having a part-time job, to having on average a lower number of sexual partners than non-pregnant women, and a higher likelihood of testing positive for $\mathrm{CT}$. Pregnant women had significantly lower negative perceptions about partner's attitude to testing for STI, were less likely to have asked a partner to use a condom and less likely to have reported intimate partner violence.

There was no significant difference between non-pregnant and pregnant consistent condom users.

\section{Comparing pregnant consistent and inconsistent condom user}

Table 2. Results of univariate logistic regression models comparing pregnant consistent and inconsistent condom users 


\begin{tabular}{|l|l|l|l|l|l|}
\hline Pregnant & OR & SE & $P$ & \multicolumn{2}{|c|}{$95 \%$ C.I } \\
\hline Condom use at last sex & 58.76 & 34.08 & $<.05$ & 18.85 & 183.14 \\
\hline Request for condom use & 8.69 & 4.33 & $<.05$ & 3.27 & 23.08 \\
\hline Sexual communication & 0.39 & 0.18 & .04 & .16 & 0.95 \\
\hline
\end{tabular}

Table 3. Multivariate logistic regression model comparing pregnant consistent and inconsistent condom users

\begin{tabular}{|l|l|l|l|l|l|}
\hline Pregnant & OR & SE & P & \multicolumn{2}{|c|}{$95 \%$ C.I } \\
\hline Condom use at last sex & 46.89 & 31.80 & $<.05$ & 12.41 & 177.18 \\
\hline Request for condom use & 1.96 & 1.30 & .31 & 0.53 & 7.20 \\
\hline Sexual communication & 0.31 & 0.20 & .07 & 0.09 & 1.11 \\
\hline
\end{tabular}

\section{Comparing non-pregnant consistent and inconsistent condom user}

Table 4. Results of univariate logistic regression models comparing non-pregnant consistent and inconsistent condom users

\begin{tabular}{|l|l|l|l|l|l|}
\hline Non-pregnant & OR & SE & P & \multicolumn{2}{|c|}{$95 \%$ C.I } \\
\hline Condom use at last sex & 26.39 & 12.77 & $<.05$ & 10.22 & 68.12 \\
\hline Request for condom use & 7.69 & 3.74 & $<.05$ & 2.96 & 19.97 \\
\hline Partner sexual abuse & 4.39 & 3.14 & .04 & 1.08 & 17.86 \\
\hline
\end{tabular}

Table 5. Multivariate logistic regression model comparing non-pregnant consistent and inconsistent condom users

\begin{tabular}{|l|l|l|l|l|l|}
\hline Non-pregnant & OR & SE & P & \multicolumn{2}{|c|}{$95 \%$ C.I } \\
\hline Condom use at last sex & 20.36 & 10.76 & $<.05$ & 7.23 .22 & 57.37 \\
\hline Request for condom use & 2.34 & 1.38 & .15 & 0.73 & 7.43 \\
\hline Partner sexual abuse & 5.51 & 4.96 & .06 & 0.94 & 32.16 \\
\hline
\end{tabular}


Table 6. Results of univariate logistic regression models comparing pregnant and nonpregnant inconsistent condom users

\begin{tabular}{|l|l|l|l|l|l|}
\hline Inconsistent condom users & OR & SE & $P$ & \multicolumn{2}{|c|}{$95 \%$ C.I } \\
\hline Employment (Full-time job) & 1.35 & 0.56 & .47 & 0.60 & 3.03 \\
\hline Employment (Part-time job) & 0.19 & 0.10 & $<.05$ & 0.06 & 0.55 \\
\hline $\begin{array}{l}\mathrm{N}^{\circ} \text { sex partners in past 6 } \\
\text { months }\end{array}$ & 0.38 & 0.17 & $<.05$ & 0.16 & 0.91 \\
\hline $\mathrm{CT}$ (Chlamydia Trachomatis) & 2.47 & 0.83 & $<.05$ & 1.28 & 4.76 \\
\hline $\begin{array}{l}\text { Negative perceptions about } \\
\text { partner's attitude to testing } \\
\text { for STI }\end{array}$ & 0.92 & 0.03 & $<.05$ & 0.87 & 0.98 \\
\hline Request for condom use & 0.38 & 0.11 & $<.05$ & 0.22 & 0.66 \\
\hline Inter-partner violence & 0.40 & 0.15 & $<.05$ & 0.19 & 0.85 \\
\hline
\end{tabular}

Employment reference category is unemployed

Table 7. Multivariate logistic regression model comparing pregnant and non-pregnant inconsistent condom users

\begin{tabular}{|c|c|c|c|c|c|}
\hline Inconsistent condom users & OR & SE & $\mathbf{P}$ & \multicolumn{2}{|c|}{$95 \%$ C.I } \\
\hline Employment (Full-time job) & 1.15 & 0.53 & .75 & 0.47 & 2.82 \\
\hline Employment (Part-time job) & $\overline{0.13}$ & 0.08 & $<.05$ & $\overline{0.04}$ & 0.45 \\
\hline $\begin{array}{l}\mathrm{N}^{\circ} \text { sex partners in past } 6 \\
\text { months }\end{array}$ & 0.40 & 0.18 & $<.05$ & 0.16 & 0.98 \\
\hline CT (Chlamydia Trachomatis) & 3.63 & 1.40 & $<.05$ & 1.70 & 7.72 \\
\hline $\begin{array}{l}\text { Negative perceptions about } \\
\text { partner's attitude to testing } \\
\text { for STI }\end{array}$ & 0.91 & 0.03 & $<.05$ & 0.86 & 0.98 \\
\hline Request for condom use & 0.40 & 0.12 & $<.05$ & 0.22 & 0.73 \\
\hline Inter-partner violence & 0.37 & 0.18 & $<.05$ & 0.15 & 0.94 \\
\hline
\end{tabular}

Employment reference category is unemployed 